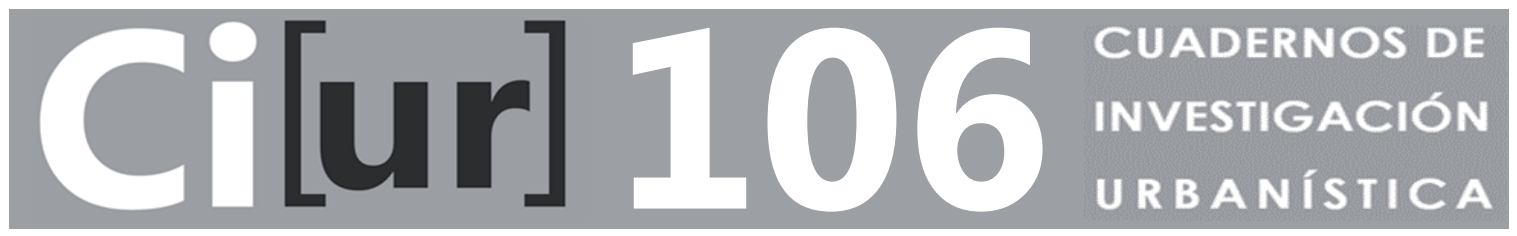

\title{
INTERVENCIÓN EN EL ALOJAMIENTO CON CRITERIOS ECOLÓGICOS
}

\section{GLORIA GÓMEZ MUÑOZ}

\author{
Doctora Arquitecta
}

Este documento es un resumen de la tesis doctoral: "Método de análisis diacrónico para la intervención en el alojamiento con criterios ecológicos. El caso de Madrid 1940-2100", dirigida por los profesores Javier Neila González y Margarita de Luxán García de Diego, leída por su autora el día 24 de junio de 2014 en la Escuela Técnica Superior de Arquitectura de Madrid

Mayo / Junio 2016 


\section{Director: José Fariña Tojo}

Consejo de Redacción:

Director Ester Higueras García

Jefe de redacción María Emilia Román López

Vocales Julio Alguacil Gómez (Univ. Carlos III de Madrid), Pilar Chías Navarro (Univ. Alcalá de Henares, Madrid), José Antonio Corraliza Rodríguez (Univ. Autónoma de Madrid), Alberto Cuchí Burgos (Univ. Politécnica de Cataluña), José Fariña Tojo (Univ. Politécnica de Madrid), Agustín Hernández Aja (Univ. Politécnica de Madrid), Mariam Leboreiro Amaro (Univ. Politécnica de Madrid), Rafael Mata Olmo (Univ. Autónoma de Madrid), Fernando Roch Peña (Univ. Politécnica de Madrid), Carlos Manuel Valdés (Univ. Carlos III de Madrid)

Consejo Asesor:

Ma Teresa Arredondo (Directora de Relaciones con Latinoamérica, Univ. Politécnica de Madrid), Luis Maldonado (Director de la Escuela Superior de Arquitectura, Univ. Politécnica de Madrid), Antonio Elizalde, Julio García Lanza, Josefina Gómez de Mendoza, José Manuel Naredo, Julián Salas, Fernando de Terán

Comité Científico: Antonio Acierno (Univ. Federico II di Napoli, Nápoles, ITALIA), Miguel Ángel Barreto (Univ. Nal. del Nordeste, Resistencia, ARGENTINA), Luz Alicia Cárdenas Jirón (Univ. de Chile, Santiago de Chile, CHILE), José Luis Carrillo (Univ. Veracruzana, Xalapa, MÉXICO), Marta Casares (Univ. Nal. de Tucumán, ARGENTINA), María Castrillo (Univ. de Valladolid, ESPAÑA), Mercedes Ferrer (Univ. del Zulia, Maracaibo, VENEZUELA), Fernando Gaja (Univ. Politécnica de Valencia, ESPAÑA), Alberto Gurovich (Univ. de Chile, Santiago de Chile, CHILE), Josué Llanque (Univ. Nal. S. Agustín Arequipa, PERÚ), Angelo Mazza (Univ. Federico II di Napoli, Nápoles, ITALIA), Luis Moya (Univ. Politécnica de Madrid, ESPAÑA), Joan Olmos (U. Politécnica de Valencia, ESPAÑA), Ignazia Pinzello (Univ. degli Studi di Palermo, Palermo, ITALIA), Julio Pozueta (Univ. Politécnica de Madrid, ESPAÑA), Alfonso Rivas (UAM Azcapotzalco, Ciudad de México, MÉXICO), Silvia Rossi (Univ. Nal. de Tucumán, ARGENTINA), Adalberto da Silva (Univ. Estadual Paulista, Sao Paulo, BRASIL), Carlos Soberanis (Univ. Francisco Marroquín, Guatemala, GUATEMALA), Carlos A. Torres (Univ. N ${ }^{\text {al }}$. de Colombia, Bogotá, COLOMBIA), Graziella Trovato (Univ. Politécnica de Madrid, ESPAÑA) Carlos F. Valverde (Univ. Iberoamericana de Puebla, MÉXICO), Paz Walker (Univ. de la Serena, Santiago de Chile, CHILE), Fernando N. Winfield (Univ. Veracruzana, Xalapa, MÉXICO)

Maquetación: Antonio Jesús Antequera Delgado: ciur.urbanismo.arquitectura@upm.es

Distribución: Mairea Libros: distribucion@mairea-libros.com

(C) COPYRIGHT 2016

GLORIA GÓMEZ MUÑOZ

I.S.S.N. (edición impresa): 1886-6654

I.S.S.N. (edición digital): 2174-5099

Año IX, Núm. 105, mayo-junio 2016, 90 págs.

Edita: Instituto Juan de Herrera

Imprime: FASTER, San Francisco de Sales 1, Madrid 


\section{DESCRIPTORES:}

Ecosistema urbano / Prospectiva ecológica / Metabolismo urbano / Capacidad de
carga KEY WORDS:

Urban ecosystem / Ecological prospective / Urban metabolism / Loading capacity

\section{RESUMEN:}

Las evidencias del impacto sobre el medio ambiente asociado al funcionamiento de las ciudades hacen que sea urgente proponer medidas que reduzcan este consumo y mejoren la eficiencia del metabolismo urbano. La existencia de límites en la disponibilidad de recursos materiales y energéticos, plantea actualmente un reto importante al ser humano: ¿son posibles otras formas de organización más adecuadas a esta condición de limitación? Para dar respuesta, resulta fundamental conocer cómo interactuarán nuestros sistemas urbanos en un modelo económico de continuo desarrollo, con la población que alojan, y si podrán adaptarse a la capacidad de carga limitada del Planeta, evitando futuras situaciones de colapso anunciadas desde distintos ámbitos científicos. En ese contexto, la tesis formula un método de análisis del alojamiento que, mediante la evaluación a largo plazo, permita proponer medidas de intervención para reducir el consumo de recursos asociado a su funcionamiento. Partiendo de un enfoque ecológico para definir el alojamiento como una parte fundamental del sistema urbano, que está compuesta por tres elementos: habitantes, viviendas y recursos naturales; por tanto, para reducir los impactos asociados al alojamiento es necesario tener en cuenta la diferente naturaleza de estos elementos y el carácter dinámico de las relaciones que se producen entre ellos.

\section{ABSTRACT:}

Evidence of the impact on the environment associated with the operation of cities make it urgent to propose measures to reduce energy consumption and improve the efficiency of urban metabolism. The limited availability of materials and energy resources currently poses a significant challenge to human beings: are more appropriate forms of organization for this limitation possible? In response, it is essential to know how our urban systems with the population they host will interact in an economic model of continuous development and whether they can adapt to the limited endurance capacity of the planet, thus avoiding future collapse situations which are being announced from different scientific fields. In this context, the thesis puts forward a method of housing analysis that by a long term assessment will enable to propose intervention measures to reduce resource consumption associated with its operation. The thesis is based on an ecological approach to identify housing as a fundamental part of the urban system, which is composed of three elements: inhabitants, homes and natural resources. Therefore, in order to reduce the impacts associated with housing it is necessary to consider the characteristics of these elements and the dynamic nature of the relationships among them. 


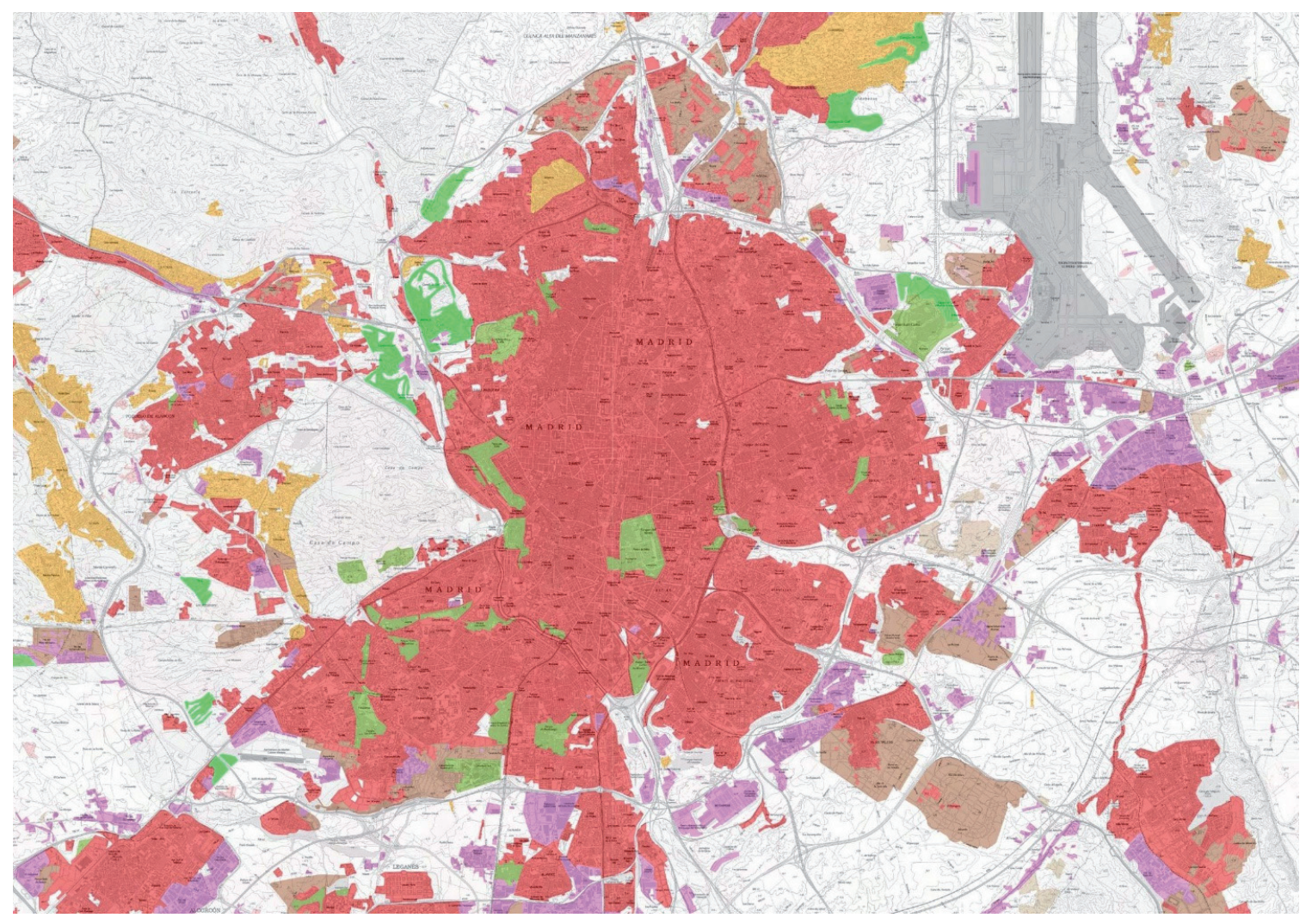

Figura 0. Mapa de ocupación del suelo de Madrid en 2007

Fuente: Visor Urbanístico de la Comunidad de Madrid

\section{CONSULTA DE NÚMEROS ANTERIORES/ACCESS TO PREVIOUS WORKS:}

La presente publicación se puede consultar en color en formato pdf en la dirección:

This document is available in pdfformat and full colour in the following web page:

http://www2.aq.upm.es/Departamentos/Urbanismo/institucional/publicaciones/ciur/ 


\section{ÍNDICE}

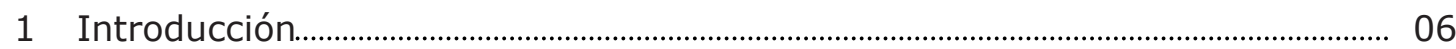

2 Un enfoque distinto para analizar el parque de las viviendas ............................... 07

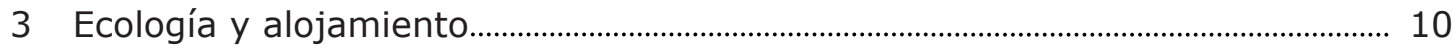

3.1 Los límites del crecimiento: población y recursos naturales............................ 10

3.2 El alojamiento desde los límites................................................................................. 15

3.3 Los modelos de la Ecología y su aplicación al alojamiento.......................... 16

3.4 Fases el ciclo adaptativo y estrategias de superviviencia aplicadas al alojamiento.

4 Definición de un método de análisis diacrónico para la intervención en el alojamiento con criterios ecológicos ................................................................................. 28

4.1 Descripción del método de análisis diacrónico.................................................... 28

4.2 Fases de aplicación del método diacrónico ............................................................ 30

5 Caracterización de los elementos del alojamiento a través de indicadores. Aplicación a Madrid................................................................................................................. 32

5.1 Definición y selección de variables .............................................................................. 32

5.2 Estrategias y evaluación de medidas mediante variables y factores dinámicos.

6 Aplicación y retrospectiva del método de análisis a Madrid entre 1940-2010 37

6.1 Cuantificación de las variables para Madrid entre 1940 y 2010.................... 37

6.2 Cuantificación de factores dinámicos para Madrid entre 1940-2010.... 41

6.3 Medidas de intervención para la evolución alternativa en Madrid

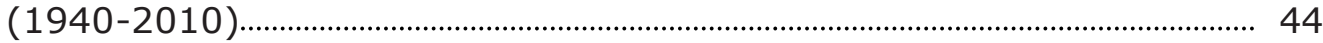

7 Aplicación del método de análisis diacrónico al caso de Madrid (2010-2100) 59

7.1 Definición del período de análisis y las proyecciones de futuro ..................... 59

7.2 Definición de es.cenar.io..p.ros.p.ectiv.o.p.ara..la.ap.li.ca.ción..del..méto.d.o..de análisis $\quad 61$

7.3 Evolución de variables y factores dinámicos en el escenario prospectivo seleccionado ...................................................................................................................... 62

7.4 Aplicación de medidas en el escenario prospectivo señalado..................... 67

7.5 Conclusiones de la aplicación del método de análisis en Madrid............. 75

8 Conclusiones de la investigación ................................................................................... 76

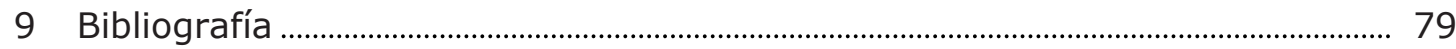




\section{INTRODUCCIÓN}

La degradación del medio ambiente por la acción del ser humano ha llevado desde hace décadas al desarrollo de líneas de pensamiento que, en base a la idea de "sostenibilidad", plantean la urgente necesidad de reconducir nuestros sistemas de organización. Uno de los principales retos es alcanzar modelos más eficientes que, con una eficiente gestión de recursos, garanticen la pervivencia de nuestros sistemas urbanos y una calidad de vida para todos. El incremento de la población y el creciente proceso de urbanización en todo el Planeta, especialmente intenso a partir de la segunda mitad del siglo XX, supone que la intervención en la ciudad existente sea uno de los principales retos en las próximas décadas ${ }^{1}$. Numerosos estudios han demostrado que los recursos naturales destinados a mantener el funcionamiento de los sistemas urbanos se ha incrementado progresivamente desde mediados del siglo pasado, sobrepasando la mayor parte de las ocasiones, la capacidad de carga del territorio en el que se ubican ${ }^{2}$. La existencia de límites físicos en el planeta implica que este continuo incremento no sea viable indefinidamente.

Una parte fundamental de las ciudades son las viviendas, soporte físico de la necesidad humana de alojamiento (Ramón Moliner, 1976). Por ello, el conocimiento del funcionamiento de éstas en relación al consumo de recursos es necesario para reconducir la situación de insostenibilidad urbana. En el caso de las ciudades españolas, cerca del $70 \%$ de las edificaciones están destinadas al uso residencial ${ }^{3}$. Esta investigación surgió en un primer momento por mi interés en un mejor conocimiento de la integración de las viviendas existente en el medio ambiente y en plantear una rehabilitación de las edificaciones con criterios ecológicos; sin embargo, el estudio de los trabajos para predecir la evolución de la población y del consumo de recursos, el conocimiento de la Teoría Ecológica y de los modelos que utiliza para describir la Naturaleza y los sistemas urbanos me sirvieron para comprender mejor la realidad física en la que se desarrolla toda la actividad humana. A partir de ahí, la pregunta que surgió fue si era posible utilizar ese conocimiento para desarrollar una herramienta que ayudara a organizar de una manera más coherente con la realidad física, al menos una parte nuestros sistemas urbanos.

Los modelos que la ciencia utiliza para describir la Naturaleza están en continua revisión. Prigogine, físico de origen ruso premiado con el Nobel en 1977, anunciaba el fin de las certidumbres y decía sobre la compleja realidad que nos rodea que sólo "podemos tener la certeza de que el carácter temporal y evolutivo de este mundo ocupará de ahora en adelante un lugar central en su descripción física" y que "la dirección del tiempo, el "elemento narrativo" ha de jugar un papel esencial" en esta

\footnotetext{
${ }^{1}$ Según los informes de Naciones Unidas para la Cumbre Río +20 celebrada en 2012, una mitad de la humanidad vive en ciudades y la población urbana aumentó desde aproximadamente 750 millones en 1950 hasta 3600 millones en 2011. Hacia 2030, casi un 60\% de la población mundial residirá en zonas urbanas.

2 Véanse las sucesivas directivas de la Unión Europea sobre la eficiencia energética de en la edificación: Directiva 2002/91/CE, de 16 de diciembre de 2002 y Directiva 2010/31/UE de 19 de mayo de 2010 en las que se incide en la cuestión de la disponibilidad de recursos para el funcionamiento de los sistemas urbanos.

3 Dato procedente del Atlas Digital de Áreas Urbanas del Ministerio de Fomento. http://atlas.vivienda.es/
} 
descripción (Prigogine, 1995). La cuestión que se planteaba tras esta reflexión y que aún está vigente es cómo incorporar el tiempo a nuestros análisis "sin destruir esas grandiosas construcciones del intelecto humano" (Prigogine, 1996, pág. 11). En esa misma línea, los trabajos de Meadows y Randers sobre los límites de crecimiento y las proyecciones de futuro sobre la evolución de la Humanidad y las posibilidades para reconducir tendencias que nos llevarían a situaciones no deseables, han resultado una fuente de inspiración para el desarrollo de esta investigación (Meadows, Randers, \& Meadows, 2006).

Ambas ideas, el tiempo y los límites de los sistemas, ilustran el contexto en el que he desarrollado la investigación y el carácter abierto del método de análisis propuesto, que asume un modelo en el que el continuo cambio y la incertidumbre son los principales retos en la descripción de los fenómenos urbanos. En su desarrollo he despejado algunas de las incógnitas que se plantearon inicialmente pero, inevitablemente, he abierto otras muchas que espero puedan responder futuros trabajos.

\section{UN ENFOQUE DISTINTO PARA ANALIZAR EL PARQUE DE LAS VIVIENDAS}

En 1976 el arquitecto Fernando Ramón proponía la utilización de alojamiento como equivalente en castellano a las palabras inglesa "housing" y francés "lodgement" (Ramón Moliner, 1976, pág. 2) por considerar que definía mejor la diversidad de tipos residenciales que no quedaban incluidos en la definición de "vivienda". En este ensayo, Ramón señala que lo propio del ser humano es "alojarse", y no "ser alojado" y considera, por tanto, que el alojamiento es una actividad. Por otro lado, y en la línea definida por la teoría del soporte de J. Habraken, señala como fundamental la relación de los individuos con el espacio físico que habitan y, por los cambios que se producen a lo largo de la vida de cualquier individuo, el soporte debe diseñarse desde los principios de la adaptabilidad. Por este carácter dinámico del alojamiento, Ramón lo definía como un proceso ${ }^{4}$ en el que los individuos debían tomar parte activa para mejorar las condiciones del soporte en función de las necesidades que tuvieran en cada momento. En cuanto a la relación con el entorno o "rededor" reivindicaba el diseño de un soporte que optimizara las ventajas de nuestro clima y la necesidad de una normativa más estricta en cuanto al consumo energético ${ }^{5}$.

Utilizar el concepto alojamiento en un contexto urbano conduce inevitablemente a pensar en el uso residencial, es decir, en el conjunto de las viviendas y en la trama urbana en la que se ubican. Las viviendas son utilizadas por una determinada población y necesitan unos recursos energéticos y materiales para desempeñar correctamente sus prestaciones. La primera cuestión que se plantea es si existe una relación entre estos elementos: población, recursos energéticos y materiales, y si esta relación se puede describir correctamente. En el caso de Madrid como ejemplo,

\footnotetext{
${ }^{4}$ Fernando Ramón profundiza en su ensayo "Alojamiento" en la aplicación de la teoría del soporte de Habraken a la situación española del momento y en la implicación de individuos en la constitución de la ciudad como soporte de la actividad humana. (Ramón Moliner, Alojamiento, 1976)

${ }^{5}$ En el momento de publicación de este libro, 1976, la crisis energética era un tema de actualidad.
} 
según los datos aportados por Naredo y García (Naredo Pérez \& García Zaldívar, 2008), en 1956 la ocupación de suelo por uso residencial era de $56,5 \mathrm{~m}^{2}$ por habitantes. En 2005, este indicador se había incrementado a casi el doble, a 116,9 $\mathrm{m}^{2}$ por habitante. La evolución muestra un incremento de intensidad en el uso de un recurso natural, como es el suelo, para la construcción de viviendas. En la figura 1 se muestra que la población en Madrid se multiplicó por 4 para el periodo estudiado, mientras que el número de viviendas lo hizo por 7 al igual que la energía necesaria para climatizar el conjunto de viviendas de Madrid.

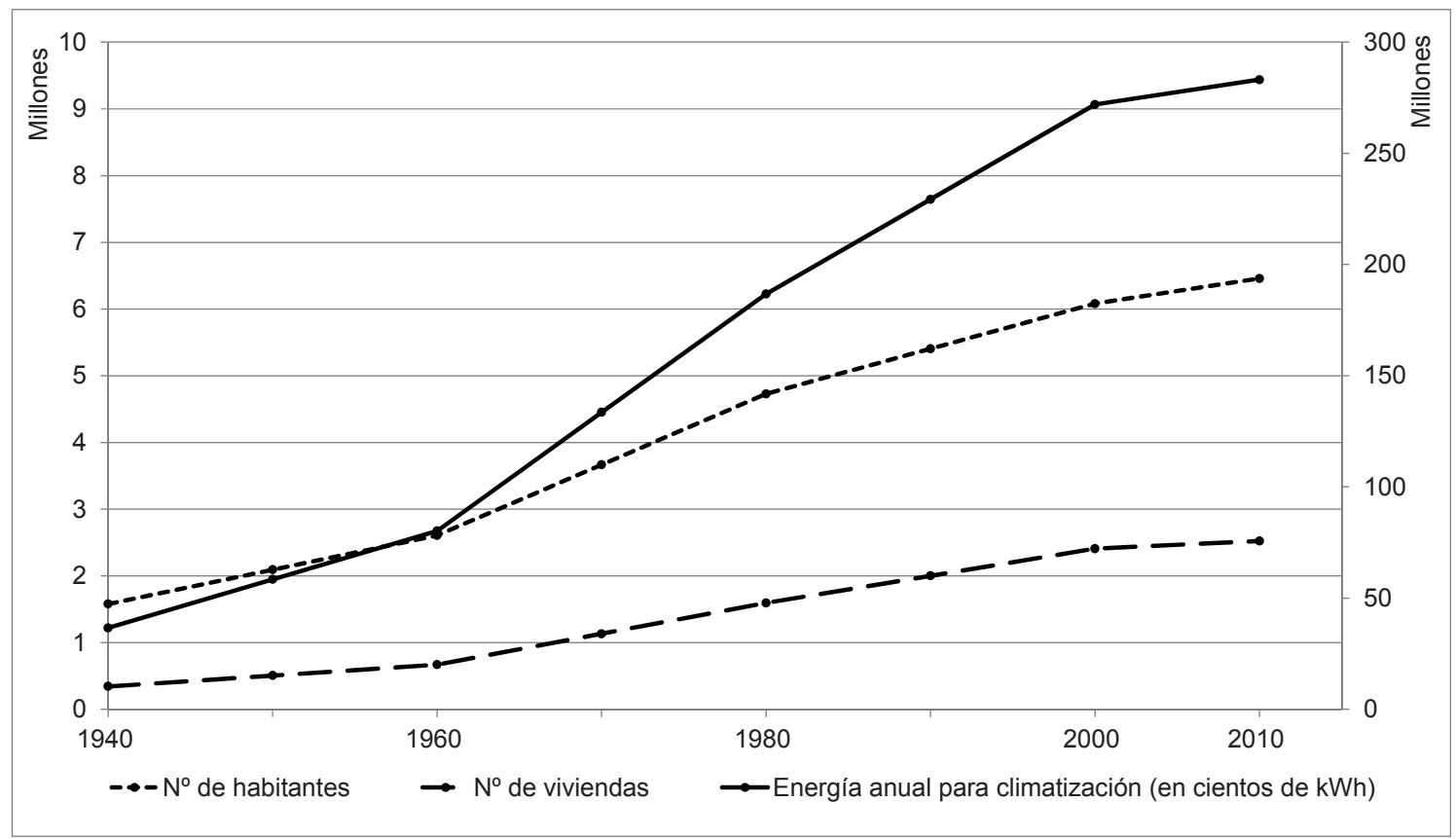

Figura 1. Evolución del número de habitantes, viviendas y consumo de energía en la Comunidad de Madrid entre 1940 y 2010

Fuente: Elaboración propia

Con estos datos se establece una relación entre los tres elementos; los habitantes, las viviendas y los recursos naturales, materiales y energéticos. La evolución para el caso de Madrid indica que en los últimos 50 años se ha producido un mayor incremento en el consumo de recursos naturales asociado a las viviendas que en la población, planteándose a continuación las causas que han conducido a esta situación y si hubiera sido posible evitarla. Para descubrirlas es necesario describir el sistema, entendiendo la complejidad en la relación entre los tres elementos y el carácter dinámico que tienen sus relaciones. El análisis de entre estos tres elementos permite encontrar similitudes con la definición de ecosistema, que es una comunidad de seres vivos cuyos procesos vitales se relacionan entre sí y se desarrollan en función de los factores físicos de un mismo ambiente. (Real Academia Española, 2001). De acuerdo con esta definición, los elementos que 
constituyen un ecosistema son la población (biocenosis ${ }^{6}$ ) y el soporte (biotopo ${ }^{7}$ ). En sistema que estamos estudiando se pueden señalar como elementos los habitantes, las viviendas y los recursos naturales. Así, en una primera aproximación, los habitantes serían equiparables a la biocenosis y las viviendas al biotopo, pero, puesto que para la construcción y funcionamiento de las viviendas es necesario el uso de materiales y energía externos a los límites del sistema urbano, se podrían considerar que las viviendas son la población o biocenosis y los recursos naturales el biotopo. De forma esquemática, esta idea se representa en la figura 2, en la que se establece la relación entre los elementos de cada uno de estos sistemas.

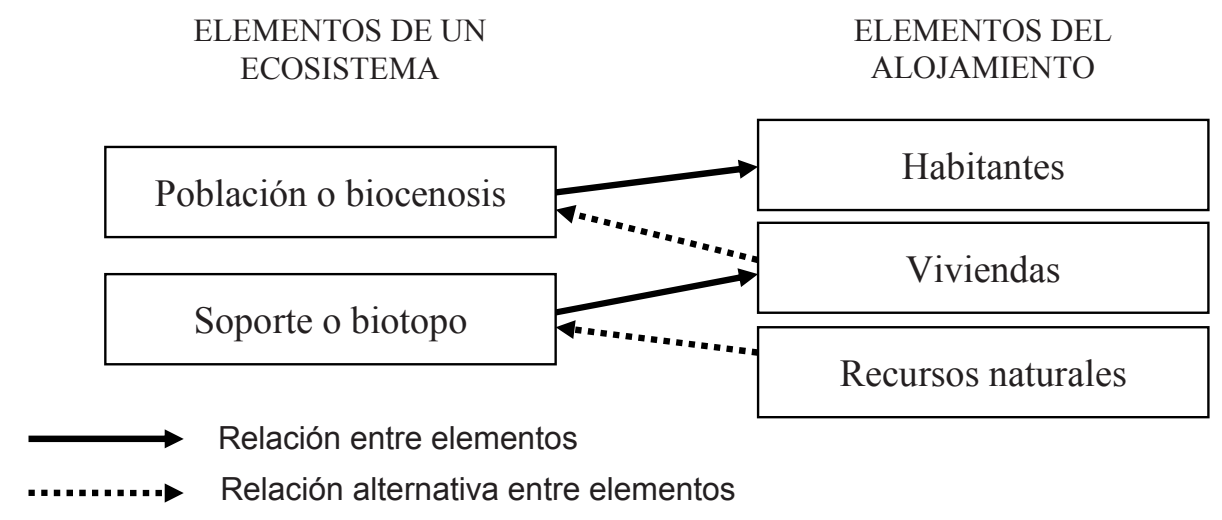

Figura 2. Comparación entre elementos de un ecosistema y del alojamiento

Fuente: Elaboración propia

La consideración de la relación entre los habitantes, las viviendas y los recursos naturales desde una perspectiva ecológica permitiría obtener información sobre nuestros sistemas urbanos y tomar decisiones para la reducción los impactos sobre medio ambiente. A partir de la consideración del alojamiento como sistema con elementos diferenciados, similar a un ecosistema, se plantea si mediante un análisis que permita establecer a largo plazo o de forma diacrónica ${ }^{8}$, las relaciones entre los tres elementos en el espacio y en el tiempo, se podrían definir medidas de intervención en el alojamiento que, con criterios ecológicos, redujeran el consumo de recursos asociado a su funcionamiento. Desde esta perspectiva, el alojamiento también se puede estudiar de una manera complementaria a la de consideración como un sistema, ya que también es un proceso que se sucede en el tiempo en sucesivas fases. Por tanto, a partir de las similitudes identificadas entre el sistema denominado alojamiento y los ecosistemas se podría desarrollar un método de análisis integral y dinámico para la intervención en el alojamiento, ya que un enfoque ecológico puede aportar ambas características.

\footnotetext{
6 "Conjunto de especies e individuos - estando mutuamente limitados y seleccionados bajo unas condiciones medias de vida - que se mantienen en posesión de un territorio determinado en virtud de su propia reproducción" (Margalef López, 1974, pág. 387)

7 "Territorio o espacio vital cuyas condiciones ambientales son las adecuadas para que en él se desarrolle una determinada comunidad de seres vivos" (Real Academia Española, 2001)

8 Se denominan como diacrónicos aquellos de los fenómenos que ocurren a lo largo del tiempo, en oposición a los sincrónicos que se producen en un momento concreto. (Real Academia Española, 2001)
} 


\section{ECOLOGÍA Y ALOJAMIENTO}

\subsection{Los límites del crecimiento: población y recursos naturales}

La aceptación por la comunidad científica internacional de que la actuación del ser humano ha cambiado las dinámicas del Planeta ${ }^{9}$, ha sido un importante respaldo para aquellos que desde hace décadas alertaban de la imposibilidad del desarrollo continuo en base a unos recursos naturales limitados. En estas circunstancias, uno de los principales problemas a los que se enfrenta la Humanidad a medio y largo plazo es el continuo incremento de la población mundial frente a estos recursos limitados, lo que conduce inevitablemente a la extralimitación y a la superación de la capacidad de carga del planeta (Meadows, Randers, \& Meadows, 2006, pág. 43). Si esta situación se mantiene indefinidamente, finalmente se alcanzaría una situación irreversible de colapso de nuestro planeta. La idea de que el crecimiento exponencial de la población está limitado por el crecimiento lineal de la producción de los recursos no es novedosa y fue apuntada por el economista británico Thomas Malthus $^{10}$ a finales del siglo XVIII. Sus predicciones no llegaron a cumplirse, pero dos siglos después, en 1972, el Club de Roma encargó a un grupo de científicos del MIT una investigación sobre esta cuestión que acabó conformando el llamado informe Meadows "Los límites del crecimiento" (Meadows D. , Meadows, Randers, \& Behrens, 1972).

A la vista de la expansión económica desarrollada después de la XX Guerra Mundial en el mundo occidental, este informe trataba de dar respuesta a las causas y consecuencias a largo plazo de un crecimiento de la población, la industria, los alimentos y la contaminación. Mediante la definición de diversos escenarios, se concluían que las dinámicas de crecimiento exponencial de la población y del producto interior bruto de los países no eran compatibles con los límites físicos del planeta. Los autores señalaban claramente que "Si el actual incremento de la población mundial, la industrialización, la contaminación, la producción de alimentos y la explotación de los recursos naturales se mantiene sin variación, alcanzará los límites absolutos de crecimiento en la Tierra durante los próximos cien años" (Meadows D. , Meadows, Randers, \& Behrens, 1972).

La figura 3 muestra como las previsiones de los modelos matemáticos aplicados por el equipo dirigido por Meadows demostraban esta afirmación. El informe revelaba la importancia de la relación entre la población y los recursos. De cara a la pervivencia del sistema social señalaban que era necesario un equilibrio entre todos los niveles que configuran la calidad de vida y la población. Estos mismos autores concluían entonces que era posible alterar estas tendencias y establecer unas condiciones de estabilidad económica y ecológica capaces de ser sostenidas en el futuro. Para ello, reclamaban la importancia de la planificación a medio y largo plazo para alcanzar los objetivos marcados. Entre las cuestiones fundamentales concluían que la estrategia debía ser global para el planeta.

\footnotetext{
9 Por ejemplo la modificación de las condiciones del clima a consecuencia de la excesiva emisión de gases de efecto invernadero como consecuencia de la actividad humana.

10 En 1798 Malthus publicó su Ensayo sobre el principio de la población en la que exponía que la población crece más rápidamente que los recursos, lo que conducía a un inevitable empobrecimiento y desigualdad económica.
} 


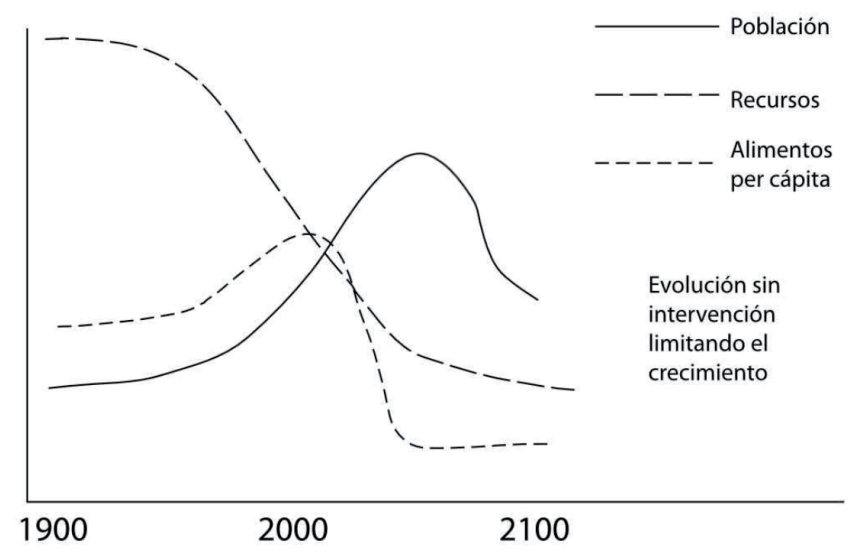

Figura 3. Modelo de evolución en caso de no existir intervención limitando el crecimiento basado en las previsiones del programa World-3

Fuente: Meadows D. , Meadows, Randers, \& Behrens, 1972

En la década de los 1970, el informe Meadows tuvo un importante impacto ya que desde una institución científica prestigiosa se cuantificaba y se ponía de manifiesto la debilidad de un modelo económico predominante basado en la idea de crecimiento ilimitado y continuo. La aparición del concepto "desarrollo sostenible" en el Informe "Nuestro futuro común" denominado Informe Brundtland y encargado por Naciones Unidas (Comisión Mundial del Medio Ambiente y del Desarrollo, 1988) quiso reconciliar conceptos que son antagónicos mediante una definición del desarrollo sostenible con un "controlada dosis de ambigüedad" (Naredo Pérez, 1996). De esta manera se pretendía extender la idea de que es posible un continuo crecimiento económico mundial con el respeto a los recursos naturales y a la viabilidad de los sistemas industriales, agrarios y urbanos.

La satisfacción de "nuestras necesidades actuales sin comprometer la capacidad de las generaciones futuras para satisfacer las suyas" no hacía referencia al problema de fondo que habían señalado los autores del Informe Meadows: los recursos del planeta son limitados $y$, en función de cómo se satisfagan las necesidades de toda la población, se pueden alcanzar escenarios sostenibles o llegar a situaciones no deseables. La revisión de los datos del Informe Meadows en 1992, bajo el título "Más allá de los límites del crecimiento" (Meadows, Meadows, \& Randers, Más allá de los límites del crecimiento, 1992) confirmó parte de estas previsiones. Según estos autores, a consecuencia del desarrollo económico basado en la explotación de recursos naturales en 1992 ya se había sobrepasado la capacidad de carga del Planeta.

En esta revisión del informe se hacía especial hincapié en que las tasas de extracción de recursos y emisión de residuos habían crecido hasta magnitudes insoportables. En 2004, se publicó una nueva revisión de este documento bajo el título "Los límites del crecimiento: 30 años después", confirmándose las hipótesis planteadas en 1974 e incidiendo en que el escenario más probable era peor en ese momento y más difícil de contrarrestar. La conclusión de este nuevo informe era que, al no haber existido ni planificación ni intervención, las predicciones del 
documento se habían cumplido. La línea de investigación de Meadows y Randers se basaba en el desarrollo de un modelo denominado World3 que permite identificar las posibles interrelaciones a largo plazo entre las pautas de comportamiento del ser humano (población mundial y economía material en expansión) con la capacidad de carga del planeta.

La aproximación de una población a la capacidad de carga del soporte en el que se asienta puede realizarse de distintas maneras. La figura 4 muestra cómo una población puede crecer de forma continua sin alcanzar la capacidad de carga (a) o crecer de forma exponencial hasta llegar al límite (b). Otra forma de aproximarse a la capacidad de carga es hacerlo mediante oscilaciones amortiguadas que permiten a la población adaptarse a los límites ya que la extralimitación de la capacidad de carga no es permanente (c). Sin embargo, la situación que ofrece más peligro para la supervivencia de la población es aquella en la que la extralimitación produce situaciones permanentes y la población se ve obligada a reducirse hasta alcanzar de nuevos el límite de capacidad de carga (d).

a. Crecimiento continuo

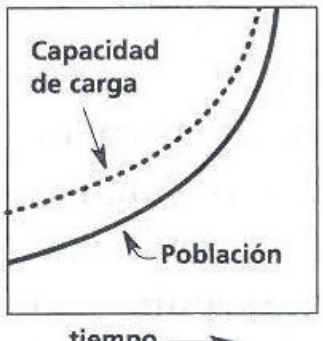

tiempo $\longrightarrow$

c. Extralimitación y oscilación

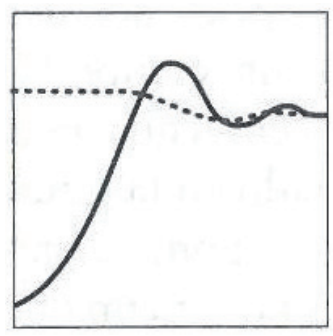

b. Aproximación sigmoidea al equilibro

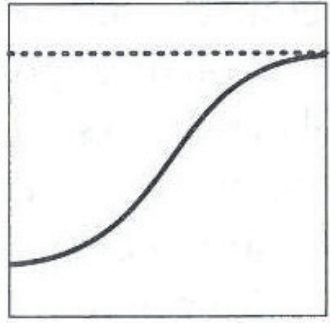

d. Extralimitación y colapso

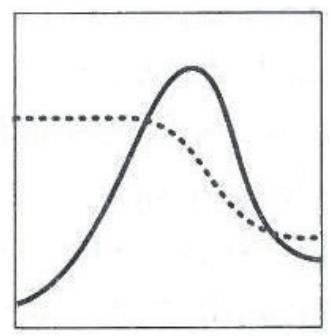

Figura 4. Posibles modalidades de aproximación de una población a su capacidad de carga Fuente: Meadows, Randers, \& Meadows, 2006, pág. 234

La aplicación del modelo World3 a la escala planetaria permite identificar situaciones no deseables y el impacto de medidas que traten de evitarlas. Para su desarrollo se identificaron como elementos fundamentales la población y los recursos naturales, entendiendo que éstos últimos son limitados y, por tanto, existe una capacidad de carga que no se puede exceder de manera continua. Dada la complejidad de factores que intervienen, este trabajo utiliza la definición de escenarios probables. Esta incertidumbre en las predicciones es la principal causa de las críticas sobre la investigación, pero los propios autores señalan que el modelo World3 se realizó para "comprender los grandes trazos, las tendencias del comportamiento del sistema. 
Nuestro propósito es plantear e influir en la elección humana. Para ello no necesitamos predecir exactamente el futuro. Basta con que definamos políticas que refuercen la probabilidad de un comportamiento sostenible del sistema y reducir la gravedad del futuro colapso." (Meadows, Randers, \& Meadows, 2006, pág. 237)

Los últimos datos sobre los indicadores ambientales a escala planetaria confirman la sobrexplotación de los recursos que señalan los sucesivos informes Meadows en los peores escenarios (Hall \& Day, 2009) y corroboran la validez de un modelo que pretende describir relaciones complejas entre elementos para alertar sobre la necesidad de provocar cambios en el funcionamiento de nuestro sistema ${ }^{11}$. Desde la publicación del Informe Meadows, se han desarrollado otros métodos para describir la relación entre la actividad humana y los límites del planeta. Entre ellos, el método de cálculo de la huella ecológica definido por el equipo dirigido por Mathias Wackernagel ha permitido cuantificar el impacto de la actividad humana en relación a la capacidad de carga. Las figuras 5 y 6 cuantifican la evolución de la huella ecológica y la población, señalando la aproximación a los límites del planeta de nuestro modelo.
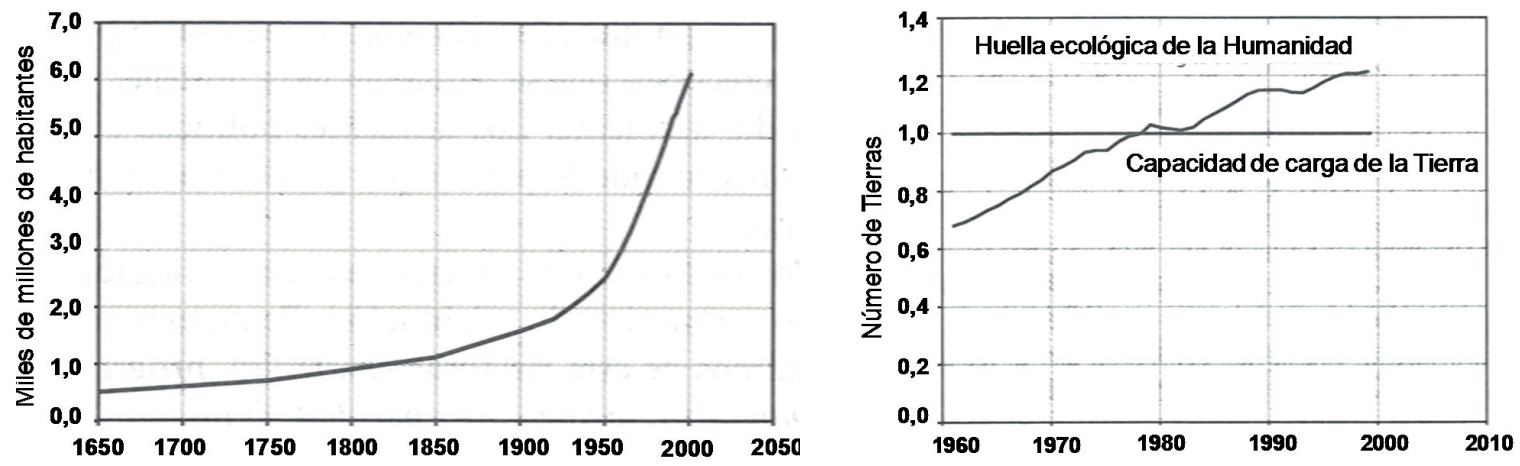

Figuras 5 y 6 . Evolución de la población mundial (izquierda) y evolución de la huella ecológica mundial (derecha)

Fuente: Meadows, Randers, \& Meadows, 2006, pág. 49 / Meadows, Randers, \& Meadows, 2006, pág. 27

Para invertir la tendencia haría falta "que la sociedad reaccione a las señales de deterioro en las condiciones de habitabilidad de la Tierra, corrigiendo el funcionamiento del sistema económico que lo origina"(Naredo Pérez, 1996). Por tanto, sería necesario un cambio de modelo de organización que permita la evaluación desde los límites físicos del Planeta.

Desde la disciplina económica sobre la relación entre las actividades humanas y el medio físico se han planteado dos posiciones: "...la economía convencional - o neoclásica - analiza sobre todo los precios (es, pues, fundamentalmente "crematística") y tiene una concepción metafísica de la realidad económica que funcionaría como un perpetum mobile lubricado por el dinero. Las empresas venden bienes y servicios, y con esto remuneran los factores de producción (tierra, trabajo y capital). La economía ecológica ve al planeta Tierra como un sistema abierto a la

${ }^{11}$ En el caso de España, la Huella Ecológica para nuestro país se incrementó de 3,67 Ha/hab en 1975 a 5,04 Ha/hab en 2003, siendo la capacidad de carga de nuestro territorio de 1,7 Ha/hab (Carpintero, El metabolismo de la economía española, 2005), (World Wildlife Foundation, 2006) 
entrada de energía solar. La economía necesita entradas de energía y materiales, y produce dos tipos de residuos: el calor disipado o energía degradada (2a ley de la termodinámica), y los residuos materiales, que mediante el reciclaje pueden volver a ser parcialmente utilizados." (Martínez Alier \& Roca Jusmet, 2000, pág. 13). Con este enfoque, la Economía Ecológica pretende aunar los principios de la Ecología con la economía social, proponiendo una contabilidad que estime el impacto que nuestra sociedad provoca sobre el planeta con la continua degradación de materiales y energía. Esta posición busca referencias en la Ecología como disciplina que estudia "la naturaleza en términos de materia, energía y organización."(Margalef López, 1974).

Los orígenes de estos planteamientos se encuentran en base a las formulaciones de Clausius en 1850 del Segundo Principio de la Termodinámica ${ }^{12}$, en la exposición del químico Frederick Soddy sobre la relación directa entre la energía y la economía ${ }^{13}$ y en el pensamiento del economista rumano Georgescu-Roegen que en la segunda mitad del siglo XX planteó la necesidad de una contabilidad económica que tuviera en cuenta la indisoluble unión de nuestra economía con la degradación del medio ambiente señalando la diferencia entre los procesos físicos y los económicos: aunque ambos se rigen por los principios de la termodinámica, en estos últimos el flujo de salida no son los residuos, sino "el placer de vivir. Esta cuestión representa la segunda diferencia entre este proceso y el avance entrópico del entorno material." (Georgescu-Roegen, 1971, pág. 353).

Por tanto, los avances en el conocimiento del funcionamiento de la Naturaleza a través de los trabajos de la Química, la Física, la Ecología y otras ciencias son fundamentales para conocer y mejorar el funcionamiento de la actividad humana. Según señala el ecólogo Ramón Margalef, desde una visión exclusivamente termodinámica la degradación de la energía y los materiales es la savia del Universo y es imprescindible para la existencia de la vida en el Planeta (Margalef López, 1993), pero, mientras los ecosistemas se auto organizan según su entorno, los sistemas organizados por el ser humano, al ser conscientes de las consecuencias de su actividad y deben ser capaces de mejorar su funcionamiento para adecuarse a los límites de la naturaleza.

\footnotetext{
12 Clausius enunció el Segundo Principio de la Termodinámica de la siguiente manera "Es imposible que una máquina. sin ayuda mecánica externa, transfiera calor de un cuerpo a otro más caliente." Otra formulación de este autor sería "Ningún proceso cíclico es tal que el sistema en el que ocurre y su entorno puedan volver a la vez al mismo estado del que partieron". Una definición más coloquial de este principio es que no todas las formas de energía son iguales y que hay transferencias de una forma a otra que se producen espontáneamente, mientras que para otras es preciso aportar trabajo externo, siendo la forma de energía más degradada es el calor. Estas cuestiones son de enorme importancia en los procesos socioeconómicos, porque en los flujos económicos no se considera la calidad de la energía, mientras que en los procesos físicos es determinante para que un sistema sea sostenible. Una descripción de este principio y de otros paradigmas científicos así como de las consecuencias en nuestro pensamiento se puede encontrar en (Vázquez Espí, La evolución de los paradigmas científicos: desde Galileo al "caos", 1996)

13 Soddy señalaba que "el economista tiende a menudo a confundir las leyes de la naturaleza humana con las leyes de la naturaleza" (Soddy, 1921)
} 


\subsection{El alojamiento desde los límites}

Para conocer el funcionamiento del alojamiento en un entorno urbano es fundamental considerar la relación entre población, viviendas y recursos naturales, que debe estudiarse desde la perspectiva de la limitación de recursos.

El análisis del alojamiento desde los límites es complicado porque, si bien se puede hacer un estudio a escala planetaria del mismo, es la definición del territorio en el que se ubica la población, la que marca las necesidades y los límites del sistema. Sin embargo, es un hecho que el intenso desarrollo urbano producido durante el pasado siglo ha conducido a que las ciudades concentren la mayor parte de la población mundial, sobrepasando estos sistemas urbanos la capacidad de carga del territorio en el que se ubican.

Esto implica la explotación de los recursos de otros lugares y que estos sistemas urbanos no hayan colapsado, a costa de incrementar la huella de la actividad en un entorno lejano. Esta situación, se aproxima a la descripción de Margalef sobre la dualidad de sistemas disipativos y auto-organizados en la Naturaleza (Terradas, 2015).

Por otro lado, la actualidad especialización de las actividades urbanas en las ciudades, en las que se concentran usos más consumidores de recursos que productores hace inviable la utopía de una red de ciudades autosuficientes. A modo de ejemplo, en el caso de una región fuertemente urbanizada como Madrid, en 2000 la huella ecológica era de 6,5 Ha/hab., lo que implicaba un déficit de más de 4 $\mathrm{Ha} / \mathrm{hab}$. (Ministerio de Medio Ambiente y Medio Rural y Marino, 2008, pág. 43).

En 2012, la huella ecológica se situaba en 4,7 Ha/hab, la mayor parte de ella debida al consumo de energía (World Wildlife Foundation, 2012). Esta situación sólo es sostenible en el tiempo porque se importan desde otros lugares recursos energéticos y materiales a este territorio. Si se quisiera reducir el consumo de recursos habría que intervenir de cualquiera de estas maneras:

- Reduciendo la población, bien por desplazamiento a otros territorios o las propias dinámicas de crecimiento de ésta.

- Disminuyendo la utilización de recursos mediante cambios en los modos de vida de los habitantes.

- Incrementando la eficiencia del sistema, lo que supondría en muchos casos la reorganización de las edificaciones y la mejora de su calidad.

Cada una de estas medidas se dirigen a cada uno de los elementos constitutivos del sistema alojamiento: habitantes, viviendas o recursos naturales, y sería necesario evaluar su eficacia a largo plazo así como el impacto en cada uno de los elementos. Por la similitud de los elementos con los que conforman un ecosistema, la Ecología puede ayudar a definir las estrategias y medidas necesarias para que el sistema evoluciones de acuerdo con las limitaciones que la Naturaleza plantea. Para ello es necesario plantear un método de evaluación de acuerdo con este enfoque. 


\subsection{Los modelos de la Ecología y su aplicación al alojamiento}

La Ecología como ciencia es relativamente reciente. Su nacimiento se sitúa hacia 1930 (Dajoz, 1974, pág. 22) cuando los botánicos ingleses Roy Clapham y Arthur Tansley definieron ecosistema, apoyándose en antecedentes aportados por las disciplinas que estudiaban la Naturaleza. El término Ecología, utilizado por primera vez en 1869 por el biólogo alemán E. Haeckel (Margalef López, 1974), significa literalmente "ciencia que estudia la casa" o, en un sentido más amplio, "el hábitat". Esta definición es la base de la que actualmente se incluye en el Diccionario de la Real Academia de la Lengua como Ecología la "Ciencia que estudia las relaciones de los seres vivos entre sí y con su entorno" o como "Parte de la sociología que estudia la relación entre los grupos humanos y su ambiente, tanto físico como social."

El estudio de las relaciones de los seres vivos entre sí y con el entorno físico ha sido la aportación más novedosa de la Ecología respecto a otras ciencias de la Naturaleza y ha sido la base para el desarrollo de métodos de análisis que han ayudado a comprender y conocer mejor el funcionamiento de nuestro planeta. La aplicación del enfoque ecológico a otras disciplinas es posible porque "/a Ecología es un ciencia de síntesis, que combina materiales de distintas disciplinas con puntos de vista propios." (Margalef López, 1974, pág. 2).

La aplicación del conocimiento sobre los ecosistemas a los sistemas socioeconómicos sirvió para que, en 1969, el ecólogo estadounidense Howard T. Odum $^{14}$ pusiera de manifiesto las semejanzas entre los modelos que planteaba la Ecología para explicar las relaciones entre los seres vivos y su entorno y el desarrollo de las sociedades humanas ${ }^{15}$. Sin embargo, aún están por desarrollar herramientas que permitan planificar la ciudad teniendo en cuenta la complejidad de relaciones en el espacio y a lo largo del tiempo que se producen en la ciudad (Alberti, 2009). Esta complejidad de procesos es la que permite definir la ciudad como un sistema de subsistemas. De esta manera, una vez identificados esos subsistemas que componen la ciudad, sería posible su análisis para comprender su funcionamiento, especialmente desde la limitación de recursos disponibles en el planeta. Con esta idea, el alojamiento podría considerarse un subsistema dentro del sistema urbano, ya que puede acotarse mediante la identificación de elementos constitutivos propios: población, viviendas y recursos naturales.

\section{De la sucesión ecológica al cambio adaptativo}

La dimensión temporal es fundamental para describir el comportamiento de cualquier sistema. En el caso de los sistemas naturales, las modificaciones que se producen a lo largo del tiempo resultan más comprensibles mediante la sucesión ecológica. La sucesión es la evolución que se produce naturalmente de los ecosistemas por sus propias dinámicas internas. Este modelo de descripción fue utilizado en primer lugar por los botánicos y, posteriormente, se amplió su uso al

\footnotetext{
14 H.T. Odum junto a su hermano Eugene publicó en 1953 una de los primeros tratados de Ecología, convirtiéndose ambos en referentes de la Ecología del siglo XX.

15 La rama del conocimiento ecológico que se ocupa del estudio de estas interrelaciones entre los habitantes de una aglomeración urbana es la Ecología Urbana.
} 
resto de sistemas. Por la gran complejidad que encierra, entre los ecólogos existen diversas posiciones para explicar el fenómeno de la sucesión, Una de las explicaciones más extendidas es la que asigna a la sucesión un carácter reduccionista, y concede mayor importancia a la aleatoriedad en los procesos de perturbación y respuesta por parte de los ecosistemas. Otras posiciones mantienen que la sucesión tiene un carácter holístico y defienden un cierto determinismo en la evolución de los ecosistemas a partir de lo que llaman propiedades emergentes de los mismos. La sucesión ecológica se define como un proceso de cambio y desarrollo en el cual, las etapas de sucesión previas son reemplazadas por etapas de sucesión subsecuentes hasta que se establece una comunidad madura. Esta evolución se produce en función de tres parámetros:

- Es un proceso de cambio de una comunidad, lo bastante direccional para resultar predecible.

- Es el resultado de la modificación de un entorno físico por parte de la comunidad. Ésta controla el proceso de sucesión, aunque el mismo entorno físico sea el que determine los patrones, el ritmo de los cambios y los límites del crecimiento. Estos procesos de degradación de recursos naturales tienen carácter irreversible pero son los que permiten la existencia de los ecosistemas, por lo que puede afirmar que "los procesos irreversibles desempeñan un papel constructivo en la naturaleza" (Prigogine, 1996, pág. 30)

- La sucesión culmina en un ecosistema estable, en el cual se mantiene un máximo de biomasa y de relaciones de simbiosis entre los organismos por unidad de flujo energético. Alcanzar este clímax o estado de estabilidad es el objetivo de la sucesión y permite al ecosistema soportar las posibles interferencias desde el exterior. Como veremos más adelante, este estado se define como mediante una estabilidad dinámica.

La sucesión se puede interpretar también como un proceso de acumulación de información (Margalef López, 1974, pág. 741) entendida ésta como acopio de energía, incremento de biomasa o complejidad de estructura (Walker, y otros, 2002). Se puede concluir que, a través de la sucesión, el ecosistema aprende las dinámicas que le conducen a un estado más estable y desecha procesos que perjudican su perduración ${ }^{16}$. La sucesión no es posible sin la existencia de energía externa al propio ecosistema. Los defensores de la aproximación holística al concepto de sucesión como Ramón Margalef y Howard Odum "coincidían en considerar el control que la energía procedente de fuentes no biológicas (exosomáticas) ejerce sobre la energía interna (endosomática) como uno de los generadores de cambio en el ecosistema." (Walker, y otros, 2002). Los seres humanos utilizamos una gran cantidad de energía externa (no metabólica) y esto conduce al transporte horizontal y a la extensión del fenómeno urbano. Esta tendencia mantenida a lo largo del tiempo al incremento de población y del metabolismo (Terradas, 2015, pág. 107).

\footnotetext{
16 La Teoría General de Sistemas define este proceso como retroalimentación. Así el primero y el tercero de los parámetros correspondería a la descripción de los objetivos del sistema, el segundo a los flujos de entrada y salida de energía y materiales.
} 
Los tres parámetros que describen la sucesión ecológica permiten definir algunas características de los ecosistemas urbanos. E. Odum señalaba que "la sucesión ecológica conlleva el desarrollo de los ecosistemas; se trata de un concepto que tiene muchos paralelismos con la biología de crecimiento de los organismos y también con el desarrollo de las sociedades humanas." (Odum E. , 1969).

Al igual que en los ecosistemas, la degradación de materia y la energía es indispensable para el funcionamiento de un sistema urbano. Su uso implica una modificación del entorno, no sólo próximo, sino también lejano. La consideración de la estabilidad de los ecosistemas como objeto de la sucesión ecológica implica un aprovechamiento de las estructuras creadas y de las relaciones para obtener un mayor rendimiento en la supervivencia del sistema. La búsqueda de la eficiencia de los ecosistemas quedó formulada con el Principio de Máxima Potencia propuesto por H.T. Odum que, en la línea de la teoría de la evolución de Darwin, afirmaba que los ecosistemas que prevalecían eran los que maximizaban la entrada de los flujos de energía disponible y la usaban de forma eficiente ${ }^{17}$.

La sucesión en un ecosistema, por tanto, es posible gracias a la transformación de la energía y los materiales y este fenómeno hace posible su evolución hacia una mayor complejidad. Sin embargo, no sólo es relevante la degradación de materia y energía, sino también la velocidad a la que esta se produce. Si bien, "la vida, en su evolución, ha dado prioridad a la acumulación de información sobre el fluir de la energía. (...) A la larga, en un contexto de menor energía, o de disponibilidades de energía más constantes, sobreviven los que renuevan más lentamente sus materiales en un uso parsimonioso de la energía. Una y otra vez los ecólogos se ven obligados a hacer referencia a estas dos llamémoslas estrategias - tan rápido como es necesario para mantener el sitio, tan lento como se pueda para mantener plena sensibilidad a la información asequible." (Margalef López, 1993, pág. 112).

Al igual que en los ecosistemas, la velocidad ocupa un papel importante en su supervivencia, ya que en función de la fase en la que se encuentren se requiere un ritmo u otro. En los sistemas desarrollados por el ser humano también es determinante. El cambio rápido y la aceleración son la primera causa de extralimitación del consumo de recursos naturales por la explotación de nuestras sociedades. El crecimiento exponencial de la población mundial a partir de la revolución industrial ha traído como consecuencia un incremento en la demanda de recursos naturales (Meadows, Randers, \& Meadows, 2006, pág. 66). Para plantear

17 Esta idea ya había sido expresada anteriormente en 1922 por Alfred Lotka de la siguiente manera: "Boltzmann ha señalado que el objeto fundamental de disputa en la lucha por la existencia, en la evolución de las especies, es la energía disponible. De acuerdo con esta observación existe el principio de que, en la lucha por la vida, tienen ventaja aquellos organismos que sus dispositivos de captación de energía son más eficientes en dirigir la energía disponible hacia procesos favorables para la preservación de la especie." (Lotka, 1922). Lotka advertía que los organismos que tratan la energía disponible de manera eficiente, además de obtener una mayor ventaja en la selección natural, mediante su gestión incrementaban el flujo energético total del sistema y optimizaban los procesos de retroalimentación. En sus palabras "la selección natural tiende a optimizar el flujo energético a través de un sistema, siempre que sea compatible con las limitaciones propias del sistema." Es decir, a medida que un ecosistema evoluciona, las relaciones entre las partes se hacen más complejas, de manera que la interacción de unas con otras permite sacar más rendimiento al flujo energético y mantener la estabilidad del conjunto del sistema. Esta estrategia busca la máxima protección, es decir el mantenimiento del mayor número de estructuras vivas complejas 
medidas que reduzcan el impacto ambiental, es preciso comprender la relación entre la velocidad de crecimiento de cualquier sistema y los recursos necesarios para su mantenimiento. Otra cuestión que no se debe olvidar al hablar de la sucesión de los ecosistemas, es la organización espacial. Margalef señala que, en las expresiones de Lotka y autores posteriores, se da toda la importancia al proceso temporal de los ecosistemas, pero no se hace referencia a otro hecho fundamental: la ocupación y organización del espacio. Como el autor catalán indica "En el curso de la sucesión, a una pérdida importante del tiempo, pues cada vez ocurren menos cambios, se combina una mayor importancia de la organización espacial, pues al mismo tiempo el ecosistema se diversifica." (Margalef López, 1974, pág. 821). Esta referencia a las cuestiones espaciales es fundamental cuando planteamos un enfoque ecológico sobre la ciudad como sistema. Por esta causa, este mismo autor afirma que "la evolución cultural humana se parece más a la sucesión ecológica que a la evolución de una especie." (Margalef López, 1974, pág. 892)

La sucesión ecológica parece determinar la dirección de la evolución del ecosistema, ya que este se encamina a alcanzar una cierta estabilidad, que le haga ser menos vulnerable a las perturbaciones exteriores. Esta estabilidad tiene un carácter dinámico, se trata de un desequilibrio o dinamismo estabilizado (Rueda Palenzuela, 1996) que, para perdurar, necesita tanto del adecuado funcionamiento de los componentes del propio sistema como de las relaciones entre éstos y su entorno. La dependencia de recursos implica que los ecosistemas tengan limitado su cambio en función de la disponibilidad, y ésta se puede definir como capacidad de carga del territorio en el que se asienta ${ }^{18}$. Cuando se alcanza la capacidad de carga es necesario un equilibrio entre la materia y energía producidas y las que se necesitan para el mantenimiento del propio sistema. La capacidad de carga está condicionada por la biomasa, la población, y especialmente por la forma de gestión de los recursos. Este último concepto lo podemos comparar con los "estilos de vida" que llevan aparejados consumos de energía y de materia per cápita diferentes según el modelo que se aplique. La superación de la capacidad de carga implica que, a largo plazo, el sistema está en riesgo de desaparecer, salvo que se apliquen estrategias adecuadas a corregir esta situación. Cuando un ecosistema alcanza un equilibrio dinámico también constituye una identidad morfológica, que lo define y diferencia ${ }^{19}$. La sucesión implica una acumulación de información que también se manifiesta en las tramas urbanas como identidad morfológica ${ }^{20}$.

Los conceptos de equilibrio dinámico e irreversibilidad han sido ampliamente estudiados por la física de los procesos del no equilibrio, y han permitido el

\footnotetext{
18 Según la Biología, la capacidad de carga de una especie biológica en un ambiente es el tamaño máximo de población que el ambiente puede soportar indefinidamente en un periodo determinado, teniendo en cuenta el alimento, agua, hábitat, y otros elementos necesarios disponibles en ese ambiente. La capacidad de carga se alcanza cuando la producción se iguala con el mantenimiento respiratorio.

19 En sistemas desarrollado por el ser humano, como es el caso de las ciudades, a lo largo de su existencia también se constituye esta identidad morfológica, que además está compuesta por diversos parámetros: físicos, sociales, económicos,... y que es no uniforme en toda su extensión, sino que tiene diferencias en función de las diversidad de tramas urbanas. Tampoco es uniforme a lo largo del tiempo, ya que puede variar a lo largo de los años

20 Sobre la relación entre la organización del soporte físico de la ciudad y la entropía y cantidad de información asociada a éste véase (Fariña Tojo, 1995).
} 
desarrollo de otros conceptos como auto-organización de sistemas o estructuras disipativas aplicados también en la Ecología más reciente (Prigogine, 1996) (Terradas, 2015). La consideración de éstas y otras cuestiones como el determinismo, la existencia de sistemas dinámicos estables y sistemas caóticos, están suponiendo la reformulación de muchas de las teorías de la física para describir el funcionamiento de la Naturaleza y a revisar el modelo de la sucesión ya que no explica la complejidad cuestiones que suceden en la realidad, por otros basados en la idea de sucesión y evolución que explican la existencia de transformaciones más dinámicas en los ecosistemas, reguladas mediante tres propiedades observadas en ellos: su potencial de cambio, el grado de conectividad entre los componentes del mismo y la resiliencia (Alberti, 2009).

El potencial de un ecosistema depende de su biomasa, nutrientes y estructura física. La conectividad refleja la cantidad y calidad de las conexiones interiores del ecosistema que, de nuevo, nos refieren a la sinergia entre los elementos de un sistema y los sistemas entre sí. Por último, la resiliencia, un concepto aplicado a la Ecología por Holling en 1973, indica la capacidad de un ecosistema de absorber perturbaciones, sin alterar significativamente su identidad, su estructura y funcionalidad, y que le permite regresar a un estado estable una vez que la perturbación ha terminado.

Estas tres propiedades ayudan a comprender las dinámicas no lineales y los procesos por los que los ecosistemas se mantienen y persisten frente $a$ perturbaciones y los cambios. Se observa que los ecosistemas más complejos y con mayores interacciones entre sus partes tienen mayor cantidad de mecanismos autorreguladores. La resiliencia como característica de un ecosistema relaciona la capacidad de cambio de un sistema complejo con el mantenimiento de la identidad del mismo, es decir sus propiedades funcionales y estructurales. También aporta información sobre la capacidad del sistema para auto organizarse, es decir para innovar y adaptarse a los cambios, sin que ello implique el retorno a una situación de equilibrio anterior ya que después de una reorganización, la situación ha variado, por lo que resulta imposible retornar a una etapa anterior ${ }^{21}$.

La evolución del conocimiento de los ecosistemas ha proporcionado a la Ecología el cambio de un enfoque más lineal y mecánico a uno multidimensional y no lineal, que describe mejor cómo se suceden de forma cíclica etapas de mayor estabilidad en los sistemas complejos. Cuando se ven afectados por perturbaciones de las condiciones en las que se desarrollan, aparecen periodos de cambio. En las etapas menos maduras, después de cada ciclo no se regresa a la posición inicial, sino que ésta ha variado. En etapas más maduras, aunque se produzcan cambios, cada ciclo retorna en algún momento a posiciones estables, ya que el propio sistema tiene un grado de resiliencia y por tanto la capacidad de recuperación. Estas ideas se ilustran en la figura 7, que recoge este modelo sucesión / evolución como un proceso autoorganizativo en el que la población acaba aumentando su control sobre el medio físico en el que vive.

21 Estas ideas remiten de nuevo a los conceptos de irreversibilidad, auto-organización y equilibrio dinámico, a la teoría general de sistemas que han permitido nuevas clasificaciones de los sistemas dinámicos en estables, inestables o caóticos y las propuestas de Prigogine para la inclusión del tiempo como elemento clave para formular una nueva relación del ser humano con la Naturaleza. 


\section{SUCESIONES}

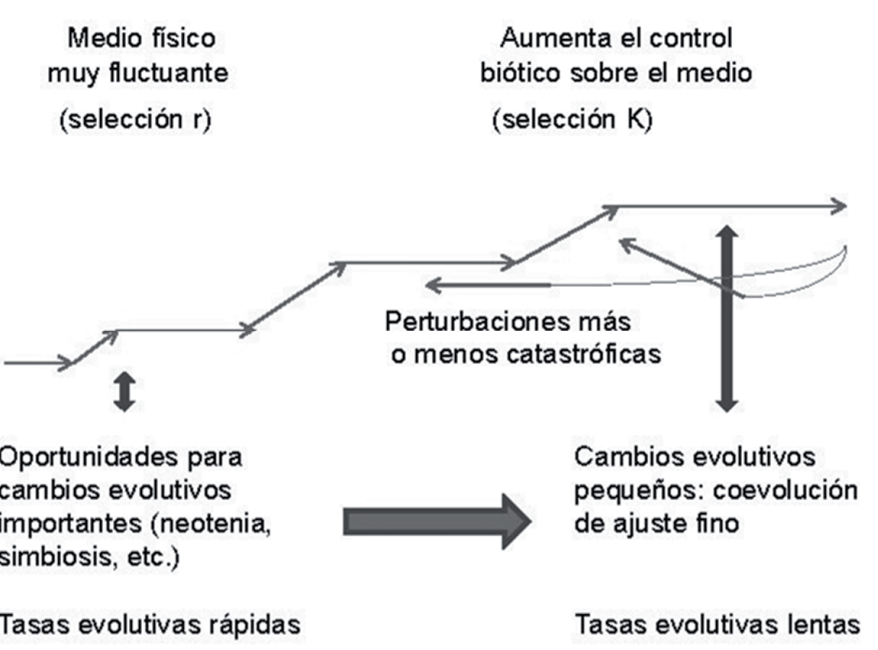

EVOLUCIÓN

Figura 7. Esquema de sucesión / evolución de un ecosistema

Fuente: Terradas, 2015, pág. 106

Estos cambios provocan situaciones lejanas al equilibrio, que describen el funcionamiento de los ecosistemas, otorgando al tiempo un valor fundamental en la interpretación de los fenómenos de la Naturaleza. La evolución biológica requiere organizaciones "lejos del equilibrio" ya que para la adaptación, la evolución o el aprendizaje se requieren dos tensiones contrapuestas: por una parte la capacidad de aprender y de cambiar; por otra, capacidad de conservar y permanecer." (Vázquez Espí, 1996). La observación del comportamiento de los Naturaleza ha permitido la formulación de otros modelos que describen los cambios y a los ecosistemas como Sistemas Complejos Adaptativos (Bermejo, 2008, pág. 28), con capacidad de cambio para adaptarse a nuevas situaciones, siempre dentro de los límites marcados por su resiliencia. El estudio de estos procesos dinámicos ha generado la llamada Teoría del Cambio Adaptativo (Holling \& Gunderson, 2002), en la que, avanzando en los planteamientos de Odum, se describe la evolución cíclica de los ecosistemas ante las perturbaciones (figura 8). Estos ciclos, llamado ciclos adaptativos permiten a los ecosistemas adaptarse a los cambios que se producen en su entorno o por su propia evolución, pero manteniendo su identidad.

En la vida de un ecosistema se producen numerosos ciclos adaptativos, y en cada uno de ellos la teoría señala cuatro fases: liberación o destrucción creativa (fase $\Omega$ ), reorganización (fase a), explotación (fase $r$ ) y conservación (fase k). En la fase $\Omega$ se produce un colapso en el ecosistema que provoca la reducción de su resiliencia y conduce a una segunda fase a en la que el sistema se reestructura para adaptarse a las nuevas condiciones que le permitan acumular recursos y energía para la supervivencia. Estas dos primeras fases son rápidas y dan lugar a una tercera fase $r$ de explotación y a la fase $k$ de conservación en la que se produce una lenta acumulación de energía y materiales, en el que se alcanza la mayor eficiencia en el uso de estos recursos. 


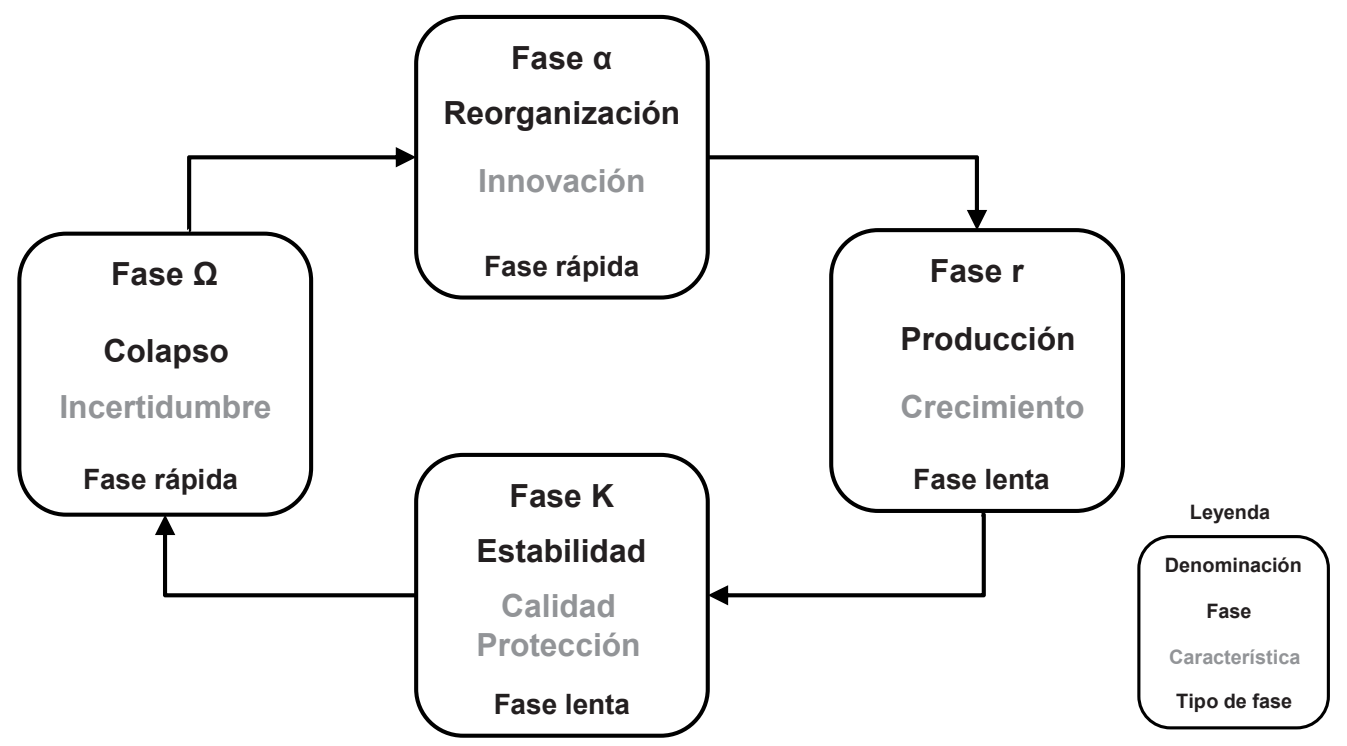

Figura 8. Características y propiedades de las fases de un ciclo adaptativo Fuente: Elaboración propia a partir de (Odum E. , 1969) y (Holling \& Gunderson, 2002)

En una etapa inicial, la comunidad del ecosistema emplea todos sus recursos en el crecimiento- "Tan rápido como es necesario para mantener el sitio"- (Margalef López, 1993, pág. 112) mientras que una vez se alcanza una etapa de "madurez", en la que las relaciones entre los individuos se han hecho más complejas, la estrategia es proteger esta estructura para sacarle el mayor rendimiento de cara a la supervivencia. En palabras de Margalef "tan lento como se pueda para mantener plena sensibilidad a la información asequible" (Margalef López, 1993, pág. 112).

Si en esa etapa de madurez se produce algún cambio, el ecosistema suele reaccionar iniciando una periodo de reorganización que le permita, manteniendo su identidad, recuperar el equilibrio dinámico de la fase de conservación (fase K). Si no es capaz o su respuesta no es lo suficientemente rápida, el ecosistema como nivel de organización desaparece, y se inicia un proceso de formación de un nuevo ecosistema a partir de los elementos del anterior. Transcurrido un ciclo adaptativo completo, el ecosistema nunca vuelve a las mismas condiciones iniciales, sino que es un proceso cíclico y dinámico, que se asocia a la idea de evolución, en el que el ecosistema se ha hecho más complejo ${ }^{22}$.

La visión tradicional de la sucesión ecológica se centraba en las fases de explotación y conservación, cualificando los sistemas como jóvenes o maduros en función de su estado de desarrollo. Sin embargo, el estudio de las otras dos fases de liberación y reorganización resultan interesantes en cuanto a que crean oportunidades para el cambio y la innovación en el ecosistema. Margalef explica claramente esta idea "En las variaciones de un ecosistema se pueden distinguir dos componentes. Una componente cíclica o, por lo menos, con cierto retorno a situaciones pasadas, y una componente con dirección definida, cuyo sentido puede

22 La complejidad se produce por la retroalimentación en forma de acumulación de materia, energía o información en el propio sistema. 
ser irreversible" (Margalef López, 1974, pág. 738). Con el paso del tiempo, se consolidan sistemas maduros en los que los cambios tienen una menor magnitud. Como se ha señalado, la evolución de los ecosistemas se produce por la degradación de materia y energía, y tiene como consecuencia la acumulación de información. Este acopio puede producirse en forma de energía, biomasa o estructura, y conlleva el incremento de complejidad del sistema. Los ecosistemas alcanzan un estado más "maduro" si han sido capaces de aprender de su propio proceso de evolución y pueden de anticiparse a las posibles variaciones de su entorno, lo que les hace más resistentes a los cambios.

En su aplicación a la ciudad, los ecólogos insisten en que aún no existen modelos que definan de forma clara las interacciones entre el desarrollo urbano y los procesos ecológicos (Alberti, 2009, pág. 34). Por ejemplo, la aplicación del concepto de resiliencia al fenómeno urbano es un hecho reciente sobre el que hay interés y expectativas. La resiliencia urbana pretende cuantificar y definir cuántas y el tipo de perturbaciones que pueden absorber los sistemas urbanos sin cambiar a un sistema alternativo menos deseable. Algunos equipos de investigadores están tratando de desarrollar este concepto de resiliencia urbana e indican cuatro elementos: los flujos metabólicos, la dinámica social, las formas de gobierno, y el entorno construido. Los modelos para describir la evolución de los ecosistemas señalan la inestabilidad y la diversidad como variables fundamentales para describir los procesos naturales. La inestabilidad está ligada a la complejidad y a la incertidumbre sobre el futuro. Por otro lado, la existencia de mecanismos de autoorganización y adaptación explican la supervivencia de los ecosistemas ante los cambios.

\section{La aplicación del enfoque ecológico al alojamiento}

Como se ha visto, la Ecología es una ciencia que permite comprender mejor el funcionamiento de la Naturaleza. Sus modelos amplían nuestro conocimiento del entorno, conectando diferentes (Margalef López, 1974, pág. 882). En ese sentido, los trabajos de la Ecología Urbana (Holling, Walker, Gunderson) en la búsqueda de referencias en los ecosistemas naturales para explicar los fenómenos urbanos, han señalado que teorías como la sucesión ecológica o el cambio adaptativo puede ser aplicadas a los sistemas socioeconómicos. El propio Margalef reflexionaba sobre las similitudes entre las organizaciones humanas y los ecosistemas y su impacto en la biosfera. La transmisión del conocimiento en nuestras sociedad nos ofrece la ventaja de una evolución más rápida que la biológica, pero nos impide en algunos casos detectar cuestiones fundamentales, como los límites de nuestros propios sistemas (Terradas, 2015, pág. 108).

El enfoque de la Ecología Urbana pasa por la consideración de la ciudad como un sistema organizado, basado en múltiples procesos adaptativos complejos en el que intervienen factores sociales, metabólicos y físicos. En la Ecología entendida como biología de los ecosistemas, el ecosistema no se utiliza en para definir una unidad concreta, sino un nivel de organización (Margalef López, 1974, pág. 2). El alojamiento puede ser considerado como un nivel de organización dentro del sistema urbano y por tanto como un sistema dentro de éste. 


\section{La ciudad como sistema y el alojamiento proceso y subsistema}

La Ecología define ecosistema como una unidad de organización biológica formada por todos los organismos existentes (población, comunidad o biocenosis) en el territorio o soporte físico definido (biotopo) que interactúan con el entorno físico de manera que el flujo de energía que se produce conduce a una serie de cadenas tróficas y ciclos de materiales (Odum E. , 1969). También se define como el nivel más bajo capaz de cerrar los flujos de materiales y la mayor estructura para captar y utilizar la energía (Bermejo, 2008, pág. 29). Aunque el término ecosistema se propuso por primera vez en 1935 por el ecólogo británico Arthur G. Tansley, está fuertemente ligado con la Teoría General de Sistemas desarrollada desde mediados del siglo XX, y algunos autores han apoyado su aplicación a los ecosistemas humanos para explicar la relación entre las teorías sociales y los procesos naturales.

La Teoría General de Sistemas amplia los conceptos tradicionalmente asociados a los ecosistemas a otras disciplinas. De esta manera define el sistema como un conjunto de partes coordinadas que interactúan para alcanzar objetivos propios y que tienen propiedades comunes que lo convierten en una totalidad. Con estas dos perspectivas la ciudad se puede considerar como una unidad organizada ${ }^{23}$ en la que interactúan los flujos de energía y ciclos de materiales y se superponen procesos sociales de múltiples formas para el desarrollo de la actividad humana. La figura 9 muestra estos conceptos, asociados a la consideración del alojamiento como unidad de organización, como sistema y proceso, así como los flujos de energía y materiales asociados a su funcionamiento.

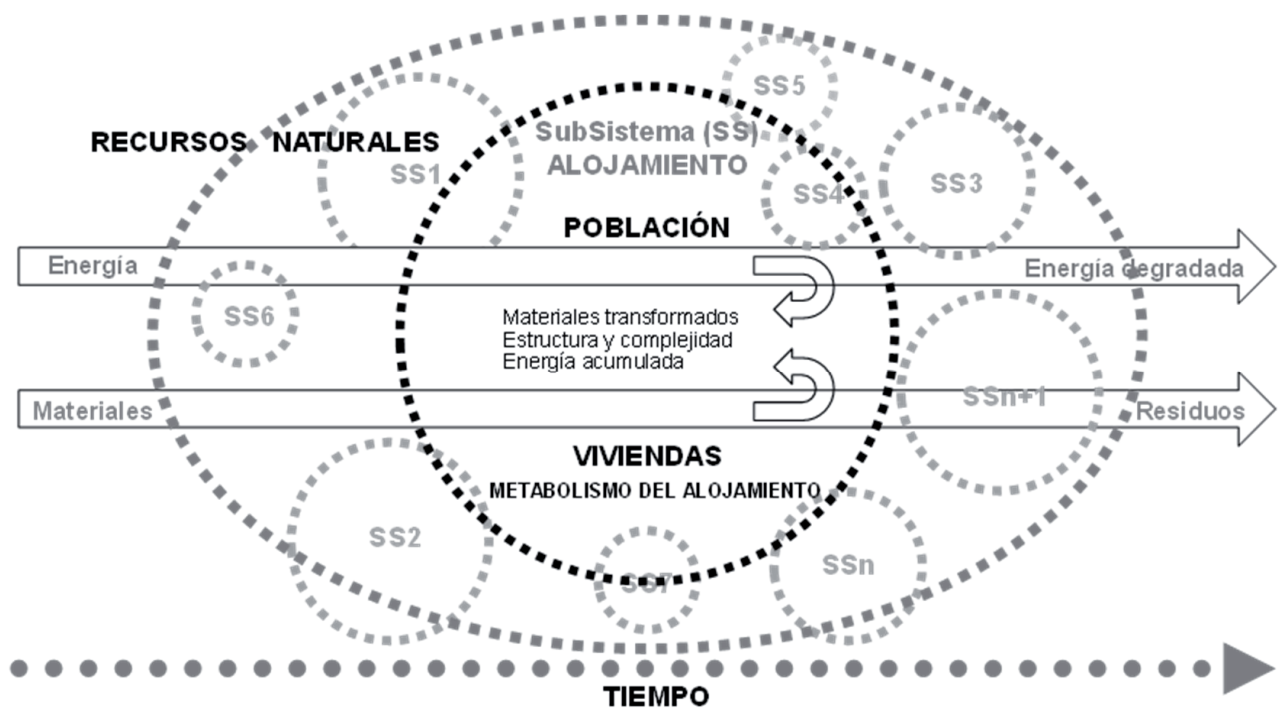

Figura 9. El alojamiento dentro del ecosistema urbano

Fuente: Elaboración propia

23 Autores como E.P. Odum definen a las ciudades como tecno-ecosistemas urbano-industriales (Odum \& Warret, 2006, pág. 408) y las caracterizan como islas pequeñas pero con amplias huellas ecológicas, es decir parasitarias de la biosfera. 
Las transformaciones de materiales y energía que se producen para permitir el funcionamiento del sistema ciudad y del subsistema alojamiento se pueden entender desde el concepto del metabolismo aplicado a la ciudad. Así, los flujos y transformaciones de materiales y energía destinados a producir el soporte del alojamiento (viviendas) y a su funcionamiento a lo largo del tiempo, se puede denominar metabolismo del alojamiento.

\section{El metabolismo del alojamiento}

El concepto de metabolismo ${ }^{24}$ originalmente se inscribía en el ámbito de la biología, pero su aplicación a otras disciplinas se ha consolidado. La comparación de los procesos naturales con los procesos socioeconómicos ha dado lugar al "metabolismo de la economía" (Carpintero, 2005). La analogía entre el comportamiento global de la biosfera y el de las ciudades permite hablar de "metabolismo urbano" (Rueda, 1997). ${ }^{25}$

En esa misma línea, se puede definir el metabolismo del alojamiento como los flujos y transformaciones de materiales, energía e información destinados a la producción y funcionamiento del alojamiento.

El metabolismo de un sistema depende de su población, del modelo de organización y de la calidad del soporte físico. La disponibilidad de recursos y la producción de residuos son factores limitantes que, en los ecosistemas naturales, obliga a la mayor eficiencia en la gestión como describe el Principio de Máxima Potencia. En los sistemas urbanos, la disponibilidad de recursos externos al sistema, permite mantener el crecimiento en el tiempo, y aunque esa situación evita enfrentarse a corto plazo con la cuestión de los límites, en un análisis a largo plazo, la dinámica de la población determinará la sostenibilidad del sistema, ya que es no es posible que la extralimitación sea permanente y conduzca al colapso del sistema. Por otro lado, en el metabolismo del alojamiento no sólo tiene relevancia el número de individuos, sino también su organización y la relación con el soporte.

La cuantificación del metabolismo depende, por tanto, de factores asociados a cada uno de los elementos. Estos factores además cambian a lo largo del tiempo en función de su evolución. Conocer anticipadamente las posibles evoluciones de estos elementos permitiría identificar situaciones no deseables y estrategias de adaptación y supervivencia así como conocer como influirían ciertas medidas de corrección que pudieran corregir situaciones de extralimitación no deseables.

La definición de estas medidas mediante estrategias de adaptación y supervivencia aplicables al sistema del alojamiento se puede realizar gracias a las analogías establecidas con los ecosistemas.

\footnotetext{
24 Metabolismo: Conjunto de reacciones químicas que efectúan constantemente las células de los seres vivos con el fin de sintetizar sustancias complejas a partir de otras más simples, o degradar aquellas para obtener estas.(Real Academia Española, 2001)

${ }^{25}$ El metabolismo urbano se entiende como el conjunto de procesos de transformación de materia y energía que permiten el funcionamiento del ecosistema urbano, cuyo fin, de forma simplificada, es permitir el desarrollo de la actividad humana en sus múltiples formas.
} 


\subsection{Fases del ciclo adaptativo y estrategias de supervivinecia aplicadas al alojamiento}

En 1969 Eugene Odum hablaba sobre la necesidad de nuestra especie de pasar de "una fase de crecimiento vertiginoso a la que hemos demostrado estar bien adaptados a otra de un mayor equilibrio y densidad, aún poco comprendida." (Odum E. , 1969). Margalef señalaba también las dificultades de los seres humanos en percibir el límite superior de población (Terradas, 2015). Hay, por tanto, una posible analogía entre la sucesión/evolución de los ecosistemas y los sistemas socioeconómicos y físicos de nuestras ciudades.

De esta manera, la fase $\Omega$ o de colapso se produciría si se sobrepasan los límites de consumo y reposición de recursos en un ecosistema natural y, de igual manera en un sistema como el alojamiento, aunque en el segundo caso, la percepción de superación de los límites es difícil porque, como hemos visto, el sistema funciona gracias a la sobreexplotación de otros sistemas.

A partir de la superación de los límites, se produce una situación de incertidumbre por la indeterminación de cómo evolucionará el sistema ante una situación que no es sostenible a lo largo del tiempo. Esta fase debe dar lugar a una segunda etapa de reorganización, caracterizada por la innovación para identificar estrategias que reconduzcan la situación y definir las medidas que deben ejecutarse para conseguir este objetivo. La siguiente etapa corresponde a la aplicación de estas medidas y podría identificarse con la fase de producción y crecimiento de un ciclo adaptativo que conduciría a la fase de estabilidad 0 madurez ${ }^{26}$, que se caracteriza por una mejora de la calidad del sistema que le permita prolongar la fase de estabilidad y protegerse ante los cambios.

La similitud entre ambos sistemas se recoge la figura $10 \mathrm{y}$, a partir de ella, la cuestión que se plantea es cómo identificar las fases de estos ciclos en el alojamiento para intervenir en el sistema siguiendo las estrategias adecuadas en cada momento. Éste es el objetivo del método de análisis diacrónico que se propone, que pretende conocer la evolución del alojamiento a lo largo del tiempo para prever situaciones no deseables y plantear medidas en base a las estrategias de adaptación que se utilizan los ecosistemas. Para una mejor comprensión, las fases de un ciclo adaptativo aplicadas al alojamiento se nombrarán de la siguiente manera:

$\begin{array}{ll}\text { Fase } \Omega & \text { Fase variación } \\ \text { Fase } \alpha & \text { Fase reorganización } \\ \text { Fase } r & \text { Fase producción } \\ \text { Fase K } & \text { Fase estabilidad }\end{array}$

\footnotetext{
${ }^{26}$ Las etapas de madurez de los ecosistemas se caracterizan por una estabilidad dinámica o fluctuante en palabras de Odum (Odum E. , 1969). Cualquier comunidad de individuos debe estar adaptada a la particular intensidad y frecuencia de las perturbaciones, y esta capacidad que se consigue mediante procesos de selección muy lentos.
} 


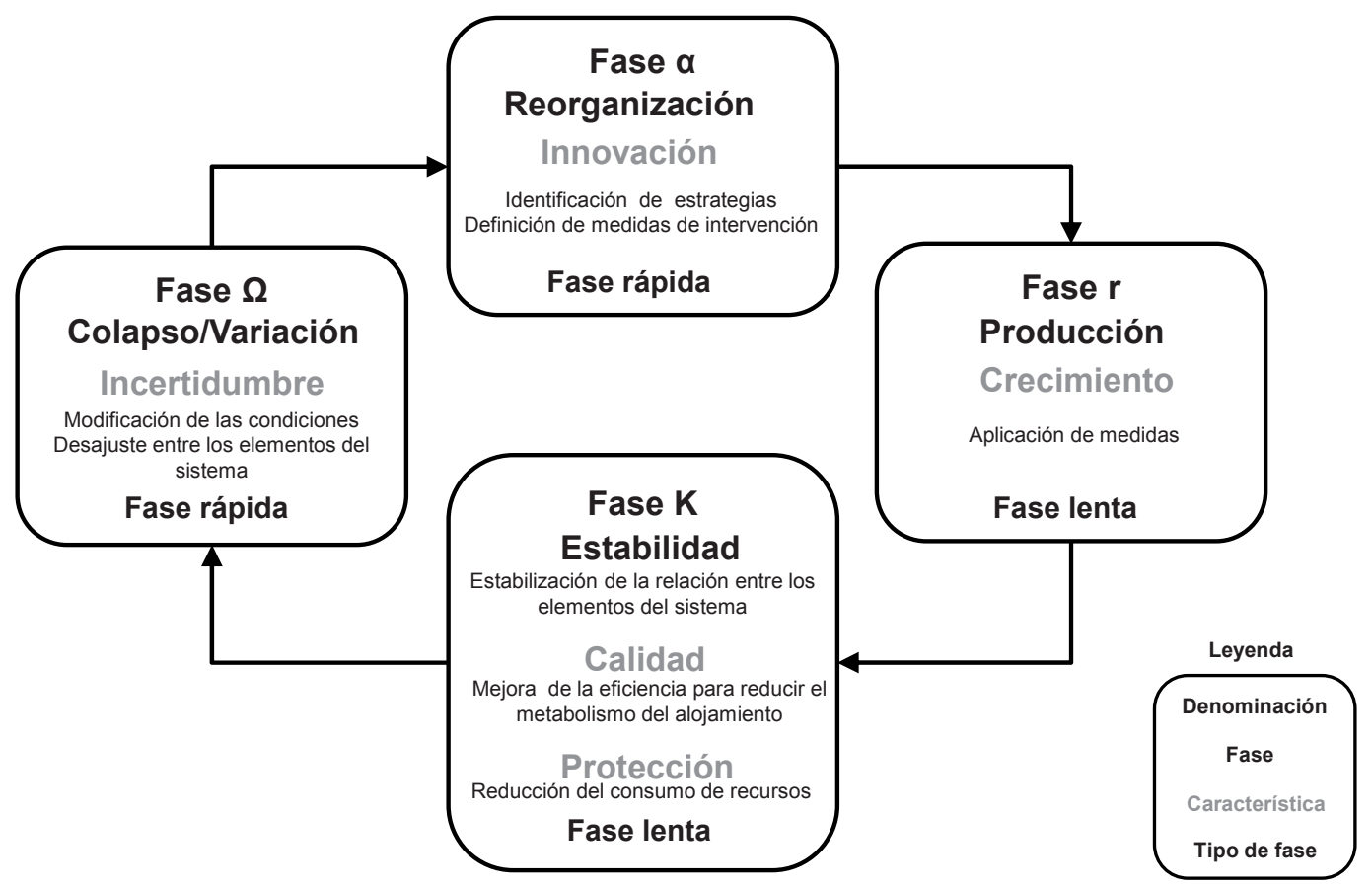

Figura 10. Características y propiedades de las fases de un ciclo adaptativo aplicado al alojamiento Fuente: Elaboración propia a partir de Odum (1969) y Holling (2002)

En lo que se refiere a las estrategias, la parte sustancial del ciclo es la que se refiere a la fase de estabilidad, ya que es la que permite perdurar al sistema. En esta fase las estrategias observadas en los ecosistemas son la estabilidad, la calidad y la protección.

Mantener la estabilidad del alojamiento implica que existe control en la relación entre los tres elementos, habitantes, viviendas y recursos naturales. Esto supone que, por ejemplo, en la búsqueda de la estabilidad, el número de viviendas debe estar dimensionado en función de la población a la que sirve. Por tanto, una medida adecuada sería la intervención sobre el conjunto del parque de viviendas para ajustarlas a las dinámicas poblacionales.

Una estrategia de calidad del alojamiento implica mejorar la eficiencia del metabolismo. Para ello una medida es la intervención en las viviendas para mejorar su eficiencia en la transformación de recursos energéticos y materiales para proporcionar las condiciones adecuadas al alojamiento.Si bien la aplicación de medidas de estabilidad y calidad implica la protección del propio sistema, también se puede considerar que las medidas de protección de las viviendas como soporte construido mediante la rehabilitación contribuyen por un lado a conservar recursos naturales al evitar nuevas transformaciones $y$, por otro, a preservar la identidad morfológica y la información acumulados a lo largo de todo el proceso de construcción del soporte existente. 
El método de análisis propuesto trata de evaluar las medidas a largo plazo sobre el alojamiento como parte del sistema urbano ${ }^{27}$, por lo que sería necesario contrastar si a largo plazo, una medida dirigida a la rehabilitación de las viviendas o cualquier otra acción, ofrece los resultados que se espera en relación a las estrategias definidas para el alojamiento a partir de criterios ecológicos ${ }^{28}$.

\section{DEFINICIÓN DE UN MÉTODO DE ANÁLISIS DIACRÓNICO PARA LA INTERVENCIÓN EN EL ALOJAMIENTO CON CRITERIOS ECOLÓGICOS}

\subsection{Descripción del método de análisis diacrónico}

A partir de las conclusiones establecidas sobre los modelos de la Ecología, su aplicación al alojamiento y las herramientas para la contabilidad del metabolismo urbano, se propone un método de análisis diacrónico para la intervención en el alojamiento con criterios ecológicos. La consideración del tiempo y el carácter complejo del alojamiento (compuesto por tres elementos: habitantes, viviendas y recursos naturales) implica que la inestabilidad dinámica es intrínseca al sistema. Por tanto, resulta inevitable contar la incertidumbre sobre su evolución, especialmente en la aproximación a los límites físicos del propio sistema.

Los trabajos sobre los límites del crecimiento y las observaciones realizadas en el campo de la Ecología indican que, ante una situación de sobreexplotación, es posible reaccionar y reorganizarse. Los sistemas auto-organizativos, es decir aquellos que tienen mayor resiliencia, tienen mayor probabilidad de supervivencia en el tiempo ya que funcionan mejor ante los cambios que aquellos que mantienen estructuras rígidas. En este contexto de extralimitación en el consumo de recursos asociado a los sistemas urbanos, es preciso el desarrollo de métodos que evalúen a largo plazo el funcionamiento del alojamiento en relación a los límites y su capacidad de adaptación. Predecir la evolución de cualquier sistema urbano es una cuestión compleja y llena de incertidumbres. Hay, sin embargo, una serie de claves derivadas del conocimiento de los sistemas lejos del equilibrio (Vázquez Espí, 1996) que la Ecología ha reconocido en la evolución de los ecosistemas y que pueden ayudar en la definición del método de análisis para intervenir en el alojamiento:

1. Un sistema puede tener muy diferentes comportamientos a lo largo del tiempo, pero las condiciones iniciales son determinantes en su funcionamiento. El conocimiento de las mismas es fundamental para definir posibles evoluciones futuras.

2. En un determinado momento, los pequeños cambios pueden implicar modificaciones importantes en el largo plazo. Si se conoce el impacto de

\footnotetext{
27 "perseguir la minimización de la entropía, al mismo tiempo que maximizamos la complejidad de nuestros sistemas urbanos, maximizando la entropía que convertimos en información, obliga a volver a recalificar los intercambios, a reconceptualizar muchas variables y poner valor a otras con la voluntad de aumentar la capacidad de anticipación del sistema." (Rueda Palenzuela, 1996)

28 "La selección natural, esa función de fuerza sin compromisos, requiere que todos los organismos encuentren un equilibrio óptimo entre la energía que inviertan en la supervivencia a futuro y la energía invertida en la supervivencia en el presente." (Odum \& Warret, 2006)
} 
medidas de intervención en el alojamiento con una perspectiva temporal dilatada, se podrían evitar estos impactos no deseables y alcanzar situaciones más adecuadas en un contexto de limitación de recursos.

El método que se propone evalúa los impactos ambientales asociados al alojamiento en un determinado sistema urbano a través de la cuantificación a largo plazo de una serie de indicadores representativos de los tres elementos que componen el alojamiento: habitantes, viviendas y recursos naturales. El análisis de la posible evolución de estos indicadores en un ámbito temporal prospectivo permitiría detectar situaciones no deseables en la evolución del alojamiento y proponer medidas de intervención correctoras, así como cuantificar el impacto de éstas a largo plazo. Sin embargo, para realizar esta aplicación es necesario el conocimiento de la configuración, características y comportamiento del alojamiento hasta el momento de análisis, ya que éstas serían las condiciones iniciales del sistema. Por ese motivo, es precisa una aplicación con carácter retrospectivo y la cuantificación de la evolución de los indicadores. El método diacrónico, por tanto, se basa en un análisis continuo del alojamiento que permite identificar anticipadamente fases de los ciclos que se producen en el sistema alojamiento, y evitar alcanzar situaciones no deseables para el sistema por la configuración de los elementos en relación a los límites del mismo. Este carácter continuo y cíclico se muestra en la figura 11.

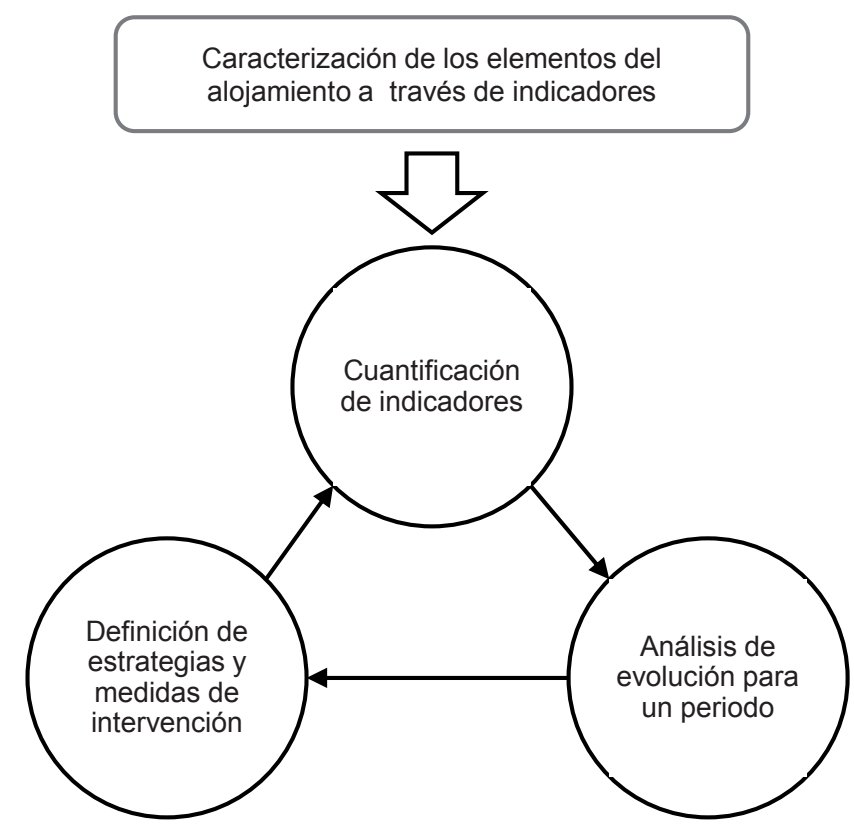

Figura 11. Esquema del método de análisis propuesto

Fuente: Elaboración propia

El objetivo final del método de análisis es servir como herramienta para la toma de decisiones para la intervención en el alojamiento. Desde esta perspectiva, es preciso señalar las limitaciones ya que en su desarrollo se ha considerado los datos disponibles en la actualidad y por ello, las relaciones entre los indicadores 
seleccionados serán lineales y no se han tenido en cuenta ni dinámicas no lineales ni procesos de retroalimentación entre unos elementos y otros ${ }^{29}$.

\subsection{Fases de aplicación del método diacrónico}

Se proponen las siguientes fases para la aplicación del método de análisis para la intervención:

1 Caracterización de los elementos del alojamiento mediante la selección de indicadores

Para la caracterización del alojamiento se han identificado un conjunto de indicadores característicos de la población (habitantes) y del soporte (viviendas y recursos naturales). El método debe ser capaz de evaluar la evolución tanto de los elementos como de las relaciones entre ellos. Por ese motivo los indicadores deben ser de dos tipos, absolutos y relativos. A los primeros se les denominará variables y a los segundos factores dinámicos.

2 Definición de la línea base y el periodo de análisis

La definición del periodo de análisis debe considerar un ámbito temporal retrospectivo que permita comprender la evolución y características de los elementos del alojamiento hasta el momento en que se está realizando el análisis (línea base) y un ámbito temporal, que permita evaluar la aplicación de estrategias a largo plazo.

\section{ÁMBITO TEMPORAL RETROSPECTIVO}

3 Cuantificación y análisis de evolución de indicadores para el periodo retrospectivo

La cuantificación de variables y factores dinámicos permitirá conocer las características del sistema alojamiento así como su evolución hasta el momento del análisis.

4 Definición de estrategias

Las medidas de intervención en el alojamiento deben considerarse desde la adaptabilidad del sistema (o auto-organización del mismo) a lo largo del tiempo. Las estrategias identificadas son las mismas que utilizan los ecosistemas para adaptarse a los cambios: estabilidad, calidad y protección.

\footnotetext{
29 Por ejemplo, el incremento del número de viviendas puede ser un elemento de atracción para la
} población de otro territorio. 


\section{ÁMBITO TEMPORAL PROSPECTIVO}

5 Definición de escenarios a largo plazo

Se trata de identificar posibles escenarios según la evolución futura de variables y factores dinámicos. Para ello, se analizarán las características de cada uno de los indicadores propuestos en relación a la definición de escenarios de futuro. Este análisis permitiría, para cada uno de los escenarios, detectar anticipadamente situaciones no deseables en función de las estrategias definidas previamente y plantear medidas de intervención que corrijan estas situaciones antes de que se produzcan.

6 Cuantificación y análisis de evolución de indicadores

La cuantificación de los indicadores a partir de disponibilidad de estudios prospectivos permitiría conocer su evolución y analizar todos ellos desde un enfoque integral y dinámico.

7 Identificación de situaciones no deseables

En función de las estrategias definidas con criterios ecológicos, se podrán identificar tendencias no adecuadas para mantener el alojamiento en condiciones adecuadas a largo plazo

8 Definición de medidas de intervención

Una vez identificadas las situaciones no deseables, se propondrán medidas de intervención sobre las viviendas para corregirlas anticipadamente

9 Aplicación de medidas

10 Cuantificación y análisis de la evolución alternativa de indicadores

La aplicación de las medidas de intervención modifica la evolución de los indicadores, por tanto su cuantificación en ese nuevo escenario intervenido permite analizar su adecuación a las estrategias ecológicas señaladas.

\section{Seguimiento de evolución de indicadores}

Desde un enfoque ecológico, todas las actuaciones en base a estos criterios de protección, estabilidad y calidad deben vincularse a procesos de retroalimentación, lo que implica la recuperación de la entropía en términos de información, siendo ésta una estrategia para mejorar la eficiencia del necesario proceso de degradación de materiales y energía asociada al alojamiento. El seguimiento de la evolución de los indicadores permite detectar tendencias no deseables y proponer nuevas medidas para corregirlas anticipadamente. 


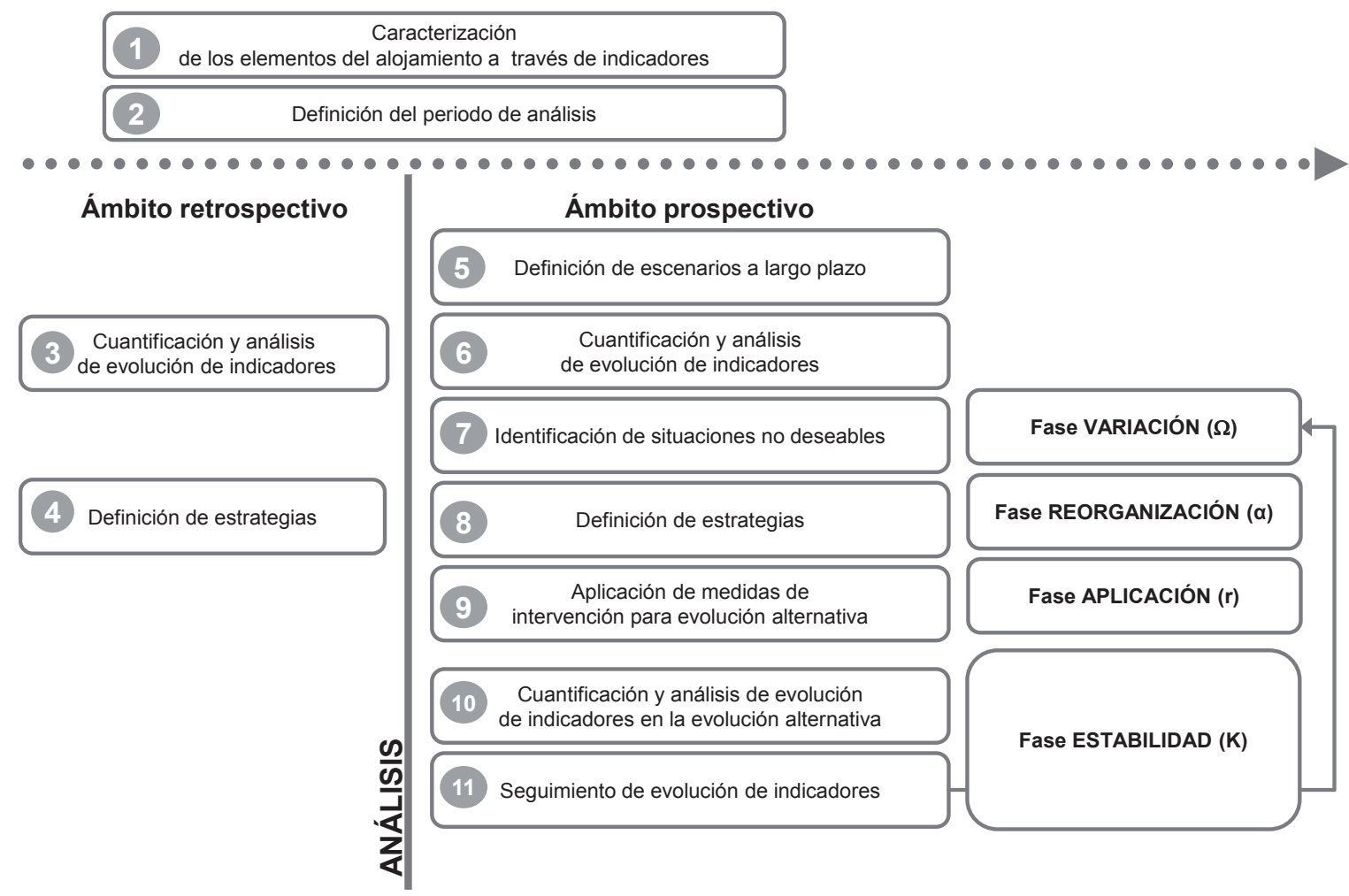

Figura 12. Fases del método de análisis diacrónico propuesto.

Fuente: Elaboración propia

\section{CARACTERIZACIÓN DE LOS ELEMENTOS DEL ALOJAMIENTO A TRAVÉS DE INDICADORES. APLICACIÓN A MADRID}

Para conocer la evolución del alojamiento en Madrid se han seleccionado una serie de indicadores asociados a los habitantes, las viviendas y los recursos naturales ${ }^{30}$. Estos indicadores se han clasificado en variables y factores dinámicos.

\subsection{Definición y selección de variables}

Se define como variable como aquel indicador de carácter absoluto que caracteriza alguno de los elementos que constituyen el alojamiento: habitantes, viviendas y recursos naturales. A partir de los indicadores estudiados, se ha realizado una selección con los siguientes criterios:

30 La inexistencia o no disponibilidad de información histórica sobre aspectos relacionados con el alojamiento, especialmente sobre los recursos naturales, implica que los valores que se proporcionan para el desarrollo del método de análisis, en algunos casos tengan carácter de estimación. No obstante, al proponerse un método de análisis, si hubiera información más precisa sobre los indicadores propuestos, ésta pueda reemplazar a la estimación considerada para obtener conclusiones más aproximadas a la realidad. 
- Sea característico de alguno de los elementos constitutivos del sistema: población (habitantes) y soporte (viviendas y recursos naturales).

- Permita cuantificar parte del metabolismo urbano asociado al alojamiento a lo largo del tiempo.

- Exista disponibilidad de datos para conocer su evolución en el tiempo.

- Pueda relacionarse con el resto de variables para constituir indicadores relativos.

Los indicadores seleccionados para conformar el conjunto de variables son los siguientes:

\section{Variables asociadas a la población}

\section{P01. Número de habitantes}

El número de habitantes determina la población que necesita un soporte para su alojamiento. Se trata de un dato necesario en un enfoque ecológico puesto que es uno de los elementos constitutivo del sistema del alojamiento.

\section{P02. Número de hogares}

El número de hogares sería el indicador para describir las características sociales, culturales y económicas en el uso del alojamiento, así como con la calidad del mismo.

\section{Variables asociadas al soporte (viviendas)}

\section{S01. Número de viviendas}

El número de viviendas existentes es el indicador que cuantifica las unidades físicas disponibles para el alojamiento.

\section{S02. Superficie construida de viviendas (en $\mathbf{m}^{2}$ )}

La superficie construida pretende caracterizar la calidad del soporte a través de su dimensión espacial y cuantificar los recursos empleados en su construcción.

\section{Variables asociadas al soporte (recursos naturales)}

\section{S03. Materiales empleados en viviendas (en $t$ )}

La transformación de los recursos materiales es necesaria para que se produzca el metabolismo en cualquier sistema urbano.

\section{S04. Consumo anual de energía en el alojamiento (en MWh)}

Sirve por un lado para describir el metabolismo energético del alojamiento y por otro su eficiencia. Esta variable se calculará atendiendo a la totalidad del proceso, incluyendo todas las fases que se producen en las viviendas como soporte (producción y construcción del soporte, uso y demolición). La diferente naturaleza de estos factores obliga a utilizar otro indicador para describir las necesidades anuales energéticas asociadas al alojamiento. 
S04 (C+R). Consumo anual de energía en climatización de viviendas (en MWh)

Con los datos de vida de las viviendas, la energía utilizada en el uso de las viviendas es el porcentaje más alto de todo el proceso. Por ello, se propone utilizar este indicador para describir las necesidades energéticas para que las viviendas proporcionen condiciones de habitabilidad adecuadas en relación al clima. Para el cálculo de esta variable se utilizarán los valores obtenidos según la clasificación de viviendas en función de su periodo de construcción.

S05. Superficie urbana ocupada por viviendas (en $\mathbf{~ m}^{2}$ suelo residencial) Caracteriza la ocupación sobre el territorio del soporte del alojamiento, ya que su transformación es parte del metabolismo del alojamiento.

S06. Superficie urbana ocupada por usos complementarios a la vivienda (en $\mathrm{m}^{2}$ suelo equipamientos)

Caracteriza de forma general la calidad de la trama urbana residencial, ya que indica la presencia de otros usos que necesarios y complementarios al uso residencial. Por la disponibilidad de datos, queda excluida en la cuantificación de esta variable el suelo destinado a las infraestructuras que soportan la trama residencial, como los viarios.

\section{Definición y selección de los factores dinámicos}

Las variables son indicadores que describen los elementos del alojamiento con carácter absoluto. Sin embargo son necesarios otros indicadores que representen la relación de los elementos y su evolución a lo largo del tiempo. Estos indicadores relativos se denominarán factores dinámicos y se definen como aquellos elaborados a partir de las variables seleccionadas. Los factores dinámicos cuantifican la relación de las variables asociadas al soporte con la población ${ }^{31}$. El conjunto de factores dinámicos que se incorporarán al método de análisis a proponer son los siguientes:

FD01. Habitantes por hogar

Población en relación a las unidades de organización social.

FD02. Habitantes por vivienda

Población en relación a las unidades físicas como soporte del alojamiento.

FD03. Superficie construida de vivienda por habitante (en $\mathbf{m}^{2} / \mathbf{h a b}$ )

Dimensión construida de vivienda en relación con la población

FD04. Materiales empleados en viviendas por habitante (en $t / h a b$ )

Recursos materiales transformados e invertidos para la vivienda en relación con la población

31 Al igual que las variables, los factores dinámicos que se propone tiene carácter abierto, ya que puede ampliarse para incorporar otros aspectos que se consideren de interés. 
FD05. Consumo anual de energía en el alojamiento por habitante (en kWh/hab)

Energía anual consumida en proceso de configuración de las viviendas como soporte del alojamiento en relación con la población.

FD05 $(\mathrm{C}+\mathrm{R})$. Consumo anual de energía en climatización de viviendas por habitante (en kWh/hab)

Energía anual total en la climatización de viviendas en relación con la población.

FD06. Consumo anual de energía anual en el alojamiento por superficie de vivienda (en $\mathrm{kWh} / \mathrm{m}^{2}$ )

Energía anual consumida en las viviendas como soporte del alojamiento por superficie construida, incluyendo todas las fases del proceso.

FD06 $(C+R)$. Consumo anual de energía en climatización por superficie de vivienda (en $\mathrm{kWh} / \mathrm{m}^{2}$ )

Energía anual invertida en invertida en la climatización de viviendas por superficie construida de vivienda.

FD07.Superficie urbana ocupada por las viviendas por habitante ( $\mathbf{m}^{2}$ suelo residencial/hab)

Superficie urbana destinada al uso residencial en relación con la población.

FD08. Superficie urbana ocupada por usos complementarios a las viviendas por habitante $\left(\mathrm{m}^{2}\right.$ suelo equipamientos/hab)

Superficie urbana destinada a equipamientos y zonas verdes para dar servicio al uso residencial en relación con la población.

\subsection{Estrategias y evaluación de medidas mediante variables y factores dinámicos}

El método de análisis, a través de la evolución de los indicadores seleccionados, quiere describir el alojamiento en relación a las estrategias y medidas de intervención que se propongan de acuerdo con un enfoque ecológico. Una medida de intervención en relación a la estrategia de estabilidad, sería vincular el número de viviendas en un determinado territorio a la población que está previsto que acoja $^{32}$. Para evaluar el impacto de esta medida habría que analizar la variable S01. Número de viviendas y los factores dinámicos FD01. Habitantes por hogar en relación FD02. Habitantes por vivienda.

En cuanto a la estrategia de calidad, una medida de intervención sería la mejora del soporte, es decir, de las viviendas para proporcionar la habitabilidad con el menor consumo de recursos naturales posible. Esta medida se podría evaluar a través de las variables relacionadas con el consumo de energía S04 y S04 (C+R) y los factores dinámicos relativos a la energía FD05, FD05 (C+R), FD06 y FD06 $(\mathrm{C}+\mathrm{R})$, que caracterizarían la calidad del soporte en relación a las condiciones del clima.

32 Otra medida en el mismo sentido podría ser que para un número determinado de viviendas, se ajustara el número de habitantes del sistema. 
Para implementar una estrategia de protección, en un contexto de limitación de recursos naturales, la medida sería la reducción del consumo de recursos energéticos y materiales. Considerando el carácter dinámico y temporal de la cuantificación de los recursos asociados al alojamiento, se podrían comparar distintos tipos de intervención sobre las viviendas (sustitución, rehabilitación,...) para evaluar la más adecuada según esta estrategia. Esta la reducción en el consumo de los materiales se podría evaluar mediante las variables S02, S03 para el consumo de materiales y S05 y S06 en lo que se refiere a transformación del suelo como recurso natural. En cuanto a los factores dinámicos, FD03 y FD04 para relación entre el consumo de materiales y el número de habitantes. En cuanto a la ocupación y transformación del suelo, los factores FD07 y FD08 servirían para evaluar las medidas de intervención en relación a las estrategias propuestas. A modo de resumen se incluye la figura 13, que recoge la relación entre las variables y factores dinámicos con las estrategias y medidas de intervención.

\begin{tabular}{|c|c|c|c|}
\hline & & Estrategia & Medidas \\
\hline P01 & Número de habitantes & & \\
\hline P02 & Número de hogares & & \\
\hline S01 & Número de viviendas & $\begin{array}{l}\text { Estabilidad } \\
\text { Calidad } \\
\text { Protección }\end{array}$ & $\begin{array}{l}\text { Adecuación del número de viviendas a las } \\
\text { dinámicas de la población }\end{array}$ \\
\hline S02 & Sup. const. vivienda & Protección & Reducción del consumo de materiales \\
\hline S03 & Materiales empleados en viviendas & Protección & Reducción del consumo de materiales \\
\hline S04 & $\begin{array}{l}\text { Consumo anual de energía en el } \\
\text { alojamiento }\end{array}$ & Calidad & $\begin{array}{l}\text { Reducción del consumo de energía } \\
\text { Mejora de la eficiencia del metabolismo }\end{array}$ \\
\hline S04 (C+R) & $\begin{array}{l}\text { Consumo anual de energía en } \\
\text { climatización de viviendas }\end{array}$ & Calidad & $\begin{array}{l}\text { Reducción del consumo de energía } \\
\text { Mejora de la eficiencia del metabolismo }\end{array}$ \\
\hline S05 & Suelo urbano ocupado por viviendas & Protección & Reducción de la transformación de suelo \\
\hline S06 & $\begin{array}{l}\text { Suelo urbano ocupado por } \\
\text { equipamiento }\end{array}$ & Protección & Reducción de la transformación de suelo \\
\hline FD01 & Habitantes por hogar & Estabilidad & $\begin{array}{l}\text { Adecuación del número de viviendas a las } \\
\text { dinámicas de la población }\end{array}$ \\
\hline FD02 & Habitantes por vivienda & Estabilidad & $\begin{array}{l}\text { Adecuación del número de viviendas a las } \\
\text { dinámicas de la población }\end{array}$ \\
\hline FD03 & $\begin{array}{l}\text { Superficie construida destinada a } \\
\text { vivienda por habitante }\end{array}$ & $\begin{array}{l}\text { Estabilidad } \\
\text { Protección }\end{array}$ & Reducción del consumo de materiales \\
\hline FD04 & $\begin{array}{l}\text { Materiales empleados en viviendas } \\
\text { por habitante }\end{array}$ & $\begin{array}{l}\text { Protección } \\
\text { Protección }\end{array}$ & Reducción del consumo de materiales \\
\hline FD05 & $\begin{array}{l}\text { Consumo anual de energía en el } \\
\text { alojamiento por habitante }\end{array}$ & Calidad & $\begin{array}{l}\text { Reducción del consumo de energía } \\
\text { Mejora de la eficiencia del metabolismo }\end{array}$ \\
\hline FD05 (C+R) & $\begin{array}{l}\text { Consumo anual de energía en } \\
\text { climatización por habitante }\end{array}$ & Calidad & $\begin{array}{l}\text { Reducción del consumo de energía } \\
\text { Mejora de la eficiencia del metabolismo }\end{array}$ \\
\hline
\end{tabular}




\begin{tabular}{|c|c|c|c|}
\hline FD06 & $\begin{array}{l}\text { Consumo anual de energía en el } \\
\text { alojamiento por superficie de vivienda }\end{array}$ & Calidad & $\begin{array}{l}\text { Reducción del consumo de energía } \\
\text { Mejora de la eficiencia del metabolismo }\end{array}$ \\
\hline FD06 (C+R) & $\begin{array}{l}\text { Consumo anual de energía en } \\
\text { climatización por superficie de } \\
\text { vivienda }\end{array}$ & Calidad & $\begin{array}{l}\text { Reducción del consumo de energía } \\
\text { Mejora de la eficiencia del metabolismo }\end{array}$ \\
\hline FD07 & $\begin{array}{l}\text { Suelo urbano de uso residencial por } \\
\text { habitante }\end{array}$ & Protección & Reducción de la transformación de suelo \\
\hline FD08 & $\begin{array}{l}\text { Suelo urbano de uso equipamientos } \\
\text { por habitante }\end{array}$ & Protección & Reducción de la transformación de suelo \\
\hline
\end{tabular}

Figura 13. Factores dinámicos y su relación con los criterios ecológicos.

Fuente: Elaboración propia

\section{APLICACIÓN Y RETROSPECTIVA DEL MÉTODO DE ANÁLISIS A MADRID ENTRE 1940-2010}

Para la aplicación del método en su fase retrospectiva, se propone situar la línea base para el análisis en 2010, momento que correspondía en el momento de elaboración de la investigación del momento de aprobación de la última directiva europea de eficiencia energética para los edificios. Por otro lado, supone un periodo de 50 años (vida útil media supuesta para las edificaciones según las actuales normativas) desde el comienzo del periodo del desarrollismo (1960), siendo este el periodo en el que se construyeron el mayor porcentaje de las viviendas existentes en Madrid.

\subsection{Cuantificación de las variables para Madrid entre 1940 y 2010}

La cuantificación de las variables se realizado utilizando datos sobre la Comunidad de Madrid procedentes de diversas fuentes que se muestran en la figura 14.

\begin{tabular}{|c|c|c|c|c|c|c|c|c|c|c|}
\hline & & 1940 & 1960 & 1980 & 2000 & 2010 & $\begin{array}{l}1940- \\
1960\end{array}$ & $\begin{array}{l}1960- \\
1980\end{array}$ & $\begin{array}{l}1980- \\
2000\end{array}$ & $\begin{array}{l}2000- \\
2010\end{array}$ \\
\hline P01 & $\begin{array}{l}\text { Número de } \\
\text { habitantes }\end{array}$ & 1579793 & 2606254 & 4726986 & 6081689 & 6458684 & 1,65 & 1,81 & 1,29 & 1,06 \\
\hline P02 & $\begin{array}{l}\text { Número de } \\
\text { hogares }\end{array}$ & 338407 & 649574 & 1337120 & 1873792 & 2313598 & 1,92 & 2,06 & 1,40 & 1,23 \\
\hline S01 & $\begin{array}{l}\text { Número de } \\
\text { viviendas }\end{array}$ & 342319 & 669600 & 1593853 & 2408872 & 2522756 & 1,96 & 2,38 & 1,51 & 1,05 \\
\hline S02 & $\begin{array}{l}\text { Sup. const. } \\
\text { vivienda } \\
\left(\mathrm{en}^{2}\right)\end{array}$ & 20605232 & 51923082 & 167526766 & 276063043 & 291229002 & 2,52 & 3,23 & 1,65 & 1,05 \\
\hline S03 & $\begin{array}{l}\text { Materiales } \\
\text { empleados } \\
\text { en } \\
\text { viviendas }\end{array}$ & 41210465 & 91319024 & 305185840 & 445861675 & 566173812 & 2,22 & 3,34 & 1,46 & 1,27 \\
\hline
\end{tabular}




\begin{tabular}{|c|c|c|c|c|c|c|c|c|c|c|}
\hline S04 & $\begin{array}{l}\text { Consumo } \\
\text { anual de } \\
\text { energía en } \\
\text { el }\end{array}$ & 5379506 & 12835816 & 36838593 & 52730977 & 58274743 & 2,39 & 2,87 & 1,43 & 1,11 \\
\hline $\begin{array}{l}\mathrm{S} 04 \\
(\mathrm{C}+\mathrm{R})\end{array}$ & $\begin{array}{l}\text { Consumo } \\
\text { anual de } \\
\text { energía } \\
\text { climatizació }\end{array}$ & 3660960 & 8026979 & 18677481 & 27196494 & 28312042 & 2,19 & 2,33 & 1,46 & 1,04 \\
\hline S05 & $\begin{array}{l}\text { Suelo } \\
\text { urbano } \\
\text { ocupado } \\
\text { por }\end{array}$ & $\begin{array}{c}131350 \\
000\end{array}$ & 300685000 & 470020000 & 612520080 & 755020160 & 2,29 & 1,56 & 1,30 & 1,23 \\
\hline S06 & $\begin{array}{l}\text { Suelo } \\
\text { urbano } \\
\text { ocupado } \\
\text { por }\end{array}$ & 88800000 & 91555000 & 116900000 & 182456733 & 248013466 & 1,16 & 1,28 & 1,56 & 1,36 \\
\hline
\end{tabular}

Figura 14. Evolución de variables seleccionadas en la Comunidad de Madrid entre 1940 y 2010 . Valores anuales y tasa de evolución.

Fuente: P01: (Instituto Nacional de Estadística, 2007) / P02: Elaboración propia a partir de datos de INE / S01 y S02. Elaboración propia a partir de datos del INE y del Ministerio de Fomento / S04: Elaboración propia a partir de datos de (Instituto para la Diversificación y el Ahorro de Energía, 2011), (Zabalza Bribián, 2011), (Wadel, 2009) y (García Martínez, 2010) / S05 y S06: (Naredo Pérez \& García Zaldívar, 2008)

La evolución de las variables en la Comunidad de Madrid muestra tendencias distintas, aunque todas ellas tienen un carácter creciente, en menor medida a partir del año 2006. Estos datos reflejan la evolución histórica descrita en el anterior capítulo. La tasa de crecimiento de la población (P01) en Madrid más elevada se produjo entre 1940 y 1980 (un periodo de 40 años), disminuyendo este indicadora partir de esta última década. En cuanto a los hogares (P02) se observa un importante crecimiento en esos mismos años, y una reducción a partir de 1980, pero en menor medida que la población. La mayor actividad constructora de viviendas se produce a partir de 1960, coincidiendo con el fin de la Autarquía, y se mantiene en un número anual de viviendas nuevas más o menos constante hasta el 2007, con algunos periodos de mayor cantidad de viviendas producidas (la década de los 1970 o el periodo de 2000 a 2007).

Asimismo, se observa un incremento en la superficie construida de las viviendas a lo largo de los años, lo que implica una mayor transformación de recursos en su construcción, aunque ambas cuestiones no parecen tener relación con la evolución de la población. La tasa de crecimiento del número de viviendas (S01) y la de la superficie construida (S03) se han mantenido positivas, alcanzando sus mayores valores en $1980^{33}$. La causa fue la emigración a partir de la década de los 1950 desde el mundo rural y el fortalecimiento del sector inmobiliario como motor económico del país, contribuyendo ambos a que en la segunda mitad del siglo XX se produjera el mayor crecimiento de la ciudad de Madrid.

Por otro lado, la evolución de la tasa de crecimiento de superficie construida en Madrid supone un cambio en los tipos de vivienda demandados, que se refleja en un mayor espacio para sus habitantes así como para servicios e instalaciones. Sin embargo, esta mejora no se ha traducido en una reducción del consumo energético de las viviendas. Los valores generales reflejan que el consumo de energía ha ido aumentando desde mediados de siglo. El aumento del número de viviendas, así

33 Durante ese periodo siempre es mayor el valor en Madrid que el conjunto nacional, y a partir de ese momento se invierten los valores, siendo mayor en España que en Madrid. 
como el incremento de la superficie de éstas ha implicado un aumento exponencial del consumo de energía para el funcionamiento del conjunto de las viviendas en términos absolutos. En el análisis histórico de las características de las viviendas construidas se indicaba que la mayor parte de éstas no tienen las condiciones necesarias para proporcionar la habitabilidad durante el uso si no es mediante un aporte elevado de energía.

La construcción de este tipo de viviendas durante más de 40 años ha supuesto un incremento constante del consumo anual de energía dedicada a mantener las condiciones de confort como muestra la variable S04 $(C+R)$. Las normativas para limitar el consumo energético en las viviendas, especialmente a partir de 2006, han tenido cierto efecto ya que el incremento del consumo de energía en climatización es menor, aunque el consumo de las edificaciones existentes hace que los valores totales sigan siendo elevados.

Sobre la ocupación del suelo, la actividad productora de viviendas se refleja en el incremento gradual y constante de suelo residencial (S05). El incremento de esta variable hasta 2010, a pesar de la reducción de la construcción de viviendas a partir de 2006 puede deberse a que los procesos de urbanización de las nuevas zonas residenciales de Madrid se finalizaran pero no llegaran a construirse las viviendas previstas. Desde el punto de vista de los recursos esta situación supone un consumo innecesario, incluyendo la pérdida de suelo natural, una dinámica absurda desde un enfoque ecológico.

En el caso del suelo destinado a usos complementarios (S06) se observa una tendencia constante hasta 1980 pero menor que la del suelo residencial. Este periodo hasta 1980 corresponde al desarrollismo del franquismo y a la construcción en Madrid de numerosos polígonos periféricos, sin los equipamientos necesarios para sus habitantes. A partir de 1980 esta situación se empieza a corregir y se incrementa esta variable a mayor ritmo.

En el caso de la figura 15 que muestra de forma comparada la evolución de habitantes, viviendas y hogares se observa cómo a partir de 1960 se inicia una fase de variación ya que la evolución de las viviendas y de los habitantes sigue patrones diferentes a la de los hogares. A partir de la mitad de la década entre 2000 y 2010 esta tendencia parece estabilizarse, apareciendo una fase de reorganización. Este cambio se produce para la reducción de la actividad constructora de viviendas a causa de factores económicos.

La conocida burbuja inmobiliaria puede identificarse a partir de la comparación de la evolución del número de viviendas y el número de hogares. Se observa el inicio de la misma a mediados de la década de los años 1990 por el desfase entre ambas variables, incrementarse hasta aproximadamente 2006 y posteriormente estabilizarse hacia el año 2010. 


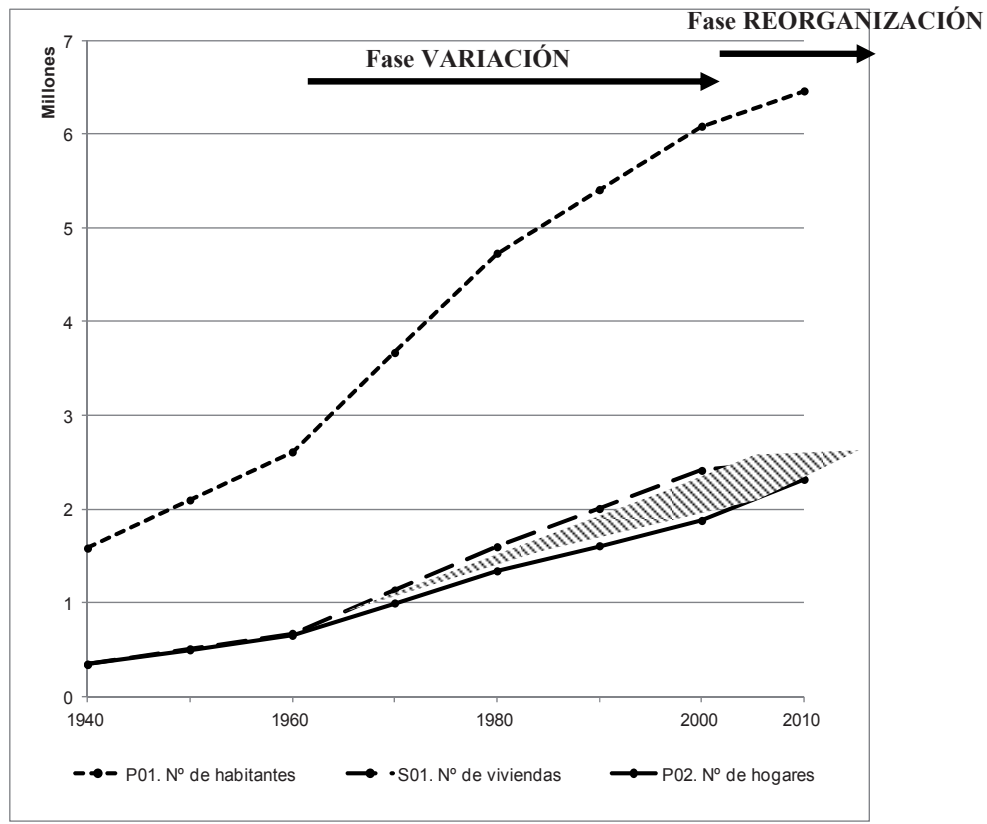

MM

Desfase viviendas hogares (burbuja inmobiliaria)

Figura 15. Evolución 1940-2010 de P01 Número de habitantes, P02 Número de hogares y S01 Número de viviendas en Madrid.

Fuente: Elaboración propia

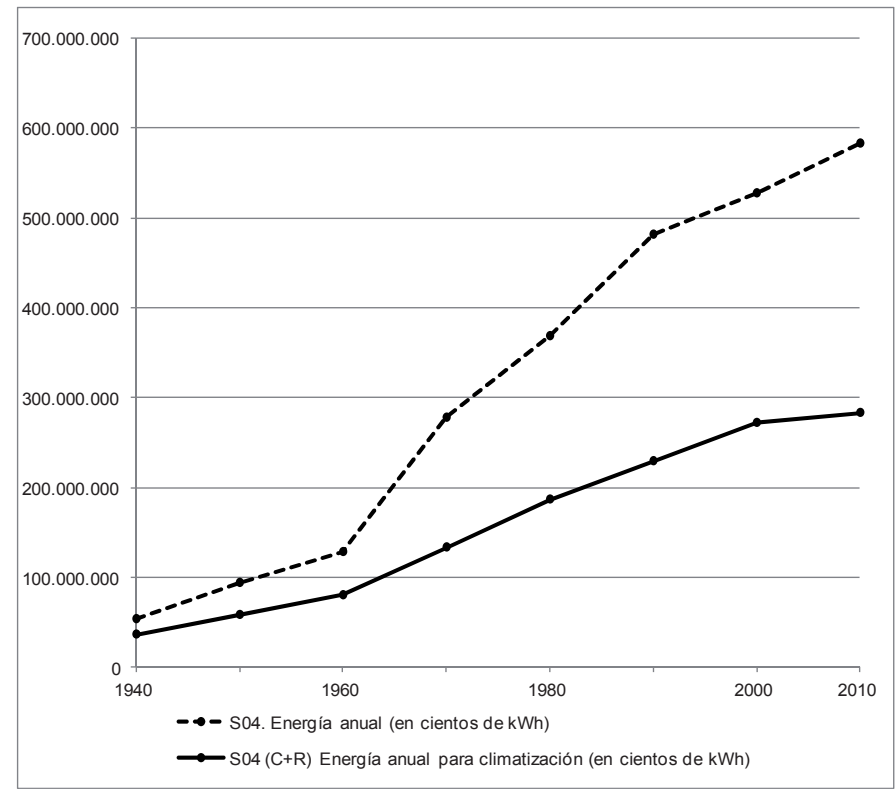

Figura 16. Evolución 1940-2010 S04 Consumo anual de energía y S04 (C+R) Consumo anual de energía en climatización en Madrid. Fuente: Elaboración propia

Fuente: Elaboración propia 


\subsection{Cuantificación de factores dinámicos para Madrid entre 1940-2010}

La cuantificación de los factores dinámicos para Madrid para el periodo entre 1940 y 2010 se recoge en la figura 17, analizándose los resultados en los siguientes apartados.

\begin{tabular}{|c|c|c|c|c|c|c|}
\hline & & 1940 & 1960 & 1980 & 2000 & 2010 \\
\hline FD01 & Habitantes por hogar & 4,67 & 4,01 & 3,54 & 3,25 & 2,79 \\
\hline FD02 & Habitantes por vivienda & 4,61 & 3,89 & 2,97 & 2,52 & 2,56 \\
\hline FD03 & $\begin{array}{l}\text { Superficie construida destinada a } \\
\text { vivienda por habitante }\left(\mathrm{m}^{2} / \mathrm{hab}\right)\end{array}$ & 13,04 & 19,92 & 35,44 & 45,39 & 45,09 \\
\hline FD04 & $\begin{array}{l}\text { Materiales empleados en viviendas } \\
\text { por habitante }\left(t / \mathrm{m}^{2}\right)\end{array}$ & 26085 & 35038 & 64562 & 87658 & 87660 \\
\hline FD05 & $\begin{array}{l}\text { Consumo anual de energía en el } \\
\text { alojamiento por habitante (kWh } \\
\text { año/hab) }\end{array}$ & 3405 & 4925 & 7793 & 8670 & 9023 \\
\hline FD05 (C+R) & $\begin{array}{l}\text { Consumo anual de energía en } \\
\text { climatización por habitante (kWh } \\
\text { año/hab) }\end{array}$ & 2317 & 3079 & 3951 & 4471 & 4383 \\
\hline FD06 & $\begin{array}{l}\text { Consumo anual de energía en el } \\
\text { alojamiento por superficie de vivienda } \\
(\mathrm{kWh} \text { año/m²) }\end{array}$ & 261,07 & 248,22 & 220,84 & 187,15 & 193,70 \\
\hline FD06 (C+R) & $\begin{array}{l}\text { Consumo anual de energía en } \\
\text { climatización por superficie de } \\
\text { vivienda }(\mathrm{kWh} \text { año/m²) }\end{array}$ & 177,67 & 156,86 & 121,10 & 100,38 & 99,17 \\
\hline FD07 & $\begin{array}{l}\text { Suelo urbano de uso residencial por } \\
\text { habitante }\left(\mathrm{m}^{2} / \mathrm{hab}\right)\end{array}$ & 83,14 & 115,37 & 99,43 & 100,72 & 116,90 \\
\hline FD08 & $\begin{array}{l}\text { Suelo urbano de uso equipamientos } \\
\text { por habitante }\left(\mathrm{m}^{2} / \mathrm{hab}\right)\end{array}$ & 56,21 & 39,46 & 24,73 & 30,00 & 38,40 \\
\hline
\end{tabular}

Figura 17. Cuantificación 1940-2010 de factores dinámicos en Madrid.

Fuente: Elaboración propia

En la figura 17 se observa que el factor FD02 "Habitantes por vivienda", a partir de 1960 y hasta 2000, inicia una tendencia de descenso, siendo esta reducción más acusada que el incremento de habitantes por hogar (FD01). Esto implica que el número de personas que componen el hogar ha ido reduciéndose desde ese año. Por otro lado, al considerarse en la cuantificación del conjunto de viviendas, tanto principales como secundarias, puede concluirse que se han incrementado el número de viviendas por hogar. La evolución de estos factores dinámicos permite identificar las fases de variación y reorganización señaladas anteriormente. Según los estudios demográficos respecto a la composición y tamaño de los hogares madrileños (Recaño, 2002) y la evolución de la ocupación de territorio, es probable que se hayan producido los dos fenómenos, concluyéndose a partir de los datos elaborados que, a partir de mediados de la década que se inicia en 2000 , la tendencia creciente de viviendas por habitantes se esté invirtiendo mientras que el número de 
habitantes por hogar continua reduciéndose. La evolución entre 1940 y 2010 de la superficie construida destinada a vivienda por habitante (FD03) y de los materiales empleados en las viviendas por habitante (FD04) en Madrid indica que ambos factores se han incrementado, siendo este aumento mayor en el periodo $1960 \mathrm{y}$ 1980 (Figura 18). La superficie construida ha tenido mayor incremento por habitante que los materiales empleados en el soporte del alojamiento.

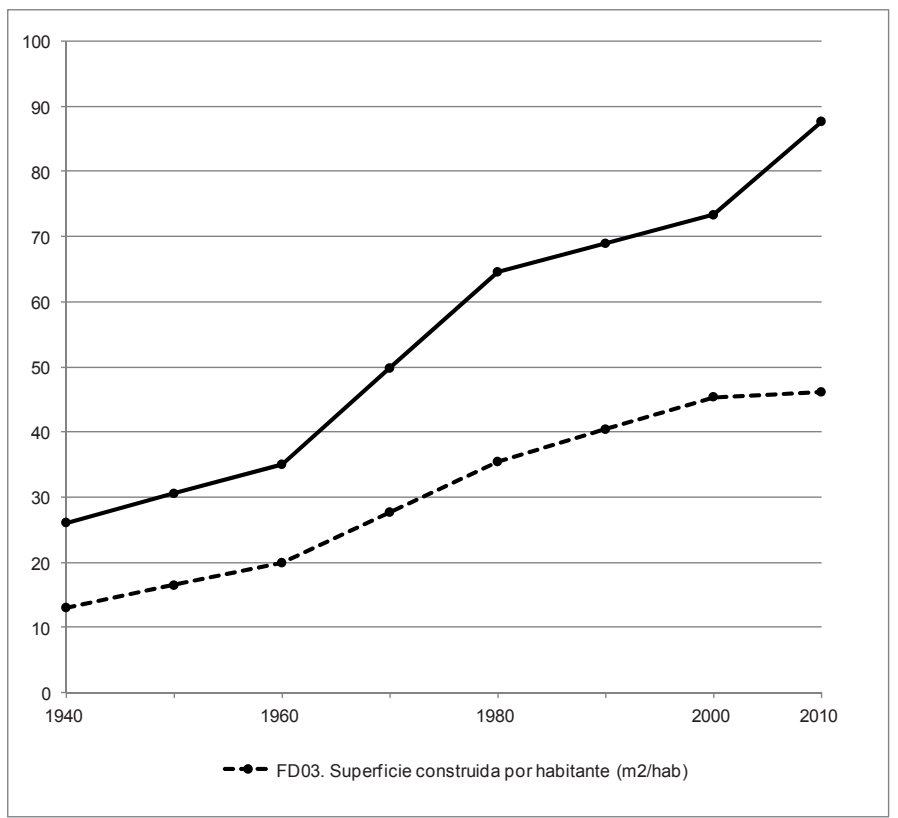

Figura 18. Evolución 1940-2010 de FD03 Superficie construida por habitante (en $\mathrm{m}^{2} / \mathrm{hab}$ ) y FD04 Materiales empleados por habitante (t/hab) en Madrid. Los factores dinámicos FD05 y FD06 tienen en cuenta el consumo de energía anual en el alojamiento por habitante y por superficie de vivienda, y se consideran los consumos energéticos de producción, construcción y uso en cada momento. Se observa la distinta evolución que han tenido ambos factores, mientras el primero de ellos relativo a la población presenta una tendencia creciente hasta 2000, estabilizándose a partir de ese momento, el segundo, relacionado con la superficie es decreciente desde 1960 hasta 2000, estabilizándose hasta 2010. Con estos datos se puede concluir que, en el periodo analizado, el mayor aumento de la superficie construida respecto a la población ha supuesto que el consumo de energía por habitante se haya incrementado considerablemente, mientras que las distintas políticas de limitación de consumo de energía en las viviendas mediante normativas más exigentes, han permitido reducir el consumo de energía por superficie construida. Ambos factores presentan a partir de 2000 una tendencia de estabilización como se observa en la

Fuente: Elaboración propia

El incremento del número de viviendas implica una tendencia creciente del factor referido a la población hasta el año 2000, en que este crecimiento se estabiliza, en parte por el menor incremento del número de viviendas en relación a la población. En la evolución de estos factores dinámicos se pueden identificar las fases de reorganización tras la crisis del petróleo de 1973, de aplicación de diversas normativas y de estabilización. 


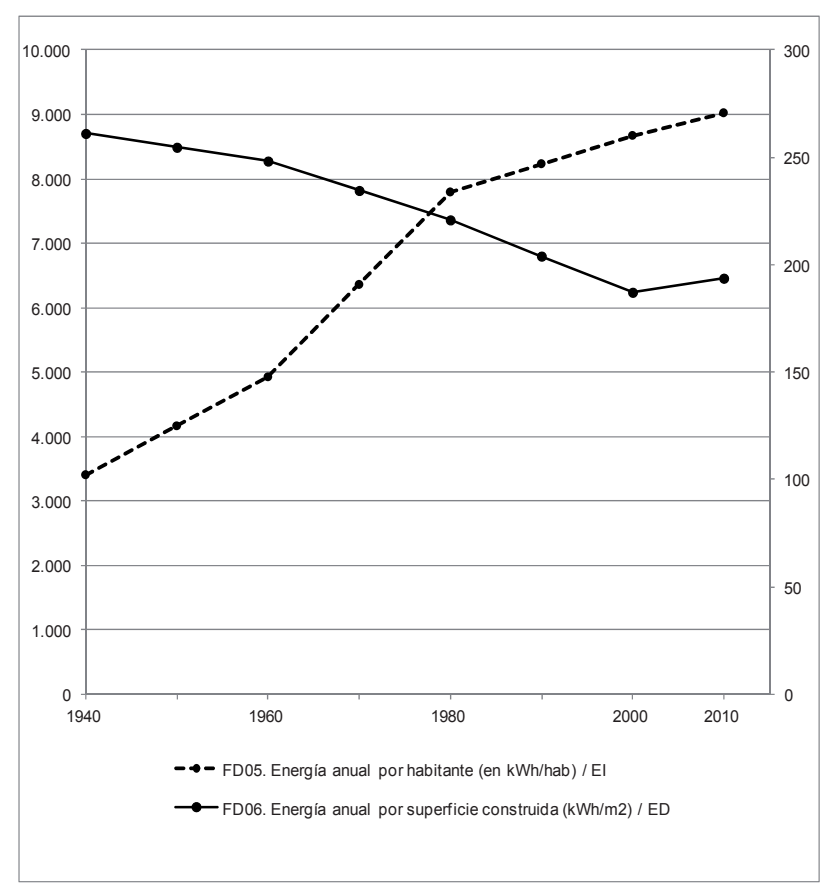

Figura 19. Evolución de FD05 Consumo anual de energía por habitante y FD06 Consumo anual de energía por superficie de vivienda $\left(\mathrm{kWh} / \mathrm{m}^{2}\right)$ en Madrid 1940-2010.

Fuente: Elaboración propia

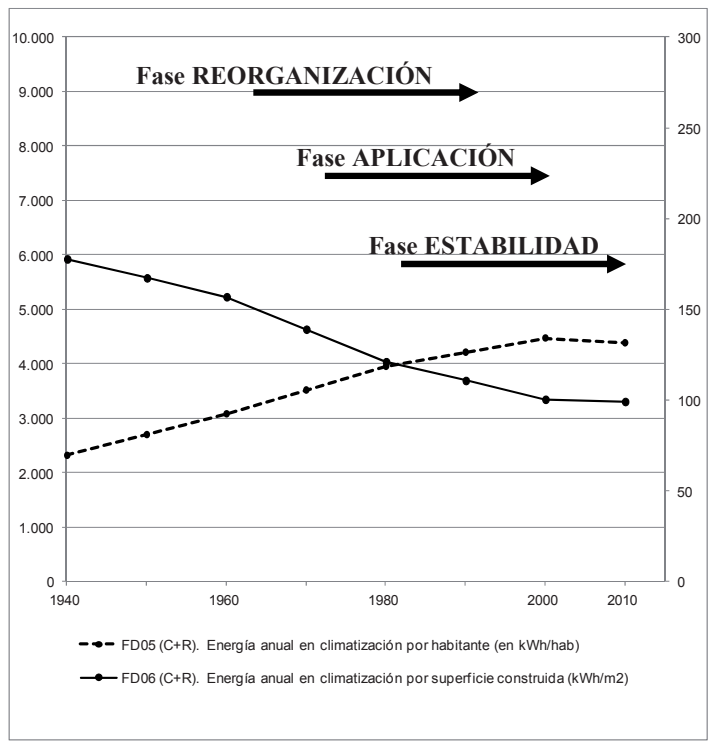

Figura 20. Evolución de FD05 $(C+R)$ Consumo anual de energía en climatización por habitante (kWh/hab y FD06 ( $\mathrm{C}+\mathrm{R})$ Consumo anual de energía en climatización por superficie de vivienda $\left(\mathrm{kWh} / \mathrm{m}^{2}\right)$ en Madrid 1940-2010.

Fuente: Elaboración propia 
Al inicio del periodo analizado, se partía de una situación en que ambos factores se aproximaban, a partir de esa fecha y especialmente en la década de los ochenta, la relación del espacio urbano destinado a los equipamientos en Madrid con el número de habitantes disminuyó considerablemente, dedicándose todo el esfuerzo urbanizador a la creación de suelo residencial.

En el periodo entre 1980 y 2000, la relación entre el uso residencial se estabilizó, incrementándose a partir de 2000 hasta 2010, con un crecimiento similar al del uso destinado a los equipamientos. Si se compara con el número de viviendas por habitantes construidas en ese periodo puede responder a una tipo urbanización más dispersa o como se ha indicado anteriormente a que no se han construido las viviendas previstas en los suelos urbanos desarrollados.

Estos indicadores referidos en su mayoría a la población muestran una tendencia creciente por habitante hasta 2010, es decir un mayor consumo de recursos empleados en el alojamiento por habitante. La tendencia decreciente de la energía consumida por superficie muestra que el soporte construido es cada vez más eficiente en el consumo para la climatización, sin embargo, el aumento de la superficie construida hace que a pesar de realizarse este esfuerzo, el consumo total sigue siendo cada vez mayor.

\subsection{Medidas de intervención para evolución alternativa en Madrid (1940-2010)}

Aunque el objetivo del análisis diacrónico es evaluar a largo plazo medidas de intervención sobre el alojamiento mediante un enfoque ecológico, para validar el método propuesto, se realiza su aplicación con carácter retrospectivo al caso de Madrid. Se trataría de definir una serie de medidas de intervención en el alojamiento en base a las estrategias identificadas (estabilidad, calidad y protección) y evaluar si su aplicación hubiera supuesto un desarrollo alternativo en Madrid entre 1940 y 2010 más adecuado a los objetivos planteados. Estas estrategias serían las siguientes:

Estabilidad Adecuación del número de viviendas a las dinámicas de la población y hogares

Calidad Mejora de la eficiencia del metabolismo del alojamiento

Protección Reducción del consumo de recursos asociado al alojamiento

De acuerdo con el análisis de la evolución de variables y factores dinámicos para Madrid entre 1940 y 2010 , estas tres estrategias se concretan en las medidas que se muestran en la figura 21 . A continuación se analiza la aplicación de cada una de estas medidas mediante la cuantificación de variables y factores dinámicos en el periodo definido. 


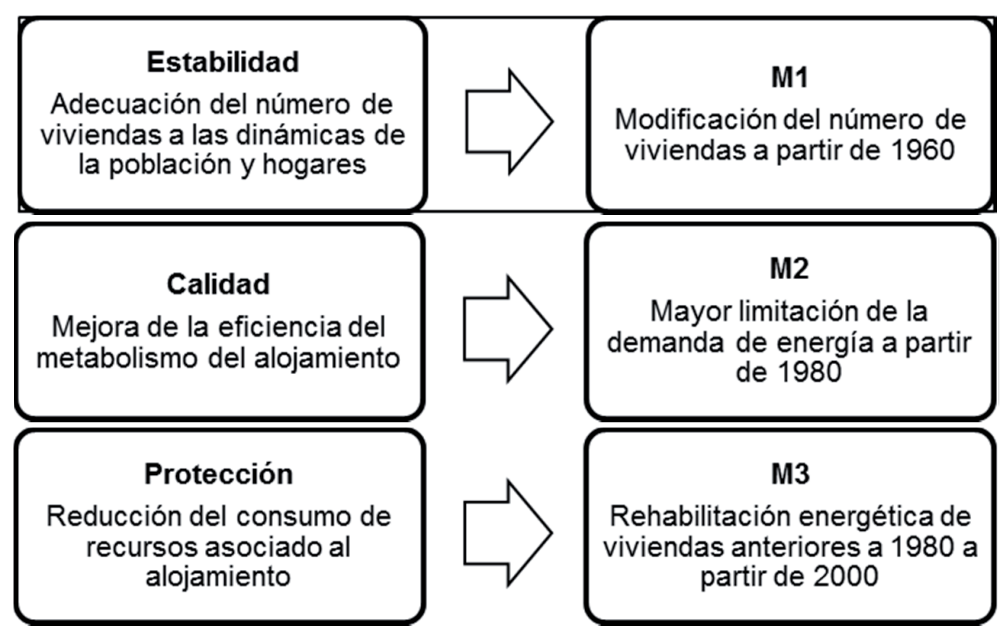

Figura 21. Estrategias y medidas de aplicación retrospectiva a Madrid 1940-2010.

Fuente: Elaboración propia

\section{Estabilidad. Aplicación de la medida M1. Modificación del número de viviendas a partir de 1960}

En el año 1960 se inicia el periodo de mayor actividad en la construcción de viviendas en Madrid como consecuencia de la inmigración a este territorio de personas en búsqueda de mejores oportunidades y de la activación de este sector como motor de la economía española. En el año 1940 el número de habitantes por hogar era de 4,61 y el número de habitantes por vivienda de 4,67, por lo que ambos factores dinámicos tenían una magnitud similar. No obstante, se detecta que ambos factores presentan tendencias dispares por lo que se propone mejorar la estabilidad del sistema a través de la siguiente medida

Medida M1. Se propone planificar el número de viviendas en función de las previsiones de crecimiento del número de hogares, que, a su vez, depende del número de habitantes.

El número de habitantes por vivienda (FD02) habría tenido una evolución a lo largo del periodo que concluiría en el año 2010 en un valor superior al real (2,79 frente a $2,56)$. Aunque en ese año, las cifras son similares, la evolución de este factor habría sido muy distinta. Mientras el desarrollo real indica periodos en que el número de habitantes por vivienda ha descendido hasta 2,52 para luego incrementarse, tras la aplicación de la medida M1, este factor dinámico tiene una evolución similar al número de hogares. En lo que se refiere a la variable S01. Número de viviendas, la adecuación a la previsión de la formación de hogares implicaría que, en el año 2010, habría un $8,29 \%$ menos de viviendas que en la evolución real, lo que significa que aunque el número fuera menor, el ritmo de construcción más sincronizado con las dinámicas de la población, hubiera significado que una parte las viviendas construidas en el periodo entre 1960 y 1980 se habrían realizado en las dos últimas décadas del siglo, y por tanto, al ser más recientes, serían más nuevas y tendrían una mejor calidad en su envolvente. En las siguientes figuras se recogen gráficamente la evolución de los factores dinámicos tras la aplicación de la medida 
M1. Reducción del número de viviendas y en comparación con la evolución real. En la figura 22 se observa como la reducción del número de viviendas (Medida M1) permite identificar una fase de estabilidad en el periodo de análisis que en la evolución real no se hubiera dado. Así, en dicho periodo el desfase entre viviendas y hogares no se habría producido, evitándose los efectos de la burbuja

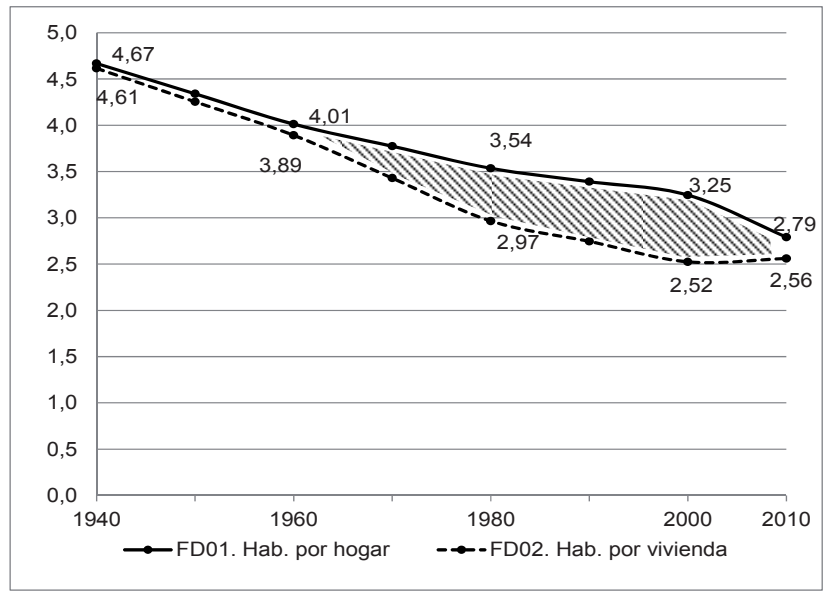

$M M$

Desfase viviendas hogares (burbuja inmobiliaria)

Figura 22. Evolución 1940-2010 de FD01 Habitantes por hogar y FD02 Habitantes por viv. (Madrid). Fuente: Elaboración propia

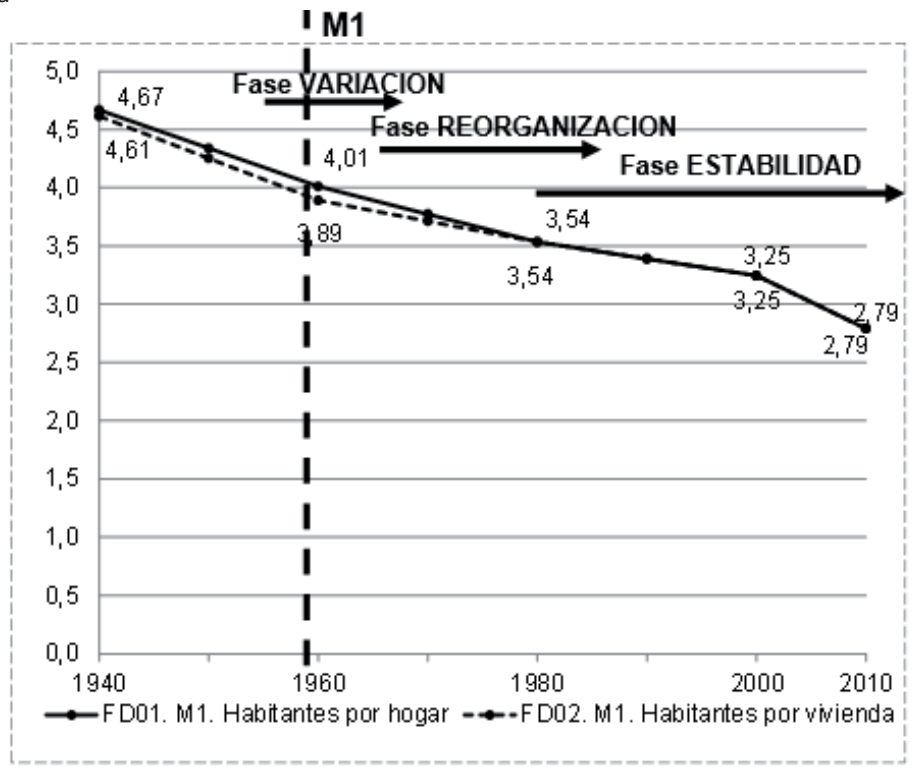

Figura 23. M1. Evolución alternativa Madrid 1940-2010 de FD01. Habitantes por hogar y por vivienda. Fuente: Elaboración propia

En lo que se refiere al consumo de recursos, un menor número de viviendas, hubiera supuesto que, tanto la superficie construida por habitante como los materiales empleados por habitante, se habrían reducido en porcentajes cercanos al $10 \%$ en 2010. La energía consumida en todo el proceso (S04) tendría una reducción menor, al distribuirse el consumo debido a la producción de las viviendas en las 
décadas posteriores a 1980. El consumo anual de energía ( $\mathrm{S04}(\mathrm{C}+\mathrm{R})$ ) en climatización en 2010 sería un $8 \%$ menor que la evolución real. Los factores dinámicos relacionados FD05 y FD06 tienen una evolución dispar. El primero de ellos se mantiene en 2010, mientras el segundo, a pesar de que entre 1980 y 2000 se reduce por el menor número de viviendas del periodo, en 2010 éste se hubiera incrementado un $61 \%$ respecto a la situación real por el mayor número de viviendas construidas en el periodo entre 2000 y 2010, repercutiendo la energía empleada en la construcción en estos primeros años de vida de la edificación

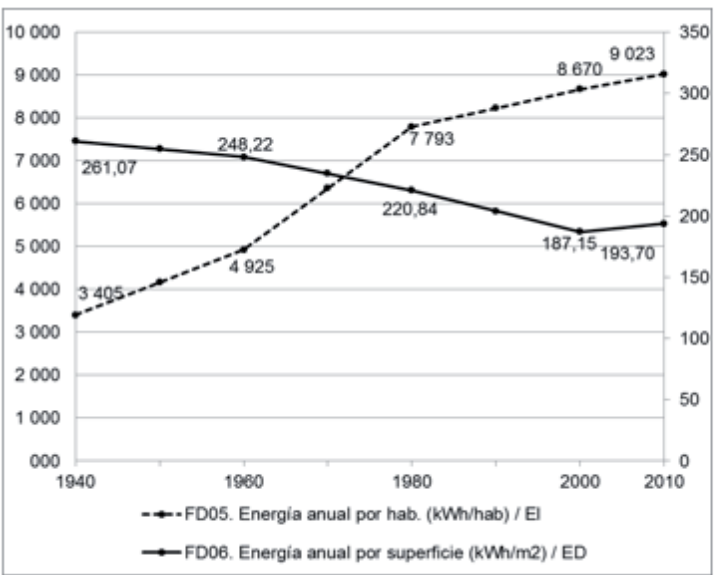

Figura 24. Evolución real en Madrid 1940-2010 de FD05 Consumo anual energía por habitante, y FD06 Consumo anual energía por sup. de viv. $\left(\mathrm{kWh} / \mathrm{m}^{2}\right)$

Fuente: Elaboración propia

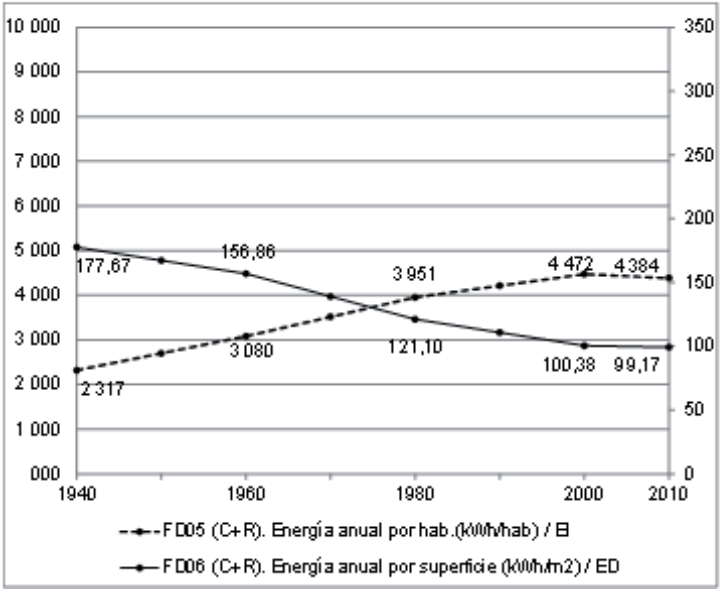

Figura 26. Evolución real en Madrid 1940-2010 de FD05 ( $C+R)$ Consumo anual de energía en climatización por habitante (kWh/hab) y FD06 (C+R) Consumo anual de energía en climatización por superficie de vivienda $\left(\mathrm{kWh} / \mathrm{m}^{2}\right)$

Fuente: Elaboración propia

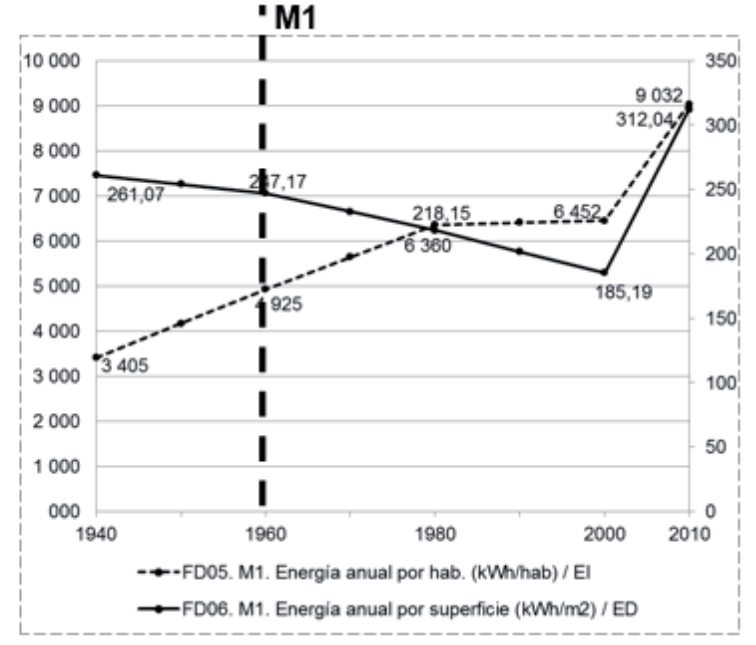

Figura 25. M1. Evolución alternativa en Madrid 19402010 de FD05 y FD06 Consumo anual de energía por sup. de viv. $\left(\mathrm{kWh} / \mathrm{m}^{2}\right)$.

Fuente: Elaboración propia

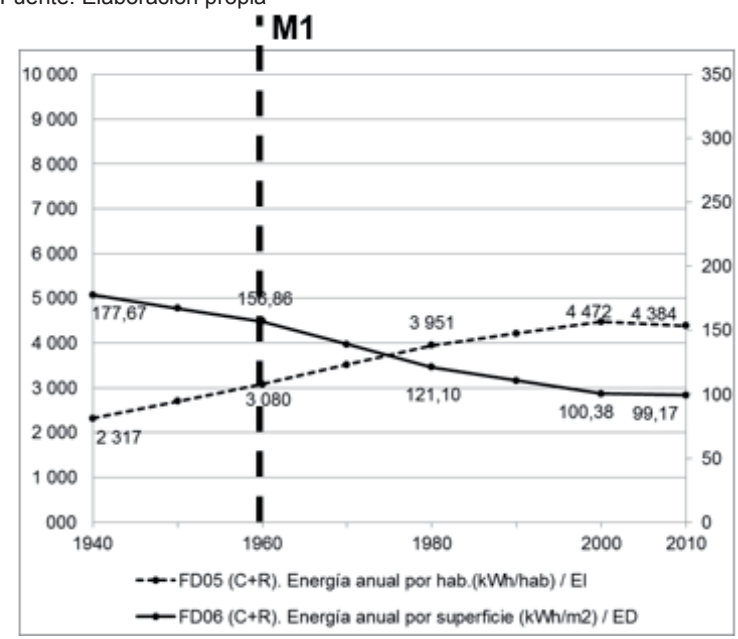

Figura 27. M1. Evolución alternativa en Madrid 19402010 de FD05 (C+R) Consumo anual de energía en climatización por habitante $(\mathrm{kWh} / \mathrm{hab})$ y FD06 $(\mathrm{C}+\mathrm{R})$ Consumo anual de energía en climatización por superficie de vivienda $\left(\mathrm{kWh} / \mathrm{m}^{2}\right)$.

Fuente: Elaboración propia 
La superficie urbana destinada a vivienda por habitante también se reduce en porcentajes similares y aplicando al crecimiento de suelo de equipamientos la proporción conocida hasta el momento la variable por habitante se reduce también en torno al 7,6\%. Las consecuencias de la aplicación de la medida M1 frente a evolución real se resumen en los siguientes puntos:

- Se ha adecuado el número de viviendas (S01) a las necesidades de formación de hogares de la población.

- La utilización de recursos energéticos y materiales por habitante se habría realizado de forma más homogénea a lo largo del periodo estudiado, evitando momentos de mayor intensidad en el consumo sobre todo de materiales. Esta reducción en la velocidad de producción de las viviendas implicaría una ligera reducción de estos factores por habitante respecto a la situación real en 2010.

- La mejor distribución de la construcción de viviendas respecto a la formación de hogares implica que el consumo de energía por superficie (FD06) en 2010 hubiera sido un $11 \%$ mayor al aplicar la medida M1 que en la evolución real. Esto se debe a que en el periodo entre 2000 y 2010 se habrían tenido que construir las viviendas que no se hicieron anteriormente. El coste en inversión de materiales y energía en esa década habría sido mayor si se hubiera aplicado la medida 1.

- No obstante, estas viviendas tendrían mejor calidad en cuanto al consumo energético porque se habrían realizado según las limitaciones normativas de la época.

- En cuanto al suelo residencial y de equipamientos por habitante, su evolución tras la aplicación de la medida M1 resultaría cerca de un $7,6 \%$ inferior a la evolución real en 2010.

\section{Calidad. Aplicación de la medida M2. Mayor limitación de la demanda energética en viviendas a partir de 1980}

En el año 1980, tras varios años de encarecimiento del precio del petróleo desde 1973, se aprueban diversas normativas para reducir la dependencia de energías fósiles del país. En el sector de la edificación también se realizan acciones concretas.

\section{Medida M2}

Se aprueba una normativa sobre limitación de la demanda energética en la edificación con un carácter más exigente que la NBE-CT-79. Además de esta medida, que se suma a la medida $M 1$, al observar una tendencia creciente de energía y materiales por superficie, así como la disminución del número de personas que componen los hogares se acuerda reducir el estándar de superficie de viviendas en un $10 \%$.

Tras la aplicación de esta medida, los indicadores relacionados con los recursos naturales se ven modificados. 


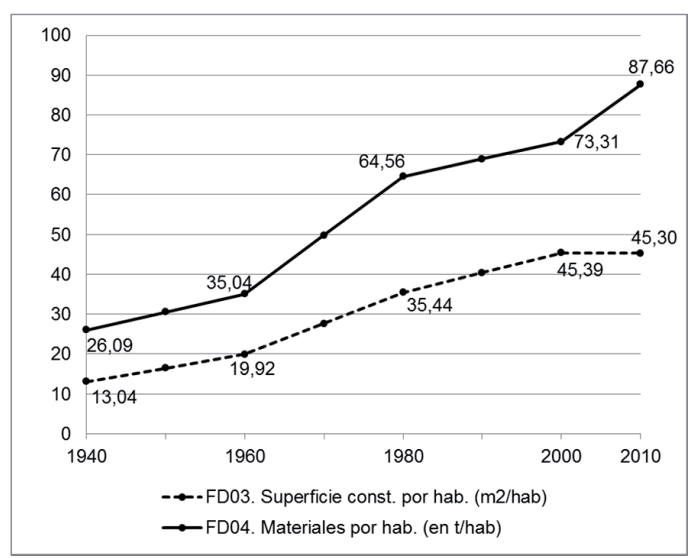

Figura 28. Evolución real en Madrid 1940-2010 de FD03. Superficie construida por habitante y FD04. Materiales empleados por habitante.

Fuente: Elaboración propia

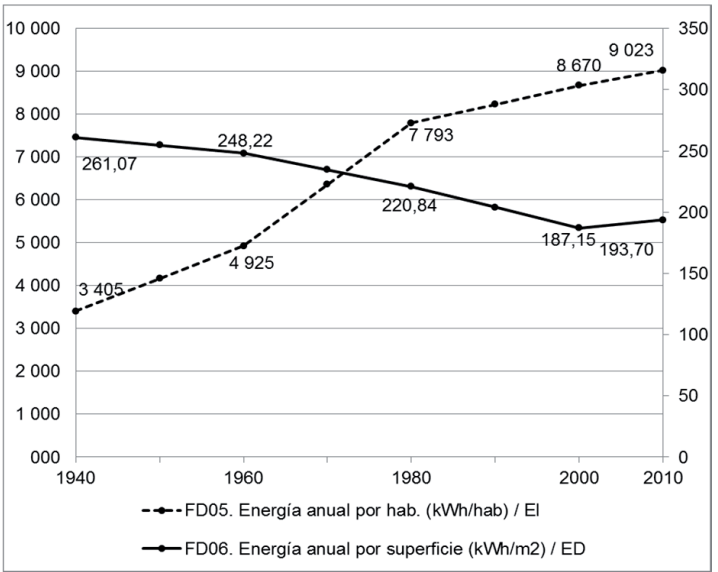

Figura 30. Evolución real en Madrid 1940-2010 de FD05 Consumo anual de energía por habitante, y FD06 Consumo anual de energía por superficie de vivienda $\left(\mathrm{kWh} / \mathrm{m}^{2}\right)$.

Fuente: Elaboración propia

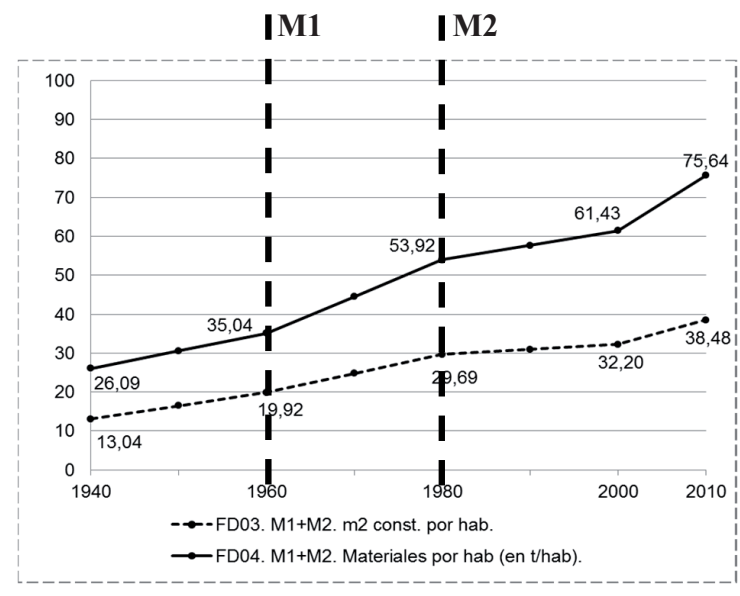

Figura 29. M1 + M2. Evolución alternativa en Madrid 1940-2010 de FD03. Superficie construida por habitante y FD04. Materiales empleados por habitante.

Fuente: Elaboración propia

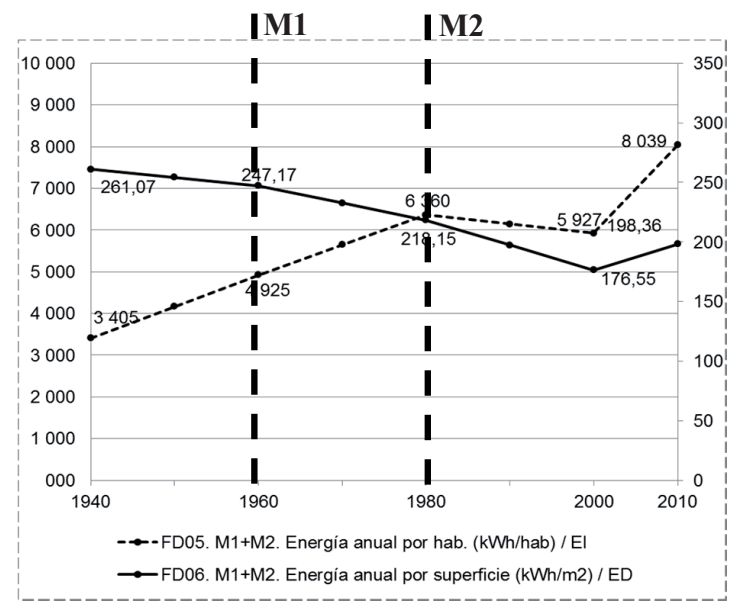

Figura 31. M1 + M2. Evolución alternativa en Madrid 1940-2010 de FD05 Consumo anual de energía por habitante, y FD06 Consumo anual de energía por superficie de vivienda $\left(\mathrm{kWh} / \mathrm{m}^{2}\right)$.

Fuente: Elaboración propia 
La aplicación de las medidas M1 y M2 respecto a la evolución real presenta los siguientes cambios:

- Los recursos energéticos y materiales transformados destinados a la producción del alojamiento en este escenario alternativo se reducen entorno al $15 \%$ en 2010 respecto a la evolución real.

- La reducción del consumo de energía por la limitación más estricta de la demanda a partir de 1980 supone que el consumo anual de energía por habitante se reduzca un $18 \%$ en 1980 , cerca del $28 \%$ en 2000 y un $10 \%$ en 2010 . Sin embargo, el consumo por superficie construida, a pesar que en 1980 y 2000 se reduce en 3,2\% y un 5,6\% respectivamente, en el año 2010 se incrementa un $2,41 \%$ respecto a la evolución real. El motivo es que se retrasa la construcción del número de viviendas a esa década y por tanto, el coste energético asociado a la producción y construcción incrementa este factor dinámico al tener las edificaciones una vida útil muy corta.

- El consumo anual de energía en todo el proceso (S04) se reduce en 2010 respecto a la evolución real en cerca del 10\%, mientras el consumo en climatización en esa fecha $(\mathrm{S} 04(\mathrm{C}+\mathrm{R}))$ se reduce en un $21 \%$.

- La ocupación del suelo por usos residenciales y equipamiento se reduce en 2010 en un $15 \%$, lo que implica una menor urbanización de suelo natural.

\section{Protección. Aplicación de la medida M3. Rehabilitación energética de viviendas a partir de 2000}

En el año 2000, se considera necesario seguir reduciendo la dependencia del sector residencial de las fuentes no renovables de energía. Por ello, las políticas de intervención en la vivienda se dirigen a potenciar la rehabilitación energética de las edificaciones existentes anteriores al año 1980. De esta manera se pretende adecuar el soporte del alojamiento en Madrid buscando además de una mayor eficiencia energética del proceso, una protección de los recursos naturales al primer la rehabilitación sobre otro tipo de actuaciones más consumidoras de recursos como la sustitución.

\section{Medida M3}

Tras analizar el estado del parque edificado se plantea la obligatoriedad de reducir al menos un $40 \%$ del consumo en las viviendas anteriores a 1980 ya que las viviendas construidas posteriormente a 1980 realizadas cumpliendo una normativa más exigente en lo que se refiere al consumo de energía.

Esta medida se suma a las dos anteriores, por lo que únicamente se modifica la evolución de los factores relacionados con el consumo de energía. Estas variaciones se pueden observar en las figuras 32 y 33. 


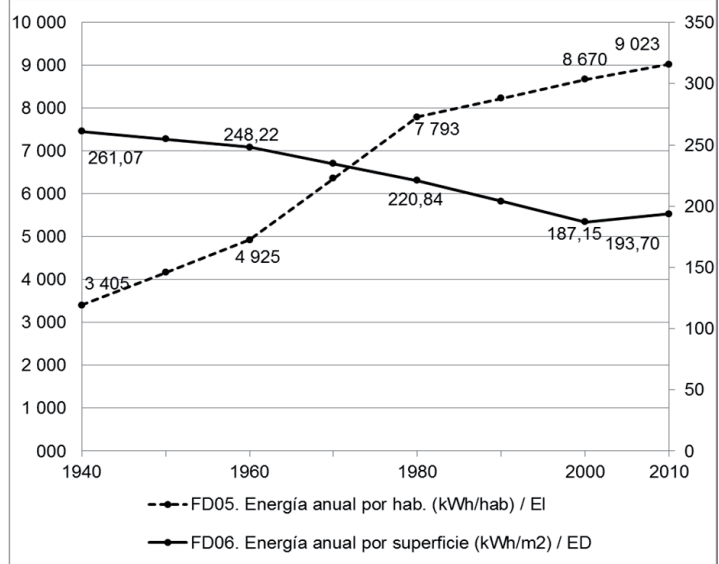

Figura 32. Evolución real en Madrid 1940-2010 de FD05 Consumo anual de energía por habitante, y FD06 Consumo anual de energía por superficie de vivienda $\left(\mathrm{kWh} / \mathrm{m}^{2}\right)$.

Fuente: Elaboración propia

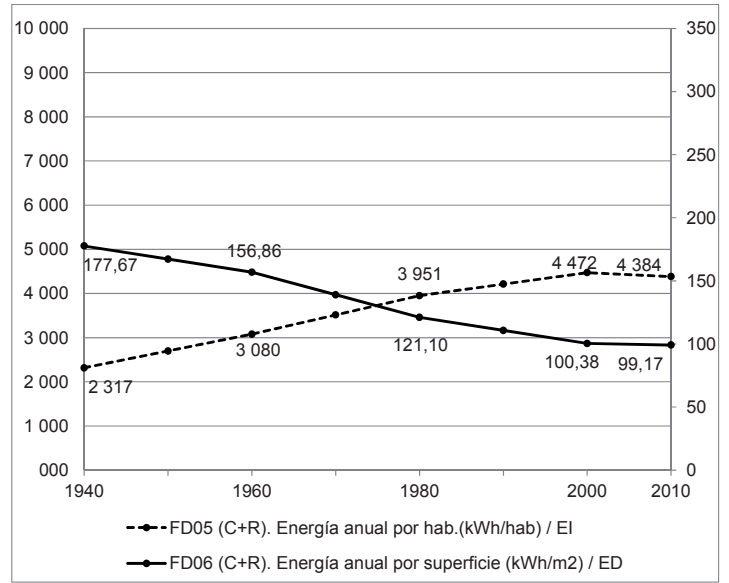

Figura 34. Evolución real en Madrid 1940-2010 de FD05 ( $C+R)$ Consumo anual de energía en climatización por habitante (kWh/hab) y FD06 $(\mathrm{C}+\mathrm{R})$ Consumo anual de energía en climatización por superficie de vivienda $\left(\mathrm{kWh} / \mathrm{m}^{2}\right)$

Fuente: Elaboración propia

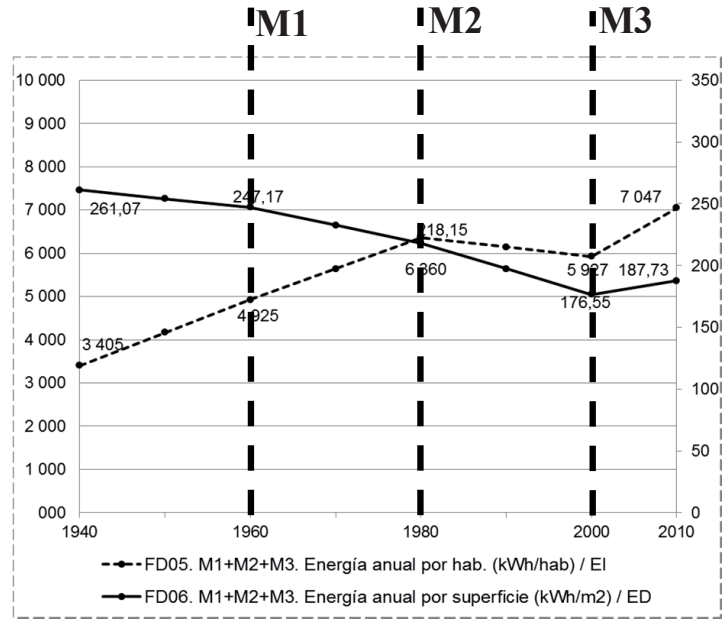

Figura 33. M1+M2+M3. Evolución alternativa en Madrid 1940-2010 de FD05 Consumo anual de energía por habitante, y FD06 Consumo anual de energía por superficie de vivienda $\left(\mathrm{kWh} / \mathrm{m}^{2}\right)$.

Fuente: Elaboración propia

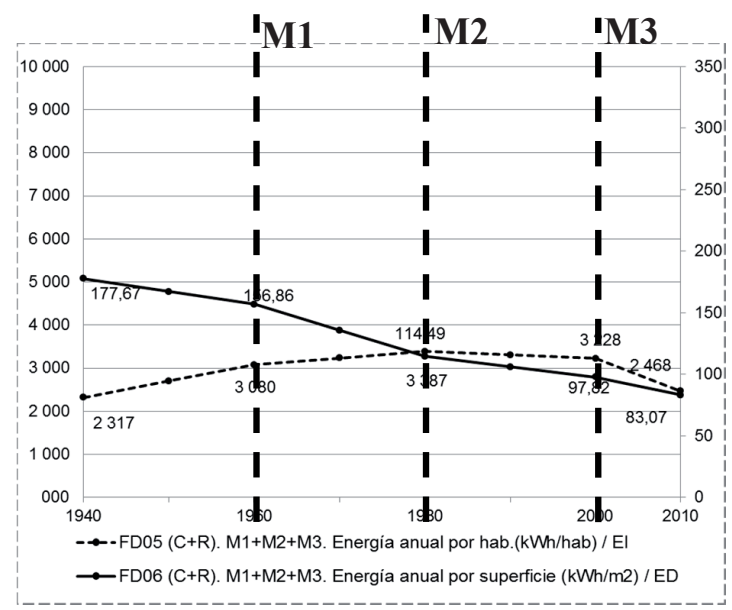

Figura 35. M1+M2+M3. Evolución alternativa en Madrid 1940-2010 de FD05 (C+R) Consumo anual de energía en climatización por habitante (kWh/hab) y FD06 (C+R) Consumo anual de energía en climatización por superficie de vivienda $\left(\mathrm{kWh} / \mathrm{m}^{2}\right)$

Fuente: Elaboración propia

En la figura 35 se observa, si en 2000 se hubiera puesto en marcha un Plan de rehabilitación energética de las viviendas en Madrid anteriores a 1980, en 2010 se habría reducido un $21,8 \%$ el consumo anual de energía en el conjunto de las viviendas. La energía anual para la climatización de la totalidad de las viviendas de 
Madrid se habría reducido un 43,7\% respecto a la evolución real en 2010.En los parámetros de energía por habitante las reducciones serían las mismas. La energía anual por superficie construida, considerando la totalidad de factores del proceso, se hubiera incrementado un 3\% debido al retraso en la construcción de viviendas en el periodo entre 2000 y 2010. La energía anual media en climatización por superficie construida se habría reducido en 2010 un 16,2\% respecto a la evolución real.

\section{Evolución real de indicadores frente a la aplicación de medidas}

A continuación se incluye el cuadro resumen de variables y factores en 2010 de la evolución real y las alternativas una vez aplicadas cada una de las tres medidas. A partir de la comparación de la evolución real y de los escenarios alternativos una vez aplicadas cada una de las tres medidas es posible extraer conclusiones que validan la aplicación del método de análisis. La evolución real y alternativa de las variables se muestra de la figura 37 a la figura 42. Se observa el cambio de su evolución a partir de la modificación del número de viviendas gracias a la medida M1. La limitación de la producción de éstas a partir de 1960 para adecuarse a las dinámicas de la población, implica que la construcción de viviendas se realizara más lentamente a lo largo del periodo hasta 2010, siendo este año un $8,21 \%$ inferior a la evolución real. Esto supone que el FD02 Número de habitantes por vivienda tenga un valor de 2,79 habitantes por vivienda frente a los 2,56 habitantes por vivienda de la evolución real. La reducción de la superficie construida de vivienda implica que las variables asociadas al consumo y transformación de materiales (S02 y S03) se reduzcan un $15 \%$ como consecuencia de las tres medidas aplicadas. El consumo anual de energía asociado al soporte construido en los escenarios alternativos planteados se reduce desde hasta el $21,8 \%$ en el caso de haber implementado las políticas de rehabilitación que se plantean gracias a la medida M3. Los valores de ocupación del suelo se hubieran reducido aplicando las tres medidas, al ser inferior el número de viviendas construidas $y$, por tanto, la transformación del suelo para uso residencial.

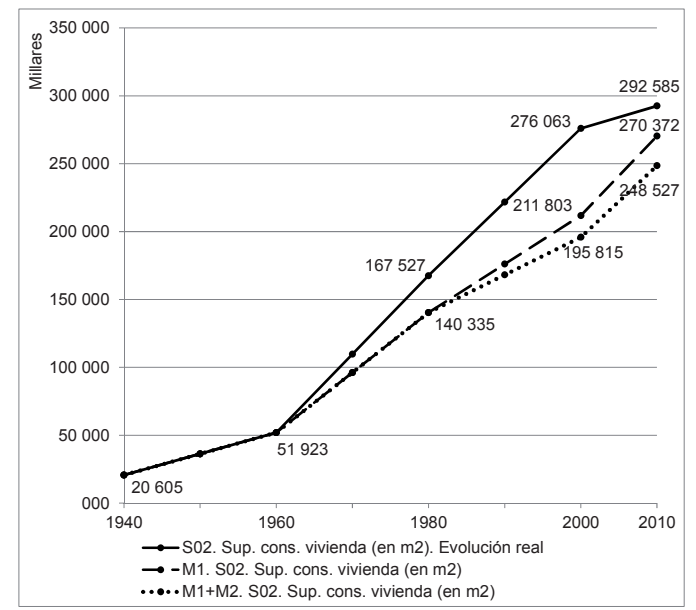

Figura 36. Evolución real y alternativa con la aplicación de M1, M2 y M3 en Madrid de S02. Superficie construida de vivienda (en miles de $\mathrm{m}^{2}$ ).

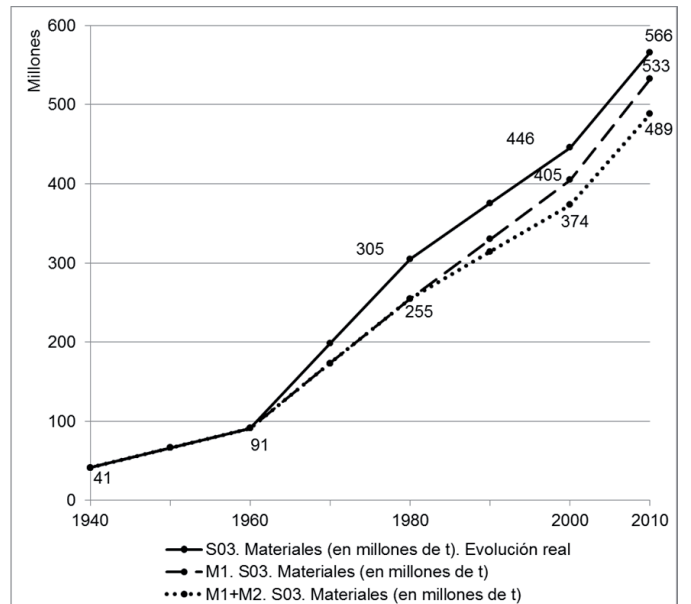

Figura 37. Evolución real y con la aplicación de M1, M2 y M3 en Madrid 1940-2010 de S03. Materiales empleados (en millones de $\mathrm{t}$ ) 


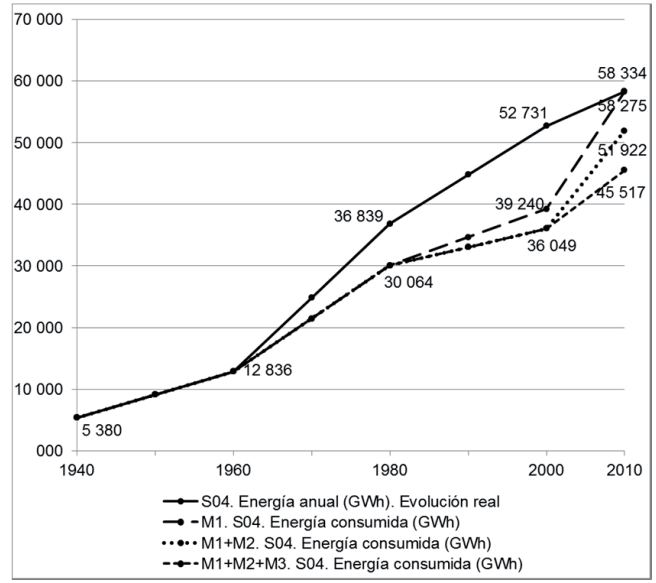

Figura 38. Evolución real y alternativa con la aplicación de M1, M2 y M3 en Madrid de S04. Consumo anual de energía en el alojamiento (en GWh)

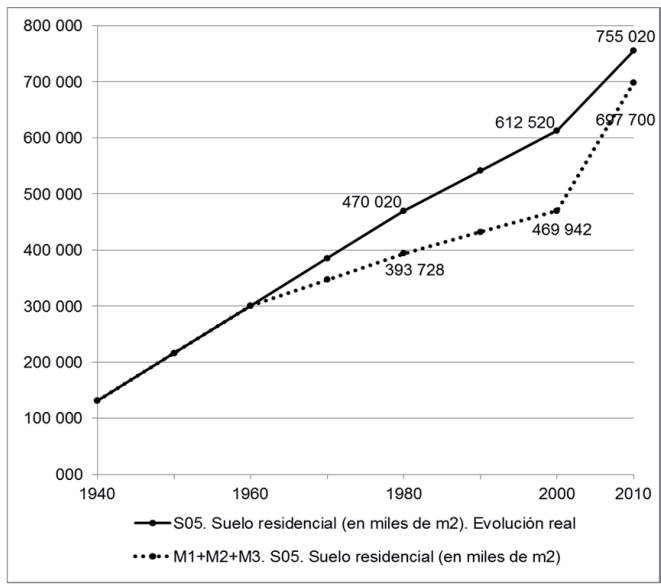

Figura 40. Evolución real y alternativa con la aplicación de M1, M2 y M3 en Madrid de S05. Suelo urbano residencial (en miles de $\mathrm{m}^{2}$ )

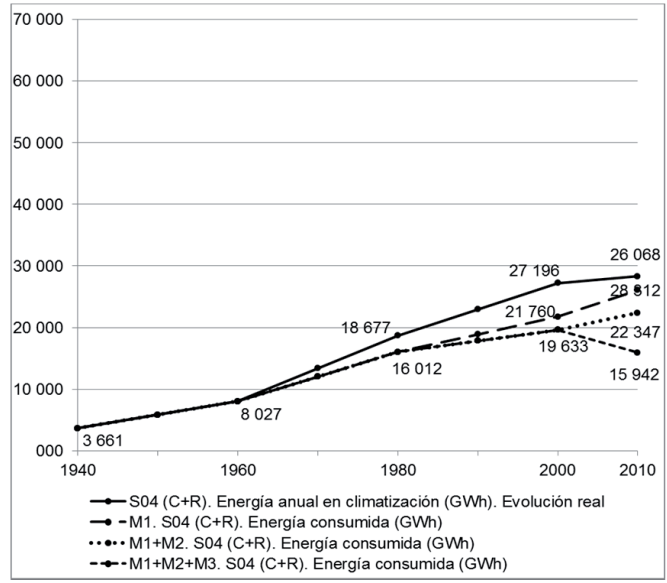

Figura 39. Evolución real y alternativa con la aplicación de M1, M2 y M3 en Madrid de S04 (C+R). Consumo anual de energía en la climatización (en GWh)

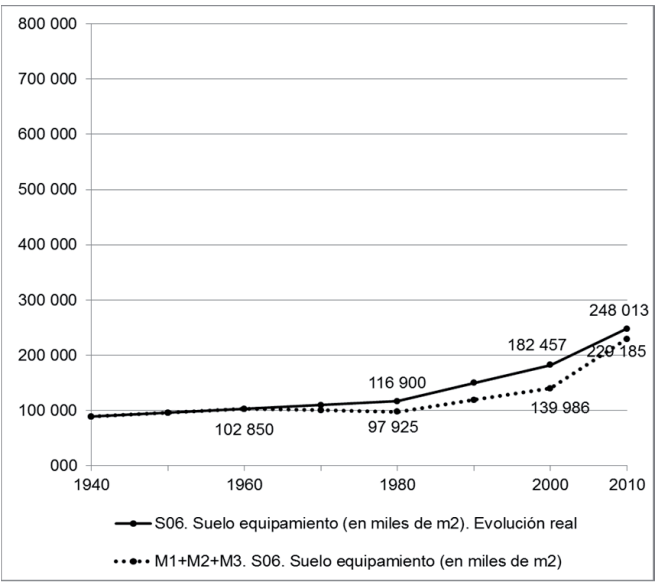

Figura 41. Evolución real y alternativa con la aplicación de M1, M2 y M3 en Madrid de S06. Suelo urbano equipamientos (en miles de $\mathrm{m}^{2}$ )

Fuente de las figuras: Elaboración propia

La evolución del FD01. "Número de habitantes por hogar", se mantiene igual entre todos los escenarios propuestos, aunque la modificación de las variables asociadas al soporte también hubiera supuesto la modificación de este indicador en la realidad. Para el FD02 Número de habitantes por vivienda, la medida propuesta de reducción del número de viviendas a partir de 1980 implica una evolución alternativa (Figura 36). En el año 2010, el FD02 se reduce en casi 1 habitante por vivienda respecto a la evolución real. Aunque entre el año 2000 y 2010, en la evolución real este factor parece estabilizarse, estaría por debajo de la formación de hogares. En la evolución alternativa tras la aplicación de las medidas, el FD02 se estabiliza a partir de 1980, siendo sus valores similares a los del FD01. 


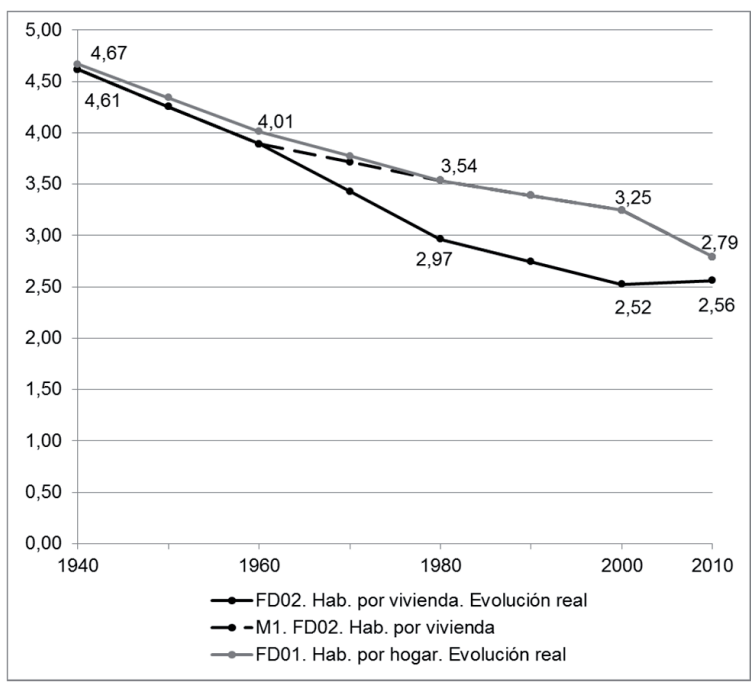

Figura 42. Evolución real y alternativa con la aplicación de M1, M2 y M3 en Madrid de FD01. Número de habitantes por hogar y FD02. Número de habitantes por vivienda.

Fuente: Elaboración propia

La superficie construida por habitante y los materiales empleados (FD03 y FD04), tienen también una reducción importante en los escenarios alternativos que surgen tras la aplicación de las medidas. La limitación del número de viviendas a partir de 1960 implica una mayor reducción de estos factores respecto a la evolución real. En el primer caso, las reducciones respecto a la evolución real el 15,06\% en 2010, mientras que la segunda alternativa implicaría el 13,7\% (figuras 44 y 45 ).

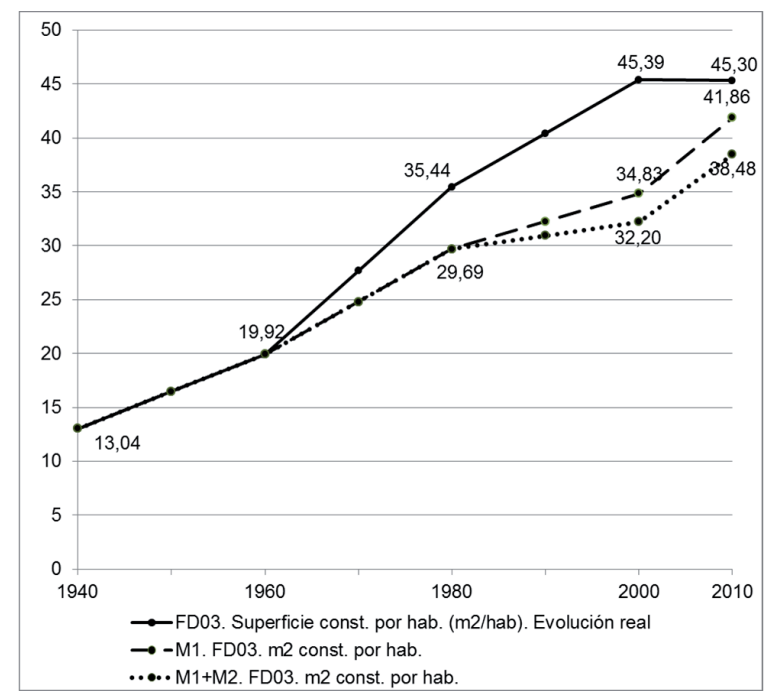

Figura 43. Evolución real y alternativa con la aplicación de M1, M2 y M3 en Madrid de FD03. Superficie construida por habitante $\left(\mathrm{m}^{2} / \mathrm{hab}\right)$.

Fuente: Elaboración propia 


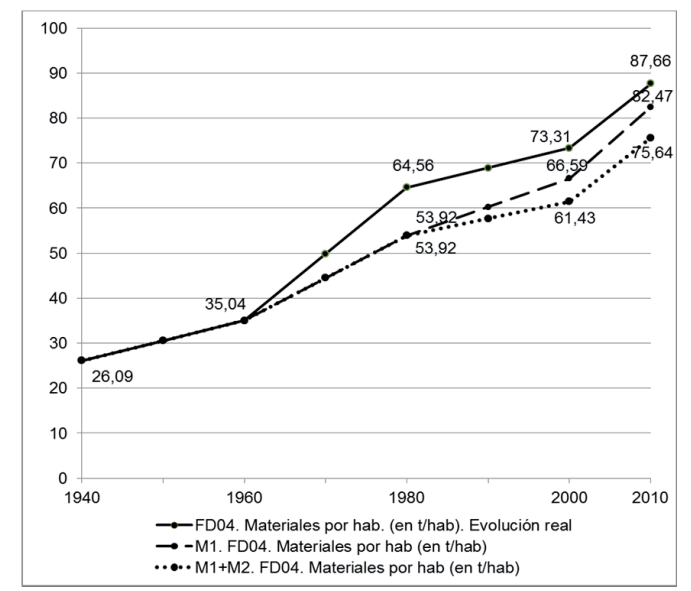

Figura 44. Evolución real y alternativa con la aplicación de M1, M2 y M3 en Madrid de FD04. Materiales por habitante (t/hab).

Fuente: Elaboración propia

El consumo anual de energía por habitante experimenta una reducción gradual con cada una de las medidas. En el caso de las medidas M1 de reducción del número de viviendas a partir de 1960 y la medida M2 la restricción de la demanda de energía en las viviendas nuevas a partir de 1980 implica que el consumo se reduzca en las décadas siguientes, pero continúe aumentando debido al crecimiento más lento del número de viviendas y habitantes. Con la medida M3 de rehabilitación energética de las edificaciones se consigue reducir aún más este consumo. La aplicación de esta medida hubiera implicado que, en 2010, el consumo anual por habitante hubiera sido un $21,8 \%$ inferior que la evolución real como se muestra en la figura 45 . En el caso del FD05 $(\mathrm{C}+\mathrm{R})$, que sólo contempla la energía anual en climatización por habitante, la reducción debida a la aplicación de medidas alternativas es más significativa porque no se contabiliza la energía de producción y construcción. La reducción de este indicador respecto a la evolución real sería del 16,2\% (figura 46).

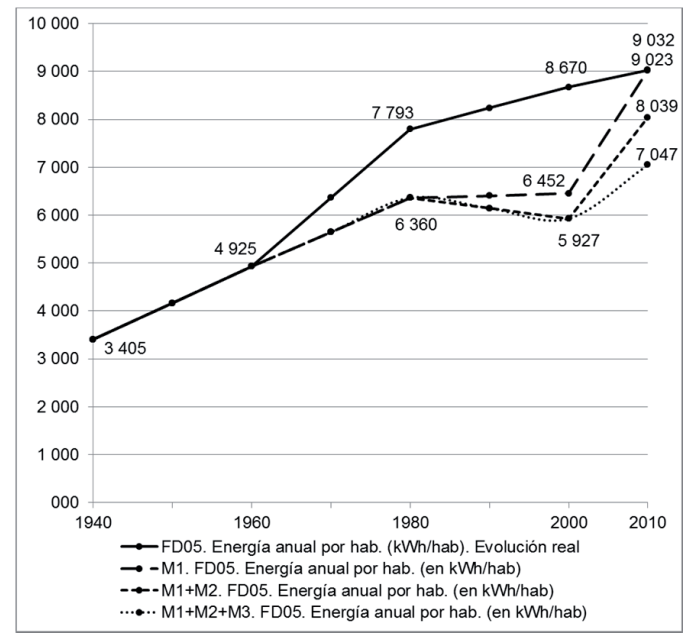

Figura 45. Evolución real y alternativa con la aplicación de M1, M2 y M3 en Madrid de FD05. Consumo anual de energía en el alojamiento por habitante (en $\mathrm{kWh} / \mathrm{hab}$ ).

Fuente: Elaboración propia 


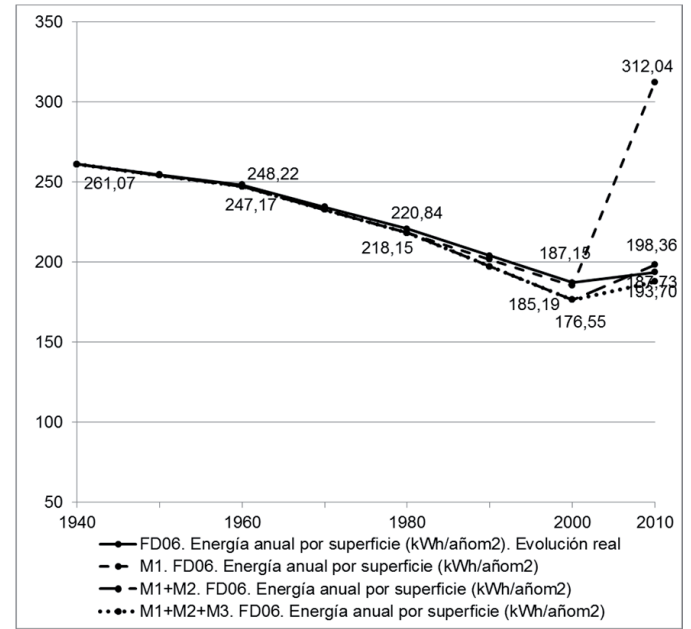

Figura 46. Evolución real y alternativa con la aplicación de M1, M2 y M3 en Madrid de FD05 (C+R). Consumo anual de energía en climatización por habitante (en kWh/hab).

Fuente: Elaboración propia

"El consumo anual de energía por superficie construida" (FD06) tiene una evolución distinta (figura 48). La desaceleración en la construcción de viviendas desde 1960 hubiera implicado que los consumos asociados a la construcción y producción de las viviendas se distribuyese en los años sucesivos, incrementando el valor medio de la energía anual por superficie construida. Con la medida M3 para el fomento de la rehabilitación energética junto con el resto de medidas apenas hubiera supuesto una reducción del $3 \%$ respecto de la evolución real. Los valores por superficie asociados a la climatización (FD06 $(\mathrm{C}+\mathrm{R})$ ) después de esta intervención supondrían una reducción del $16,2 \%$ respecto a la situación actual (figura 48 ). En los indicadores asociados a la ocupación del suelo destinado al uso residencial y equipamientos se observa que, aunque los valores finales son inferiores en las alternativas a la evolución real, éstos presentan una tendencia creciente, que debería reducirse (figuras 49 y 50). Para ello sería necesario estudiar alternativas que consideran la densidad de la trama urbana.

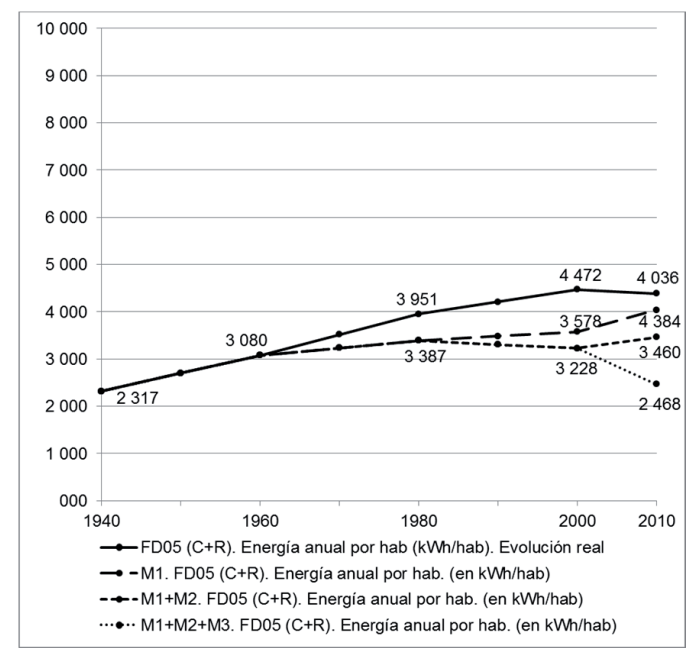

Figura 47 . Evolución real y alternativa con la aplicación de M1, M2 y M3 en Madrid de FD06. Consumo anual de energía en el alojamiento por superficie de viviendas (en $\mathrm{kWh} / \mathrm{m}^{2}$ ).

Fuente: Elaboración propia 


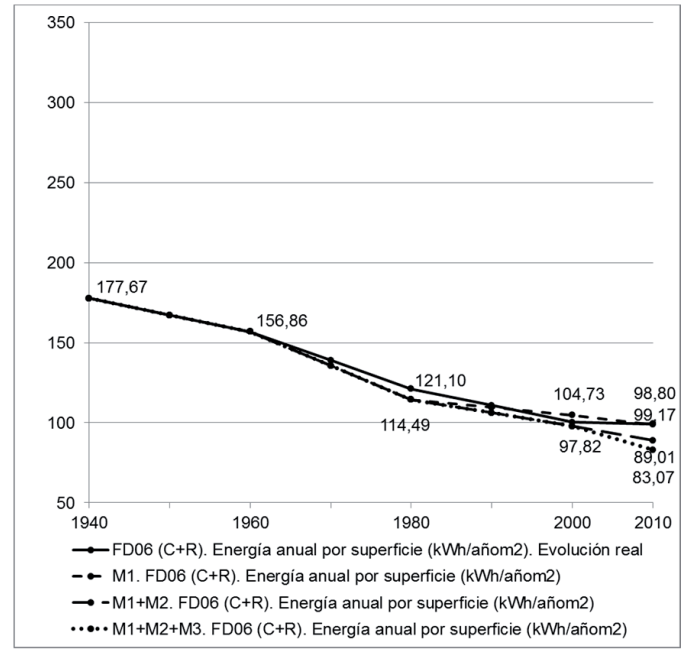

Figura 48 . Evolución real y alternativa con la aplicación de M1, M2 y M3 en Madrid de FD06 (C+R). Consumo anual de energía en climatización por superficie de viviendas (en $\mathrm{kWh} / \mathrm{m}^{2}$ ). Fuente: Elaboración propia

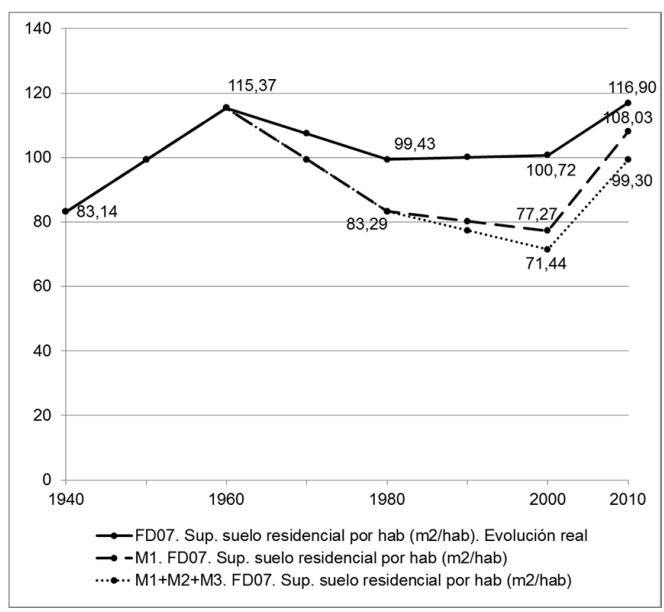

Figura 49. Evolución real y alternativa con la aplicación de M1, M2 y M3 en Madrid de FD07. Superficie destinada a uso residencial por habitante (en $\left.\mathrm{m}^{2} / \mathrm{hab}\right)$. Fuente: Elaboración propia

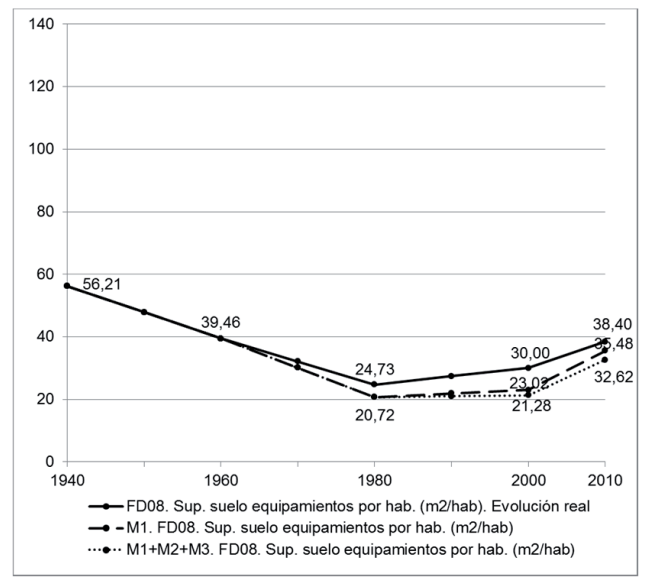

Figura 50. Evolución real y alternativa con la aplicación de M1, M2 y M3 en Madrid de FD08. Superficie destinada a uso equipamiento por habitante (en $\mathrm{m}^{2} / \mathrm{hab}$ ). Fuente: Elaboración propia 


\section{Conclusiones sobre la aplicación retrospectiva a Madrid 1940-2010}

La aplicación restrospectiva de medidas definidas a partir de las estrategias ha permitido validar el método de análisis diacrónico como instrumento de evaluación para la intervención en el alojamiento con criterios ecológicos. Gracias al análisis de la evolución de los indicadores ha sido posible detectar situaciones no deseables y proponer medidas que hubieran supuesto su corrección, como es el caso del desajuste entre el número de habitantes y el número de viviendas (burbuja inmobiliaria).

En lo que se refiere a la medida definida a partir de la estrategia de estabilidad, la limitación del número de viviendas según el crecimiento de la población hubiera implicado que una evolución del resto de variables y factores dinámicos que hubieran conducido a un escenario en el que se habría producido un menor consumo de recursos naturales. Esta medida hubiera implicado una reducción en la velocidad de construcción de las viviendas en Madrid.

Como se muestra en la evolución real, un desarrollo muy intenso del alojamiento en un periodo corto de tiempo, implica poca capacidad de reacción para corregir los efectos de futuro no deseados, como es el consumo excesivo de recursos en el uso de las viviendas o un parque sobre o infradimensionado en relación a la población.

Las medidas planteadas en función de las estrategias de calidad y protección hubieran supuesto una reducción del consumo de materiales y energía asociado al alojamiento en todo el periodo analizado. La rehabilitación energética de las viviendas existentes a partir de 2000 es la estrategia de intervención que mayores ahorros de energía y materiales hubiera supuesto en 2010, aun aplicándose únicamente a partir de 2000.

Con esta medida, se hubiera conseguido en 2010 una mejora del soporte construido en relación al consumo de energía, lo que hubiera implicado de cara al futuro unas mejores condiciones de partida para aplicar políticas más restrictivas en las cuestiones energéticas. La aplicación de una norma más exigente a partir de 1980 , es la medida que en segundo lugar hubiera supuesto un mayor ahorro de energía en el alojamiento en 2010. La última medida en eficacia la adecuación del número de viviendas según la evolución de la población.

En lo que se refiere a la ocupación y transformación del suelo, la estrategia de reducción de superficie construida de vivienda hubiera sido la más eficaz para reducir la urbanización de suelo destinado a uso residencial. En la valoración de la evolución de estos indicadores la velocidad de crecimiento es una cuestión importante para corregir situaciones no deseadas, como la escasez de equipamientos en relación a las viviendas o desarrollos mal dimensionados. 


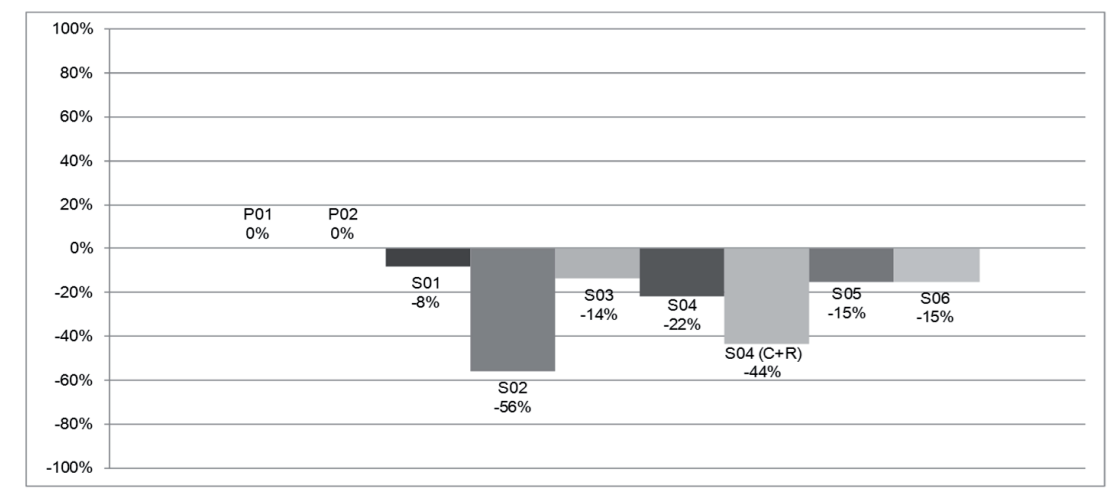

Figura 51. Porcentaje de reducción de escenario restrospectivo alternativo (M1+M2+M3) frente a evolución real de las variables en-2010 para Madrid.

Fuente: Elaboración propia

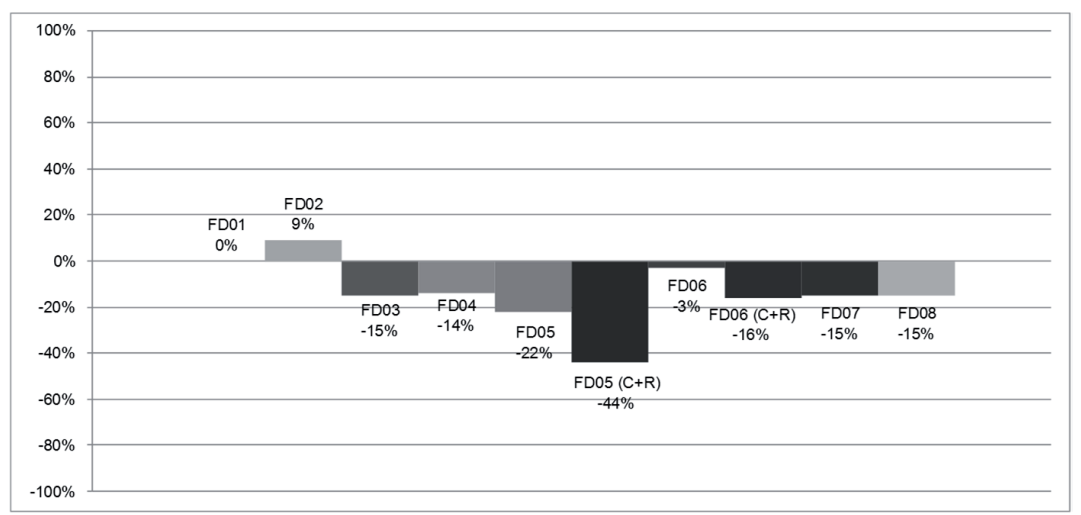

Figura 52. Porcentaje de reducción de escenario restrospectivo alternativo $(M 1+M 2+M 3)$ frente a evolución real de los factores dinámicos en-2010 para Madrid.

Fuente: Elaboración propia

\section{APLICACIÓN DEL MÉTODO DE ANÁLISIS DIACRÓNICO AL CASO DE MADRID (2010-2100)}

\subsection{Definición del período de análisis y las proyecciones de futuro (2010-2100)}

Para la definición del ámbito temporal de futuro se ha considerado la recomendación del Plan Nacional de Adaptación al Cambio Climático (Oficina Española de Cambio Climático, 2006) que define en 100 años el plazo para las propuestas para la reducción y mitigación de los efectos del cambio climático en la edificación. Por este motivo se ha fijado el año final de análisis en el año $2100^{34}$. En la línea base en

34 Los escenarios de futuro planteados por el equipo Meadows en sus investigaciones también marca hasta 2100 el periodo de análisis. Proponen 11 escenarios para conocer en qué condiciones la población, la industria, la contaminación y otros factores asociados pueden crecer, estabilizarse, oscilar o colapsarse en el futuro (Meadows, Randers, \& Meadows, 2006, pág. 239) 
2010, las viviendas más antiguas tienen una vida media de 90 años y se ha estimado un periodo de igual magnitud para el futuro. En la figura 53 se muestra un esquema del periodo temporal de futuro.

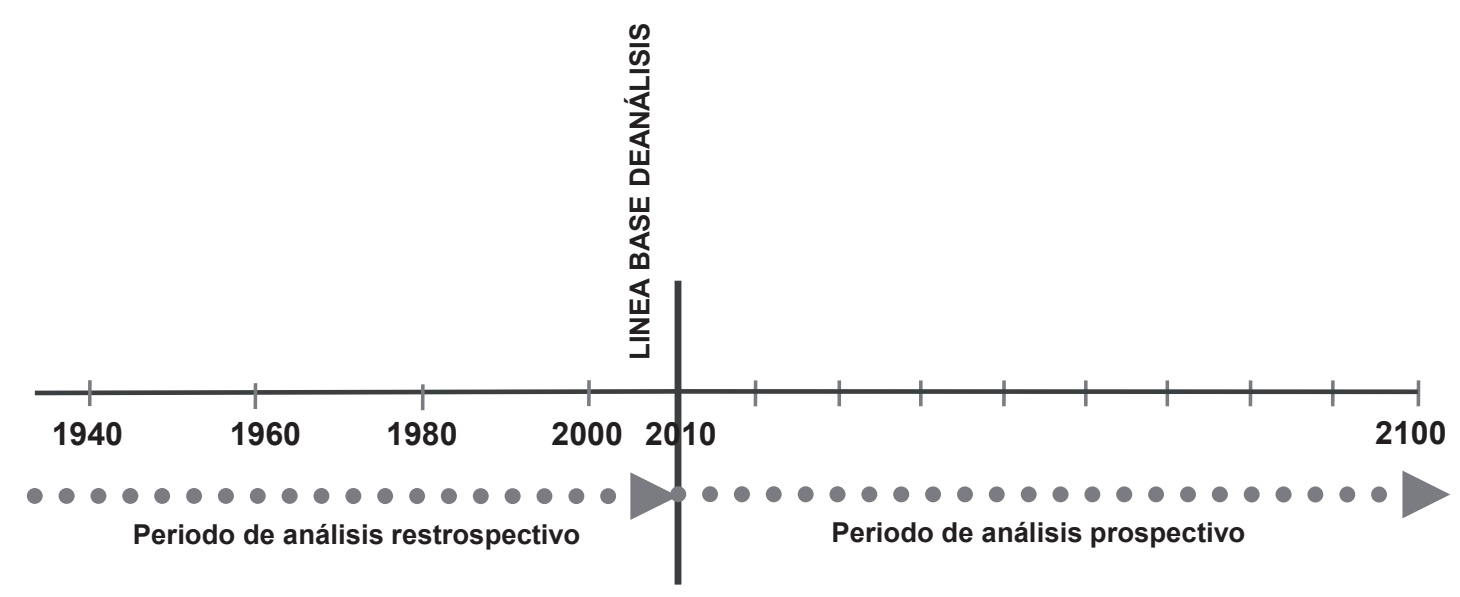

Figura 53. Esquema de ámbito temporal seleccionado para el análisis diacrónico.

Fuente: Elaboración propia

Para la aplicación del método de análisis es necesario realizar proyecciones de la evolución de los indicadores seleccionados. De esta manera, a partir de una posible evolución del alojamiento, se podrían conocer previamente si es necesario aplicar algunas medidas correctoras y evaluar sus efectos a largo plazo. La cuantificación de estos indicadores en el futuro se realizará recurriendo a la prospectiva, disciplina que trata de prever el futuro y la evolución de los sistemas socioeconómicos.

Michel Godet, investigador francés de la Prospectiva Estratégica, señala que "el futuro es múltiple, indeterminado y abierto a una gran variedad de futuros posibles. Lo que pasará mañana, depende menos de las fuertes tendencias que se impondrían fatalmente a los hombres que de las políticas que desarrollan los hombres a objeto de hacer frente a esas tendencias". (Godet, 2007). Este mismo autor cita al economista Maurice Allais que reflexiona sobre la imposibilidad de alcanzar modelos perfectos para describir la realidad, y que únicamente podemos proponer aproximaciones, precisando que "de dos modelos, el "mejor" será siempre aquel que por aproximación representará de la manera más sencilla los datos que se derivan de la observación de la realidad". El análisis de escenarios de futuro permite la toma de decisiones anticipadamente para evitar impactos negativos y alcanzar situaciones deseables ${ }^{35}$.

Los indicadores seleccionados, variables y factores dinámicos, caracterizan el proceso del alojamiento desde la perspectiva temporal, y el método de análisis, validado a través de la aplicación retrospectiva, serviría para el objetivo propuesto.

35 Algunos autores reclaman la aplicación de una metodología prospectiva a la planificación territorial porque consideran que es un instrumento adecuado para "resolver o encauzar de forma pluridisciplinar cuestiones complejas que han madurado a lo largo de muchos años y cuyo abordaje requiere un cuantioso trabajo para mentalizar a la sociedad sobre el cambio necesario de cara al futuro" (Fernández Güell, 2011, pág. 20). 
Godet (Godet, 2007, pág. 22) que indica que los escenarios prospectivos deben cumplir cinco condiciones: pertinencia, coherencia, verosimilitud, importancia y transparencia. Los escenarios de futuro se pueden clasificar en dos grandes grupos:

- Exploratorios o tendenciales: partiendo de tendencias pasadas y presentes, se plantean futuros verosímiles.

- Anticipación o normativos: construidos a partir de imágenes alternativas del futuro.

A partir de estas ideas, en la tesis se plantean para cada una de las variables, tres proyecciones de evolución hasta 2100, acotadas en periodos de 10 años, que se basan en los tipos de escenarios indicados (tendencial o normativo). En cada caso, la calificación de escenario deseable o rechazable correspondería a su evolución en relación a la limitación de recursos asociados al alojamiento.

Para algunas variables, como es el número de hogares o de habitantes, no se puede establecer esta clasificación, y por tanto se trata de escenarios tendenciales. La combinación de estas proyecciones para las variables daría lugar a la evolución de los factores dinámicos, que, de forma conjunta, da lugar a múltiples escenarios. Siendo la población el elemento determinante en la evolución del alojamiento como sistema, en función de las proyecciones de esta variable, se ha seleccionado un escenario para la aplicación del método de análisis. Para cada uno de estos escenarios se plantean posteriormente medidas de intervención en función de las estrategias definidas anteriormente (estabilidad, calidad y protección) para evaluar su impacto a largo plazo.

\subsection{Definición de escenario prospectivo para la aplicación del método de análisis}

Tras la definición del ámbito temporal hasta 2100 y la elaboración de proyecciones de futuro para los indicadores que caracterizan el alojamiento, es posible definir un escenario en Madrid para la aplicación del método diacrónico. El escenario se ha definido mediante las proyecciones en la evolución del número de habitantes (P01) y a partir de ahí se ha estimado el número de hogares (P02). En función de la evolución de estas dos variables, se han seleccionado las proyecciones de las variables características de las viviendas (S01 "Número de viviendas" y S02 "Superficie construida"). A partir de estas proyecciones se definen las diferentes opciones de evolución de las variables ligadas a los recursos naturales (S03 Materiales empleados, S04 Consumo de energía en el alojamiento, S04 (C+R) Consumo de energía en climatización de viviendas, S05 Superficie urbana destinada a uso residencial, S06 Superficie urbana destinada a equipamientos). Una vez cuantificados los indicadores para el análisis del escenario seleccionado se han seguido las siguientes fases del método (figura 54). 


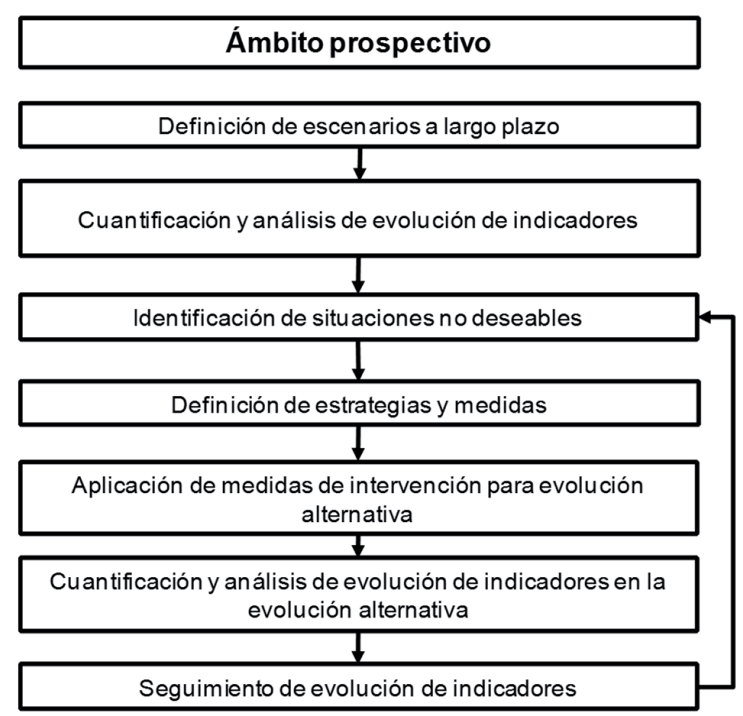

Figura 55. Fases de la aplicación prospectiva del método de análisis

Fuente: Elaboración propia

Una vez identificadas situaciones no deseables en la evolución del alojamiento, se proponen medidas de intervención a partir de las estrategias de estabilidad, calidad y protección. Al igual que en la aplicación retrospectiva del método estas medidas serán las siguientes:

Estabilidad Adecuación del número de viviendas a las dinámicas de la población y hogares

Calidad Mejora de la eficiencia del metabolismo del alojamiento

Protección Reducción del consumo de recursos asociado al alojamiento

Asimismo, como se indicaba en las proyecciones para las variables, se han planteado tres tipos de intervención sobre las viviendas.

- Rehabilitación energética de viviendas existentes

- Sustitución o en el caso de que en la proyección se prevea un incremento del número de viviendas, obra nueva.

- No intervención sobre el soporte.

A continuación se evaluará la evolución alternativa tras la aplicación de estas tres medidas y se extraerían las conclusiones para cada uno de los casos.

\subsection{Evolución de variables y factores dinámicos en el escenario prospectivo seleccionado}

Se prevé un escenario futuro de habitantes en Madrid con un crecimiento nulo, manteniéndose el número de habitantes hasta 2100 (P01 № de habitantes medio). 
También se constata una tendencia baja de formación de hogares. Considerando la evolución de personas por vivienda y hogar, se decide que el parque existente de viviendas en Madrid en 2010 es suficiente para alojar a la población prevista en los próximos años. Por otro lado se confirman las previsiones de un cambio climático alto, con incremento importante de las temperaturas a largo plazo. Por tanto se considera que la variable S01 "Número de viviendas puede reducirse", especialmente las viviendas más antiguas, que pueden desaparecer o transformar su uso. Asimismo se considera oportuno mantener el tamaño de viviendas, con una superficie media similar a la actual, lo que implica que se mantiene la tendencia de la superficie construida asociada al número de viviendas. Para las viviendas que se mantienen, se plantea un Plan de intervención, debiendo valorarse que intervención es la más adecuada a largo plazo: rehabilitación, sustitución por edificios nuevos o no intervención. El resumen de este escenario es el siguiente:

Proyección de No habitantes medio

Proyección de formación de hogares medio

Proyección de No Viviendas alta

Proyección de Superficie de vivienda media

Escenario de cambio climático alto

A continuación se muestra la evolución de los valores de variables y factores dinámicos del escenario propuesto. En la que que se observa cómo la tendencia de crecimiento de viviendas y número de hogares a partir de 2010 es distinta, lo que provocaría un sobre dimensionado del parque de viviendas, y por tanto una situación no deseable. Asimismo a partir de 2050, la población experimenta un cambio de tendencia desde un incremento de la misma hacia un descenso importante hasta 2100.

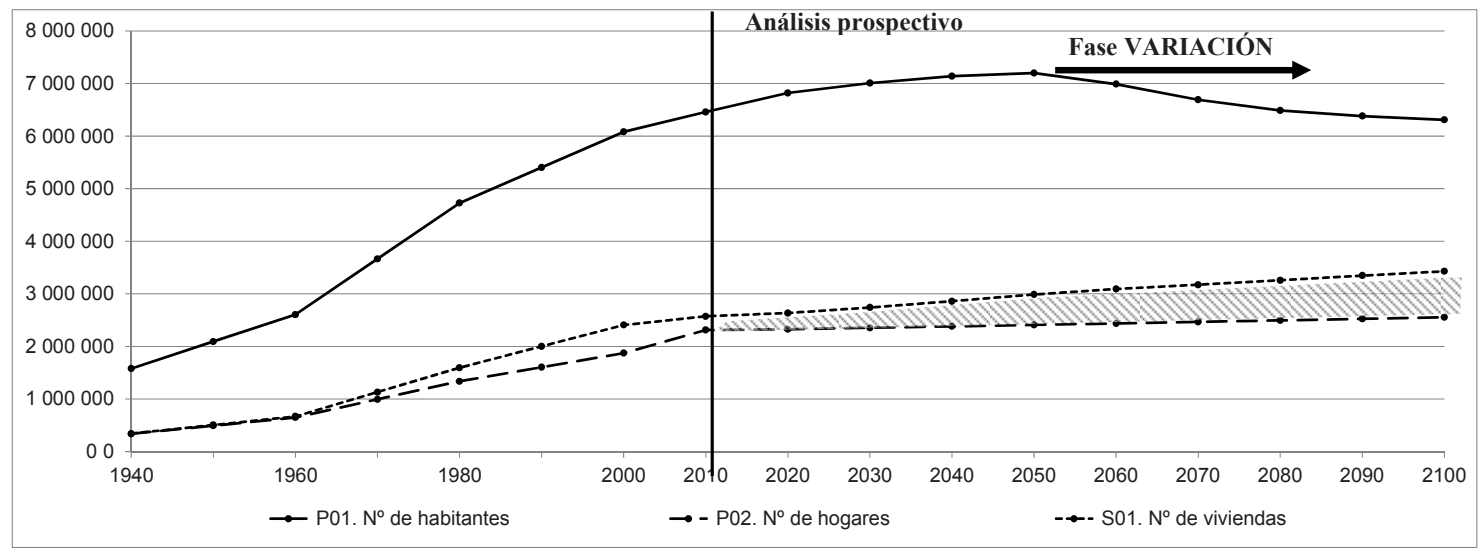

.MW Periodo de sobre dimensionamiento del parque de viviendas respecto a necesidades de la población

Figura 55. Evolución hasta 2100 de P01 No de habitantes, P02 No de hogares y S01 No de viviendas en Madrid

Fuente: Elaboración propia

En el caso de los recursos energéticos previstos para este escenario, se observa en la figura 56 que a partir del momento de la intervención en 2010, la energía 
necesaria para la climatización del conjunto de las viviendas apenas desciende debido a que, a pesar de que las viviendas son más eficientes desde el punto de vista del consumo energético, al seguir incrementándose el número de éstas, el consumo total de energía se mantiene.

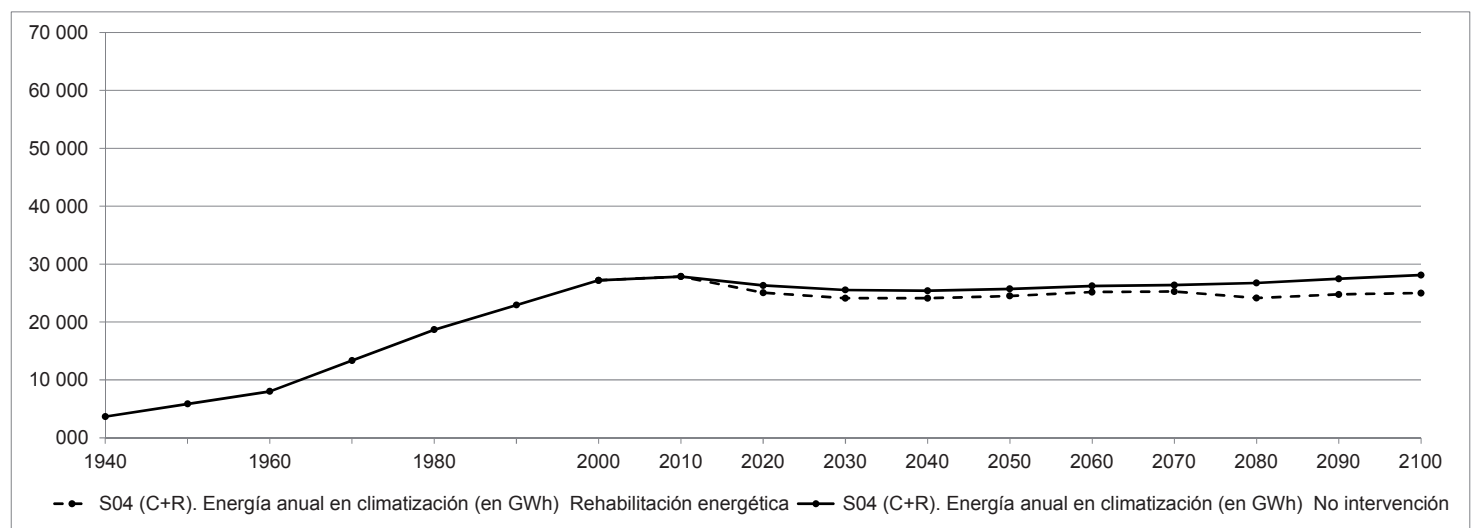

Figura 56. Evolución hasta 2100 de la variable S04 (C+R) Consumo anual de energía para climatización de viviendas en Madrid según tipo de intervención (en GWh)

Fuente: Elaboración propia

Mediante el análisis de la evolución de las variables, se puede caracterizar este escenario por un crecimiento medio del número de habitantes en Madrid (P01), lo que implica que esta variable se incrementa hasta 2050 y a partir de entonces decrece ligeramente hasta 2100, manteniendo según la gráfica una tendencia constante a partir de entonces. En estas condiciones, se prevé una formación media de hogares, que implica un ligero crecimiento de éstos en el periodo construido. Asimismo, la variable S01 "Número de viviendas tiene un crecimiento progresivo hasta 2100", pero al detectarse una tendencia decreciente en el número de habitantes, se produce una fase de variación que indica que es necesaria alguna medida de ajuste de estos indicadores (habitantes y viviendas), ya que de otra manera se mantendría una tendencia de sobre dimensionamiento del parque de viviendas respecto a la población. Esta situación implica un incremento del consumo de recursos asociado un alojamiento no necesario durante el periodo analizado. De forma proporcional, la superficie construida destinada a vivienda se incrementa, apareciendo dos opciones en los materiales empleados, la opción de rehabilitación energética que supone que además de las viviendas nuevas se destinan recursos a la rehabilitación de las existentes y la opción de nueva construcción, que implica que todas las viviendas anteriores a 2010 se sustituyen progresivamente por nuevas edificaciones. La segunda opción supone, lógicamente, un mayor consumo de materiales, pero aporta un soporte construido de mayor calidad y menor edad. La evolución de la variable S04 "Consumo anual de energía" en este escenario en función de los tipos de intervención previstos, indica que la rehabilitación energética de las edificaciones existentes es la opción menos consumidora de energía desde el momento de intervención (2010), con poca diferencia respecto a la no intervención y que hasta 2080, la opción de sustitución es la más que mayores consumos anuales de energía implica. La superficie urbana destinada a viviendas y a equipamientos se corresponde con la necesidad de suelo para nuevas viviendas. En 
2010 el porcentaje del suelo de la Comunidad de Madrid transformado para estos usos representaba aproximadamente el $10 \%$ del total de la superficie. En este escenario, podría pasar a ser del $12 \%$ en el año 2100 . A continuación se incluyen las figuran que muestran gráficamente la evolución de estas variables. La evolución de los factores dinámicos es similar a la descrita en las variables. El infradimensionamiento de las viviendas en relación a la población se puede apreciar en la figura 57, que muestra la evolución del número de habitantes por vivienda y por hogar, mostrándose la tendencia que refleja esta divergencia hasta 2100 (fase variación). El tipo de intervención que menos materiales implica es la rehabilitación de las viviendas, como muestra la figura 58, y en el caso de la energía (figura 59), para un periodo de análisis de unos 50 años desde la intervención, la rehabilitación energética es la más adecuada. Si el periodo de análisis es mayor, la sustitución es la opción que menos energía consume anualmente a largo plazo.

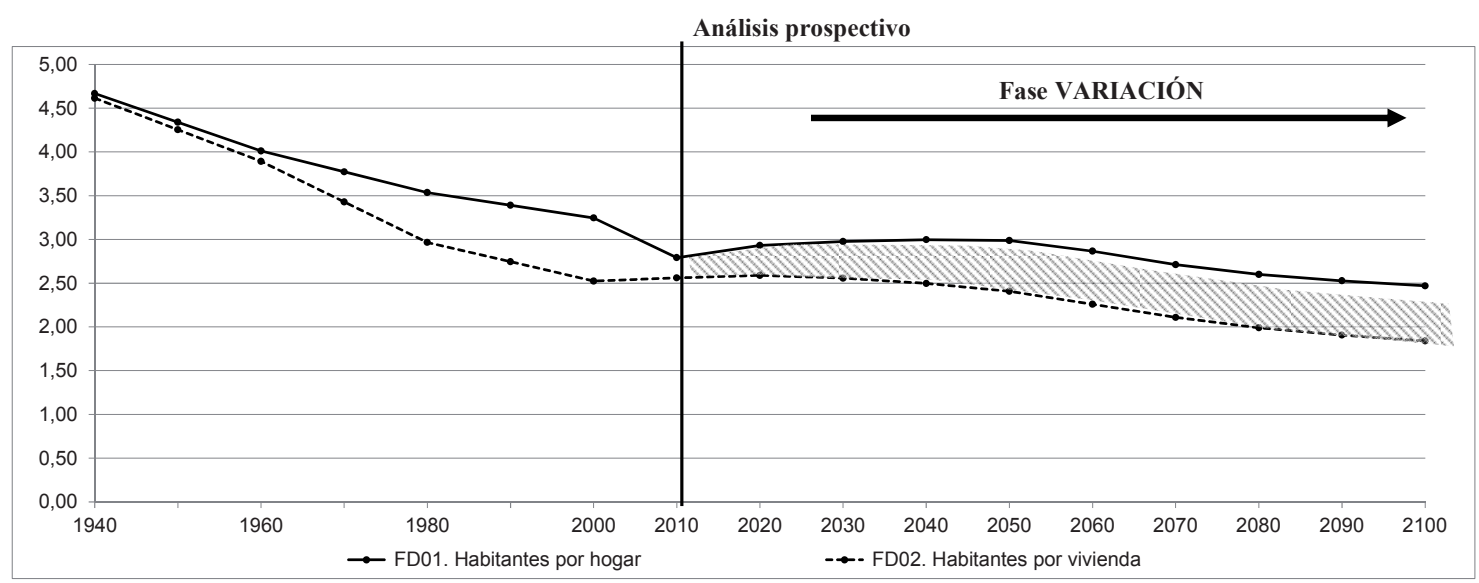

Figura 57. Evolución hasta 2100 de FD01 Habitantes por vivienda y FD02 Habitantes por hogar en Madrid

N.WPeriodo de infra dimensionamiento del parque de viviendas respecto a necesidades de la población Fuente: Elaboración propia

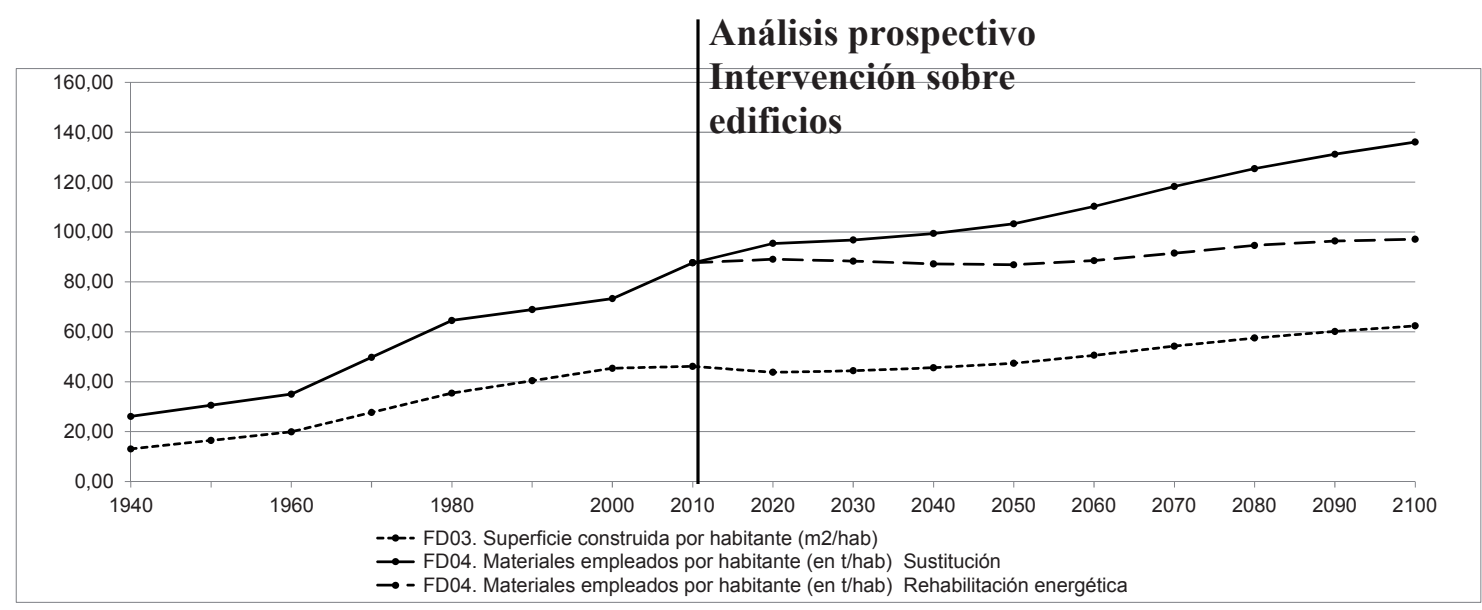

Figura 58. Evolución hasta 2100 de FD03 Superficie construida por habitante (en $\mathrm{m}^{2} / \mathrm{hab}$ ) y FD04 Materiales empleados por habitante en Madrid (en t/hab)

Fuente: Elaboración propia 


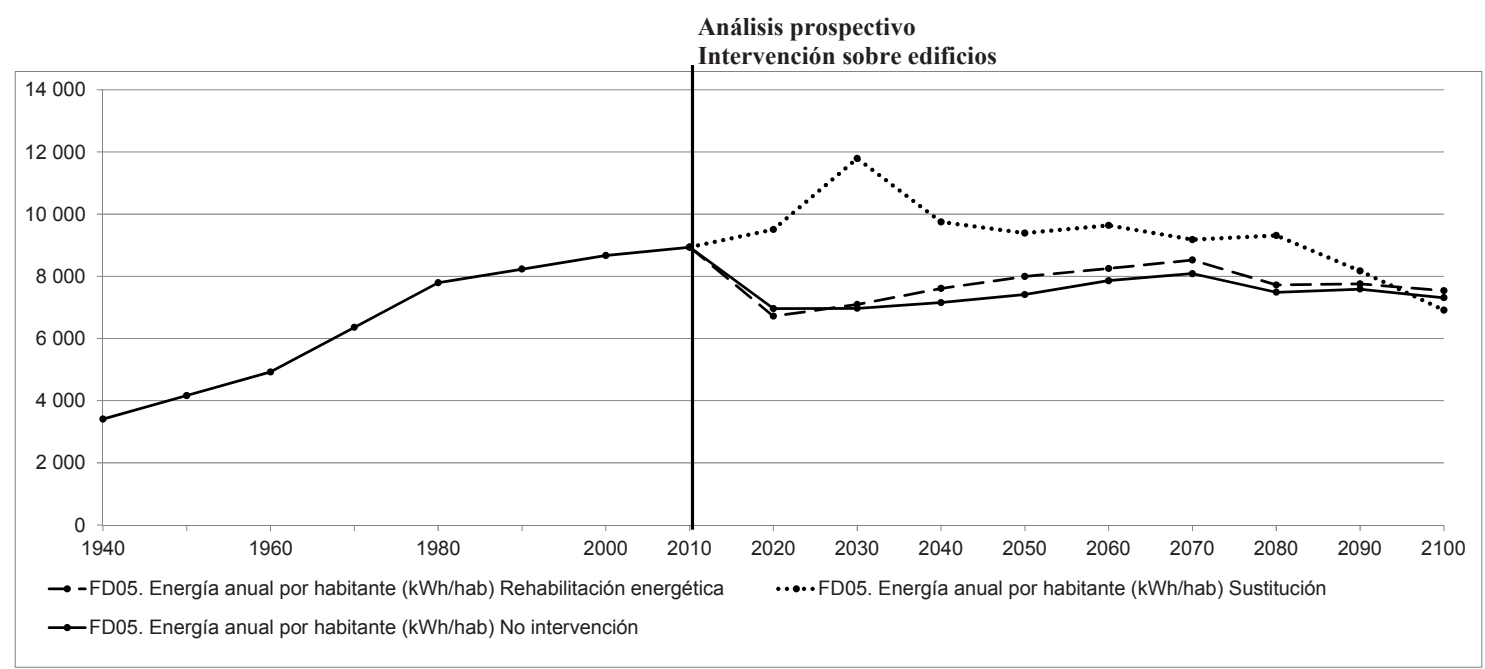

Figura 59. Evolución hasta 2100 de FD05 "Consumo anual de energía en el alojamiento por habitante en Madrid según tipo de intervención" (en kWh/hab)

Fuente: Elaboración propia

En la figura 60 se observa el impacto en la ocupación del suelo del incremento del número de viviendas, tanto por uso directo como por usos complementarios. Esta evolución parte de la hipótesis más desfavorable de que las nuevas viviendas se sitúan en nuevos desarrollos urbanos. Sin embargo, si en lugar de ser así, se incrementará el número de viviendas, por ejemplo, aumentando la edificabilidad de los edificios existentes, la ocupación del suelo sería menor.

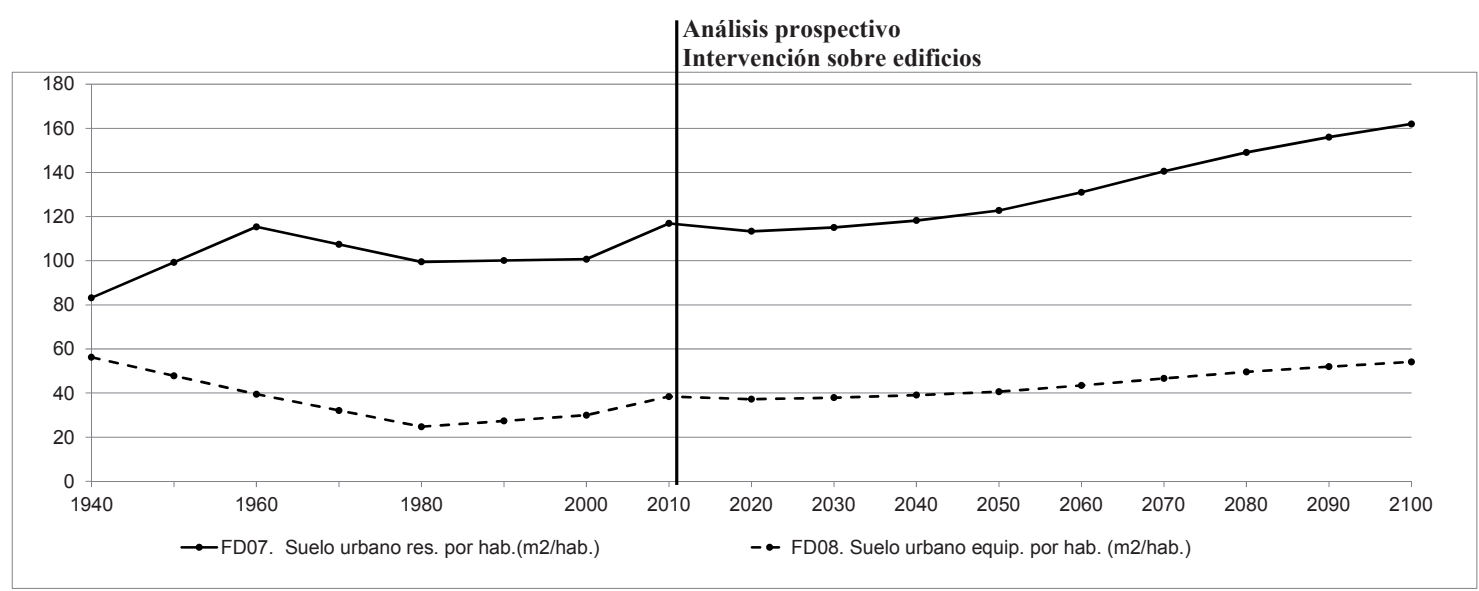

Figura 60. Evolución hasta 2100 de FD07 "Superficie urbana destinada a uso residencial por habitante" y FD08 "Superficie urbana destinada a equipamientos por habitante en Madrid" (en $\mathrm{m}^{2} / \mathrm{hab}$ )

Fuente: Elaboración propia 


\subsection{Aplicación de medidas en el escenario prospectivo señalado}

El análisis de la evolución del escenario indica que es posible reducir el número de viviendas para adecuarlas a las previsiones de crecimiento de la población. Asimismo, es posible reducir el consumo de recursos asociado al alojamiento, por lo que se plantean otras dos medidas al respecto. La relación de estas medidas con las estrategias definidas se muestra en la figura 61.

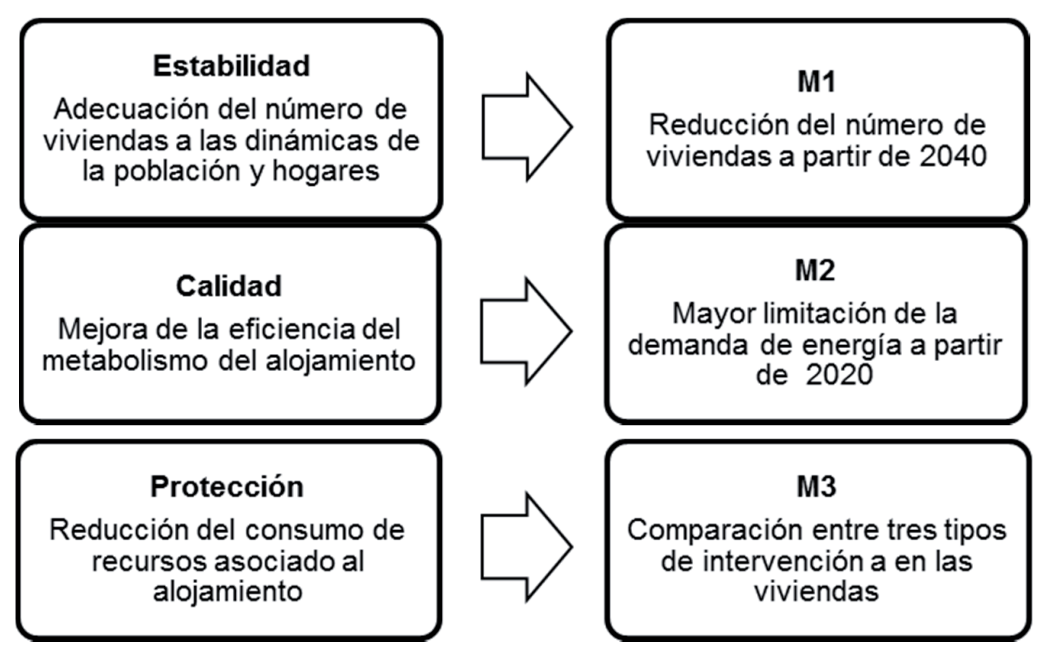

Figura 61. Estrategias y medidas de aplicación en el escenario prospectivo Madrid 1940-2100

Fuente: Elaboración propia

El análisis de los valores de las variables y factores dinámicos previstos para este escenario en Madrid permite plantear medidas para adecuar la evolución hasta 2100 a los criterios y estrategias ecológicas definidas las el alojamiento.

\section{Estabilidad. Aplicación de la medida M1. Modificación del número de viviendas a partir de 2040}

Las variables asociadas al número de habitantes por vivienda y por hogar indican que en este escenario ambos factores tienen una evolución muy dispar, de manera que mientras el número de habitantes por hogar tiene una evolución estable hasta 2100, el número de habitantes por vivienda se reduce de forma progresiva de manera que en esa fecha se reduce a la mitad que el primer valor. Para evitar este efecto que implica que el parque de viviendas está sobredimensionado con respecto a las necesidades de la población en cuanto a la formación de hogares, se trata de reducir el número de viviendas (S01) a partir de 2040, de manera que ambos factores tengan una evolución similar. Esta reducción se hace progresivamente, aplicando un 2,5\% respecto al valor inicial previsto e implica la siguiente variación en la evolución de ambos factores. Con esta medida, tras una fase de aplicación, el sistema pasaría de una fase de variación, que mantenida en el tiempo implicaría que el sistema no fuera sostenible, a una fase de estabilidad de los tres indicadores, tal como muestra la figura 62. 


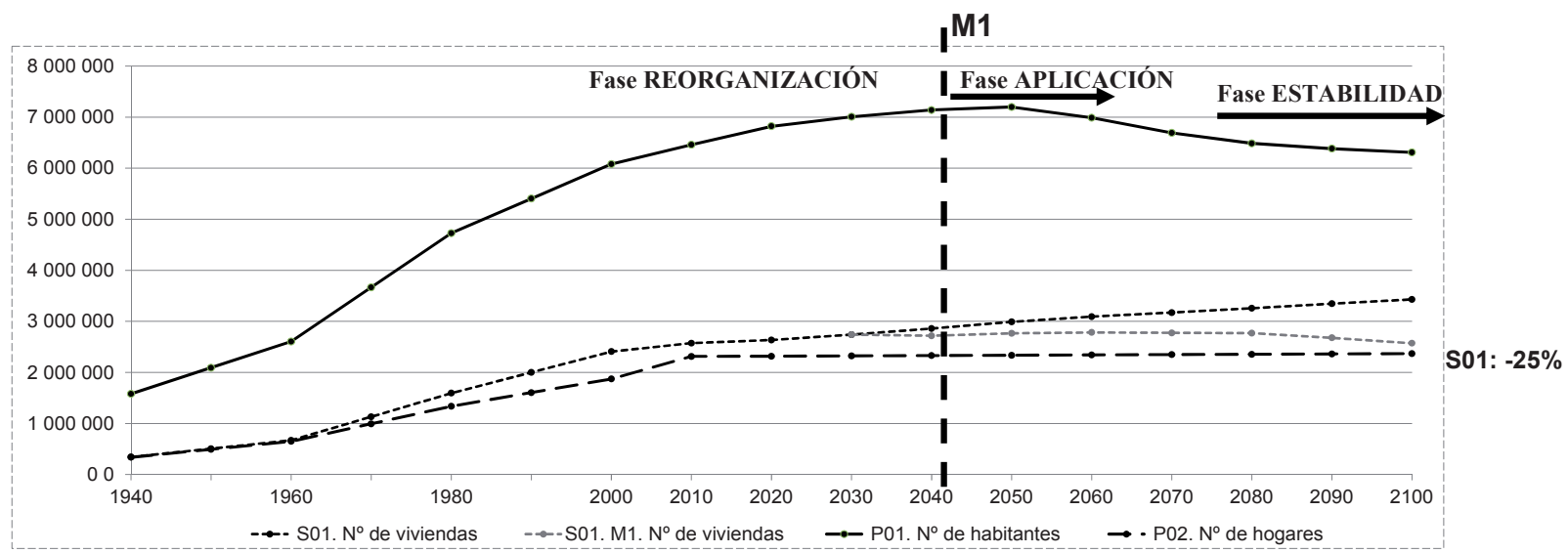

Figura 62. Aplicación de la medida M1. Evolución de S01. "Número de viviendas"

Fuente: Elaboración propia

Esta misma tendencia se observa en la figura 63, que muestra la variación de los factores dinámicos referentes a la vivienda y los hogares en relación a la población. Tras la aplicación de la medida $M 1$, el número de habitantes por vivienda se aproxima al número de habitantes por vivienda. La reducción del número de viviendas a partir de 2040, implica que respecto a la evolución inicial prevista, este factor se incremente un 33\%, lo que supone eliminar el efecto de sobredimensionamiento del parque de viviendas para el conjunto de la población prevista.

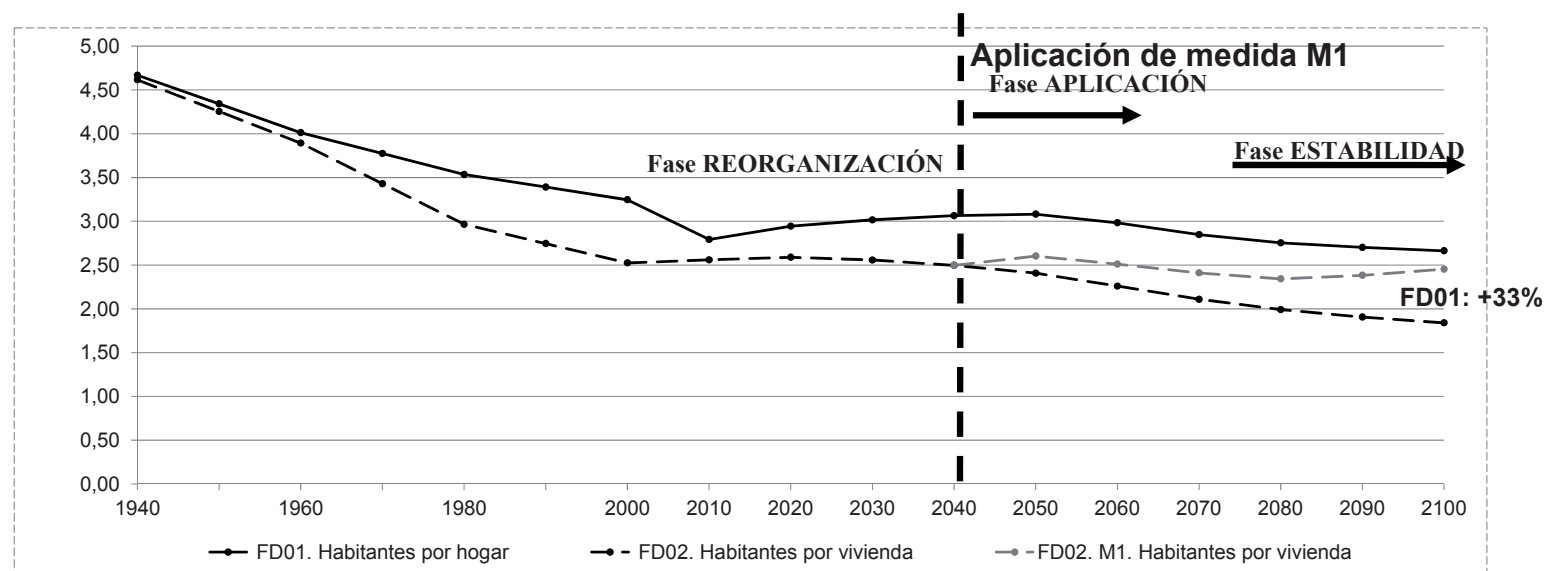

Figura 63. Aplicación de la medida M1. "Evolución de FD01 Habitantes por vivienda" y FD02 "Habitantes por hogar"

Fuente: Elaboración propia

A partir de esta alternativa habría que considerar la evolución del resto de variables y factores dinámicos ya que una reducción del número de viviendas implica la modificación de otras variables (materiales empleados, energía consumida anual y totalmente, superficie consumida, etc.). El total de los materiales empleados (S03) con la aplicación de esta medida se reduciría en 2100 un 5\% para el caso de la rehabilitación y un $37 \%$ en el caso de la obra nueva. Estos mismos porcentajes se aplicarían al factor dinámico FD04 "Materiales empleados por habitante". 
En el caso de la variable S04 "Energía anual en el alojamiento", la reducción del número de viviendas a partir de 2040 supondría un reducción en 2100 en torno al $39 \%$ en el caso de la rehabilitación, que seguiría siendo la menos consumidora de energía y del $38 \%$ para la sustitución por edificios nuevos. Si además de la reducción del número de viviendas se considera una medida alternativa que limite el consumo de energía, la reducción del consumo en 2100 puede llegar hasta el 55\%. Para la variable S04 (C+R) la aplicación de la medida de reducción del número de viviendas supone un $30 \%$ menos de consumo respecto a la evolución prevista para este escenario, que se reduce hasta el $60 \%$ en el caso que se limite el consumo en las viviendas. El factor dinámico FD05 "Energía anual media en el alojamiento" por habitante, seguiría la misma tendencia que la variable S04, sin embargo, se muestras algunas cuestiones de interés como es que este factor con el tiempo tiende a estabilizarse antes en el caso de la no intervención, siendo la rehabilitación la opción menos consumidora de energía.

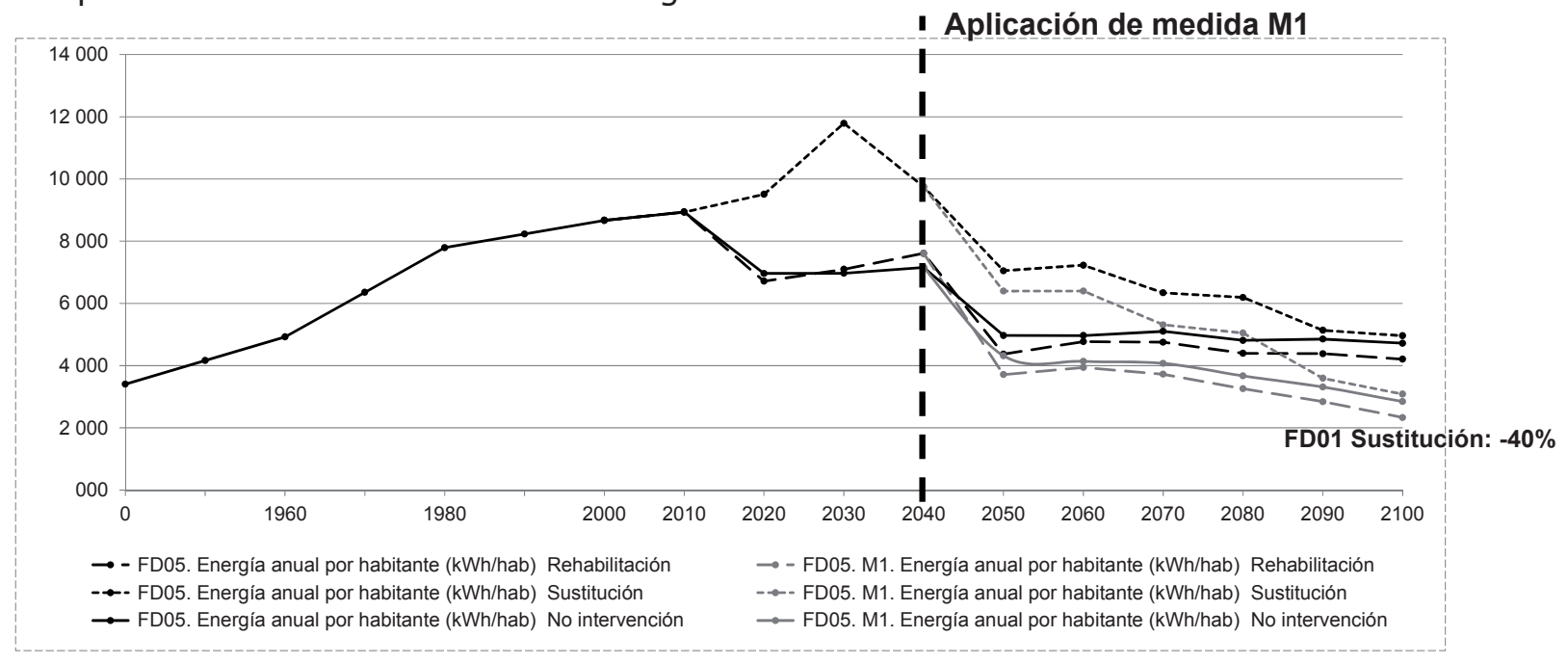

Figura 64. Aplicación de M1. Evolución de FD05 "Consumo anual de energía en el alojamiento" por habitante según tipo de intervención. (en kWh/hab)

Fuente: Elaboración propia

En lo que se refiere a la energía consumida por superficie construida (FD06 y FD06 $(C+R))$, se comprueba que, a pesar de la inversión en energía que supone la sustitución de las viviendas existentes por nuevos soportes, frente a la no intervención o la rehabilitación, esta medida amortiza su inversión en energía en un plazo aproximado de 30 años, y tras este periodo las tres medidas se estabilizan en una horquilla de consumo anual entre 50 y $100 \mathrm{kWh} / \mathrm{m}^{2}$, siendo la estrategia de obra nueva la menos consumidora si se tienen en cuenta los valores más generales. Estos factores dinámicos FD05 y FD06 que relacionan la energía con la población y la superficie construida habría que estudiarlos aplicado en función del periodo de construcción de las viviendas, ya que la estrategia más adecuada puede variar en función de la vida útil del edificio y de las características del mismo. En este caso, para las viviendas de más antigüedad, construidas antes de 1940 y hasta 2006, la intervención menos consumidora de energía a largo plazo sería la rehabilitación, seguido por la obra nueva. En el caso de las viviendas construidas a partir de esa 
fecha, no intervenir para reducir su consumo sería la medida que menores consumos ofrecería, salvo labores de mantenimiento. Para los indicadores asociados a la ocupación del territorio, en este caso la rehabilitación implica menores valores tanto globales como por habitante.

\section{Calidad y protección. Aplicación de las medidas M2 y M3. Limitación del consumo de energía en vivienda a partir de 2020 y comparación de tipos de intervención}

El mayor consumo total de energía en 2100 (variable S04) se produciría si no se interviniera en las viviendas existentes. Las medidas dirigidas a una sustitución progresiva de las viviendas por otras nuevas $(\mathrm{N})$ supondrían una reducción de más del 14\% en el año 2100 frente a la no intervención (NO). Si en lugar, de sustitución fuese una política de rehabilitación progresiva ( $R$ ), la reducción sería del $6 \%$ en ese mismo año. Sin embargo, como se observa en la figura, si el análisis se hace a largo plazo (hasta el año 2030), no intervenir es menos costoso respecto a los dos otros tipos de intervención ya que no aparecela energía necesaria en la transformación y adaptación de los edificios, bien por la rehabilitación o la sustitución, es elevada. Sin embargo, si se planteara la medida de limitar el consumo mediante la normativa técnica estos dos porcentajes serían en el año 2100 del 19,5\% en el caso de la nueva planta y del $18 \%$ en el caso de la rehabilitación y siempre serían las dos opciones menos consumidoras de energía frente a la no intervención. Los datos detallados de estos ahorros en la variable (S04) se encuentran en la figura 71.

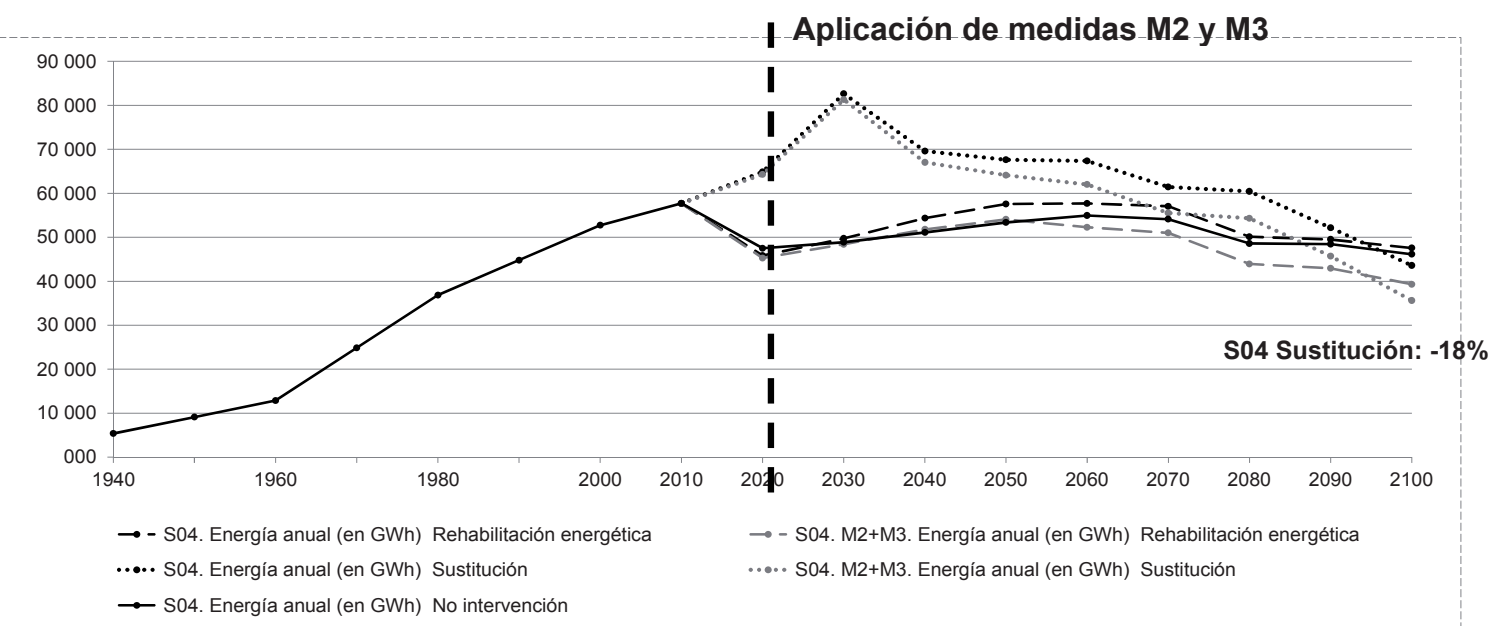

Figura 65. Aplicación de M2+M3. Evolución de S04 Consumo anual de energía en el alojamiento en Madrid (en GWh)

Fuente: Elaboración propia

\begin{tabular}{lccccccccc}
\hline & $\mathbf{2 0 2 0}$ & $\mathbf{2 0 3 0}$ & $\mathbf{2 0 4 0}$ & $\mathbf{2 0 5 0}$ & $\mathbf{2 0 6 0}$ & $\mathbf{2 0 7 0}$ & $\mathbf{2 0 8 0}$ & $\mathbf{2 0 9 0}$ & $\mathbf{2 1 0 0}$ \\
\hline Rehabilitación & $-1,77 \%$ & $-3,56 \%$ & $-6,24 \%$ & $-8,27 \%$ & $-12,02 \%$ & $-13,34 \%$ & $-14,13 \%$ & $-14,17 \%$ & $-17,99 \%$ \\
\hline Sustitución & $-1,38 \%$ & $-2,79 \%$ & $-5,24 \%$ & $-7,41 \%$ & $-10,67 \%$ & $-12,51 \%$ & $-13,94 \%$ & $-14,67 \%$ & $-19,46 \%$ \\
\hline
\end{tabular}

Figura 66. Porcentaje de reducción de S04 Consumo anual de energía en el alojamiento en Madrid según tipo de intervención tras aplicación de la medida M2

Fuente: Elaboración propia 
Los factores dinámicos relativos al consumo anual de energía en todo el proceso del alojamiento, tendrían reducciones similares a las anteriores con la aplicación de esta medida.

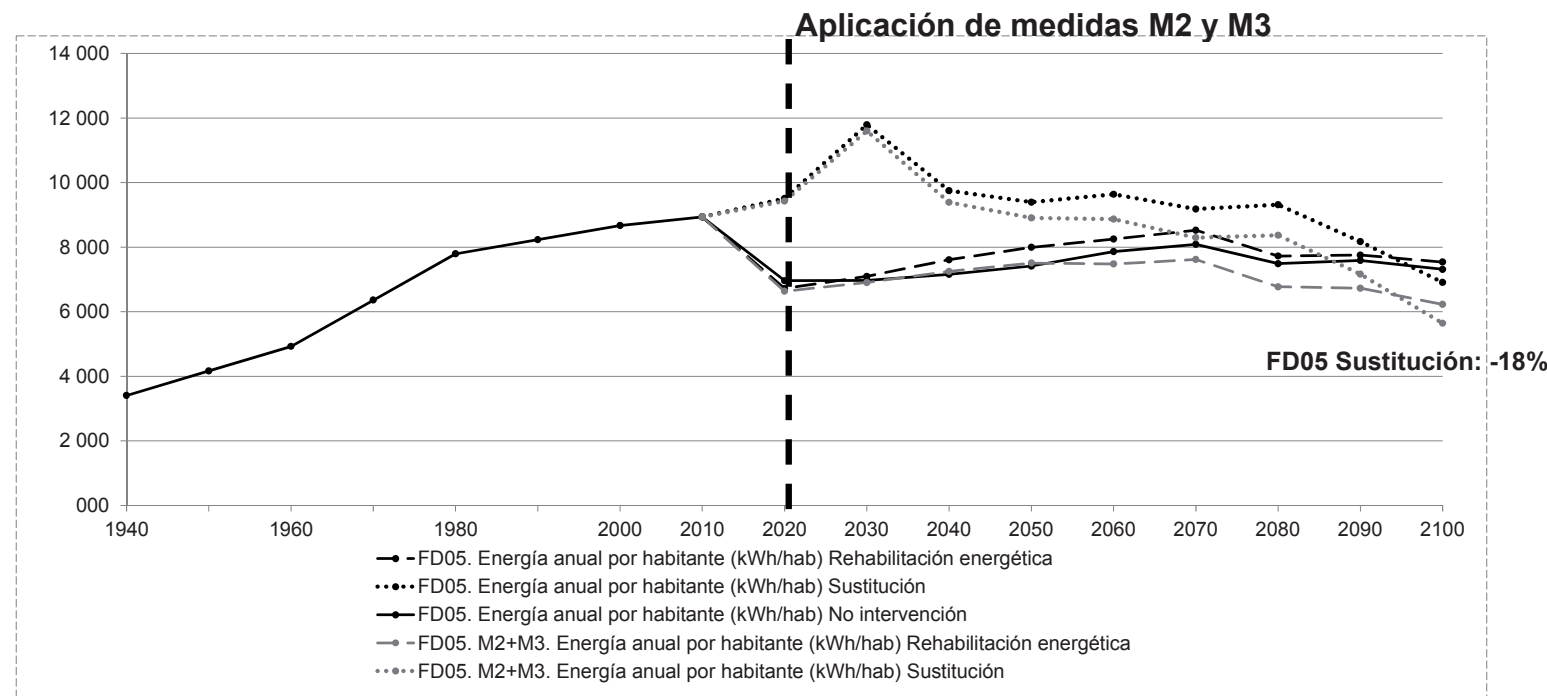

Figura 67. Aplicación de M2+M3. Evolución de FD5 "Consumo anual de energía en el alojamiento" por habitante (en kWh/hab)

Fuente: Elaboración propia

En el caso de la variable S04 (C+R) que contempla sólo la energía anual en climatización, la opción de no intervenir en las que mayores consumos anuales ofrece en todo el periodo analizado (en 2100 un $29 \%$ por encima respecto a las opciones de intervención). Tras la aplicación de la medida de limitación del consumo a partir de 2020, el porcentaje de ahorro respecto a la situación inicial de no intervención es del $47 \%$.

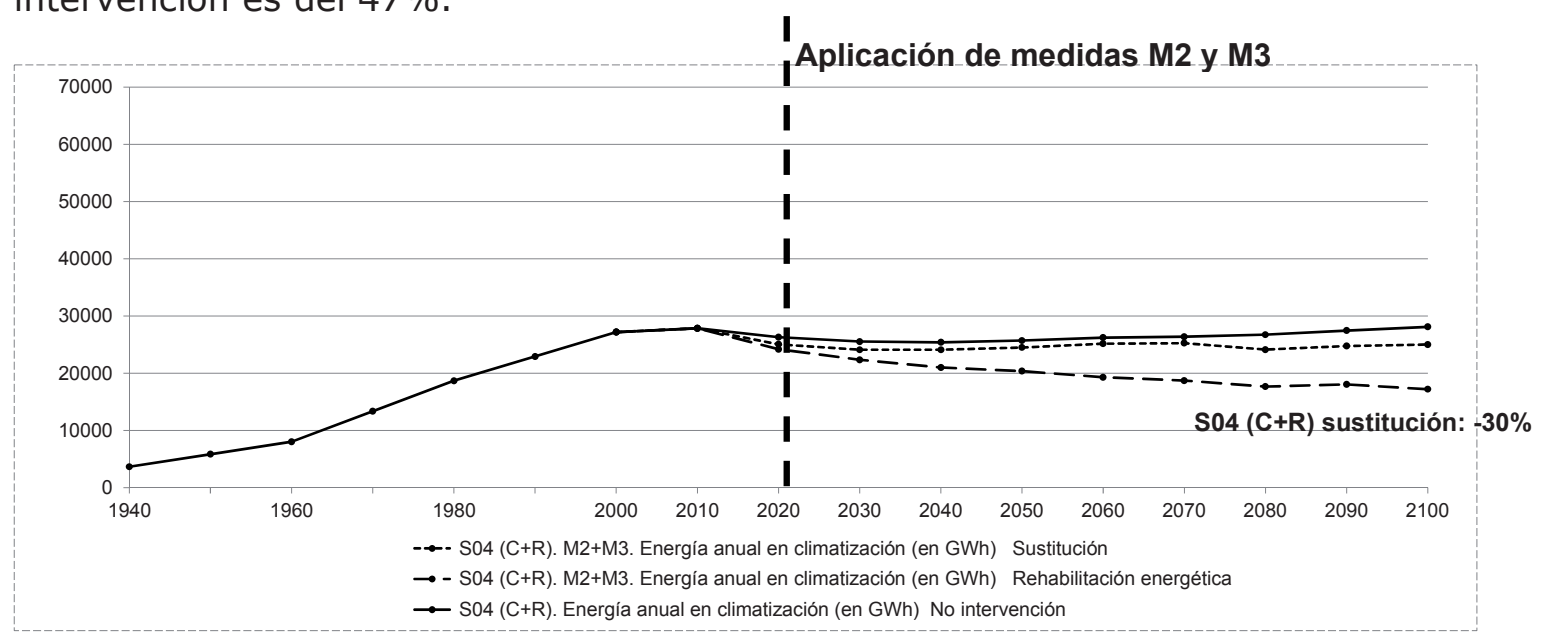

Figura 68. Aplicación de M2+M3. Evolución de S04 (C+R) "Consumo anual de energía en climatización" en Madrid (en GWh)

Fuente: Elaboración propia 


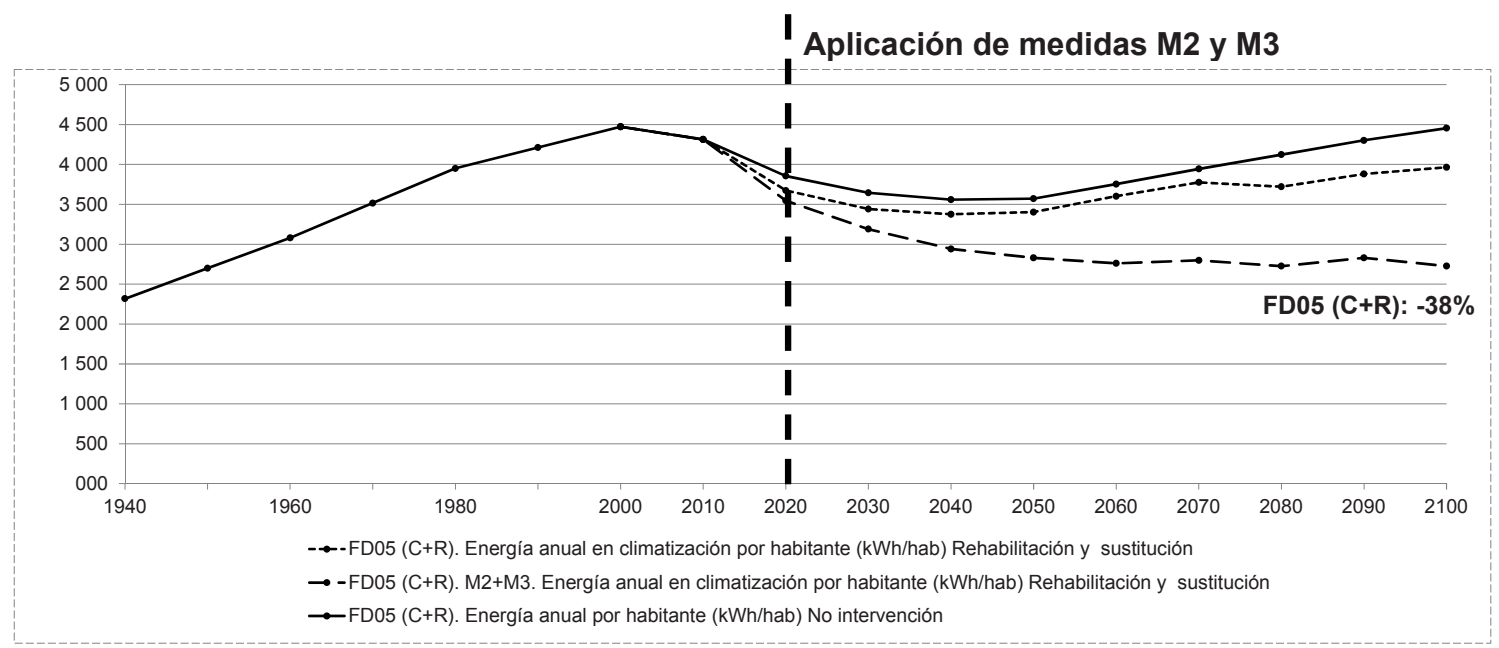

Figura 69. EP2. Aplicación de M2+M3. Evolución de FD5 (C+R) "Consumo anual de energía en climatización de viviendas por habitante" (en kWh/hab)

Fuente: Elaboración propia

\begin{tabular}{ccccccccc}
\hline $\mathbf{2 0 2 0}$ & $\mathbf{2 0 3 0}$ & $\mathbf{2 0 4 0}$ & $\mathbf{2 0 5 0}$ & $\mathbf{2 0 6 0}$ & $\mathbf{2 0 7 0}$ & $\mathbf{2 0 8 0}$ & $\mathbf{2 0 9 0}$ & $\mathbf{2 1 0 0}$ \\
\hline$-19,29 \%$ & $-19,16 \%$ & $-24,22 \%$ & $-24,22 \%$ & $-29,48 \%$ & $-28,29 \%$ & $-29,04 \%$ & $-29,04 \%$ & $-35,00 \%$ \\
\hline
\end{tabular}

Figura 70. Aplicación de M2. Porcentaje de reducción hasta 2100 de FD06 (C+R) "Consumo anual de energía por superficie de vivienda" $\left(\mathrm{kWh} / \mathrm{m}^{2}\right)$

Fuente: Elaboración propia

Al aplicar la medida, los indicadores relativos al consumo de energía se reducen considerablemente. Si se analizan estas reducciones desde el punto de vista del tipo de intervención, resultaría más eficaz iniciar una política progresiva de rehabilitación energética de los edificios existentes que implementar una normativa más exigente en la limitación del consumo ya que los ahorros de la primera opción suponen el triple de los segundos. Esta medida respondería a la consolidación de un soporte de viviendas de calidad en su totalidad frente a una puesta por la mejor calidad en algunos edificios. Ambas posturas se resumen en valorar si es más eficaz mejorar "todo un poco" o "poco un mucho".

En lo que se refiere al consumo de materiales, una estrategia de sustitución de los edificios por otros nuevos, aunque sean más eficientes, supondría, un mayor consumo de materiales a largo plazo frente a una estrategia de rehabilitación (en 2100 seria aproximadamente la mitad del consumo de una estrategia frente a otra).

Con el mismo número de viviendas, si en lugar de sustituir aquéllas que fueran quedando obsoletas por otras de mayor calidad, se optara por iniciar nuevos crecimientos urbanos supondrían un incremento en 2100 de más del $70 \%$ del suelo urbano destinado a uso residencial. Sin embargo esta situación no parece muy viable, siendo más razonable desde el punto de vista ecológico y económico limitar el crecimiento del suelo urbano, aprovechando las estructuras existentes de la ciudad ya consolidada. 


\begin{tabular}{|c|c|c|c|c|c|c|}
\hline & \multicolumn{3}{|l|}{ Variables } & $\begin{array}{l}\text { Evolución } \\
\text { prevista }\end{array}$ & $\begin{array}{l}\text { Evolución aplicando las } \\
\text { medidas M1, M2 y M3 }\end{array}$ & $\begin{array}{c}\% \text { de } \\
\text { variación }\end{array}$ \\
\hline P01 & \multicolumn{3}{|l|}{ Número de habitantes } & 6309261 & 6309261 & $0 \%$ \\
\hline P02 & \multicolumn{3}{|l|}{ Número de hogares } & 2773901 & 2773901 & $0 \%$ \\
\hline s01 & \multicolumn{3}{|l|}{ Número de viviendas } & 3429023 & 2571767 & $-25 \%$ \\
\hline S02 & \multicolumn{3}{|l|}{ Sup. const. vivienda (en $\mathrm{m}^{2}$ ) } & 399983565 & 249364968 & $-37 \%$ \\
\hline \multirow{2}{*}{ S03 } & \multirow{2}{*}{\multicolumn{2}{|c|}{$\begin{array}{l}\text { Materiales empleados en viviendas } \\
\text { (en } \mathrm{t})\end{array}$}} & M3 R & 871964172 & 297548459 & $-65 \%$ \\
\hline & & & M3 N & 612866630 & 331498293 & $-45 \%$ \\
\hline \multirow{3}{*}{ S04 } & \multirow{3}{*}{\multicolumn{2}{|c|}{$\begin{array}{l}\text { Consumo anual de energía en el } \\
\text { alojamiento (en GWh) }\end{array}$}} & M3 R & 47563 & 12525 & $-63 \%$ \\
\hline & & & M3 N & 43594 & 15940 & $-74 \%$ \\
\hline & & & M3 NO & 46143 & 17942 & $-61 \%$ \\
\hline \multirow{3}{*}{$\begin{array}{l}\text { S04 } \\
(C+R)\end{array}$} & \multirow{3}{*}{\multicolumn{2}{|c|}{$\begin{array}{l}\text { Consumo anual de energía en } \\
\text { climatización de viviendas (en GWh) }\end{array}$}} & M3 R & 25006 & 6979 & $-72 \%$ \\
\hline & & & M3 N & 24998 & 6994 & $-72 \%$ \\
\hline & & & M3 NO & 28100 & 15874 & $-43 \%$ \\
\hline S05 & \multicolumn{3}{|c|}{ Suelo urbano ocupado por viviendas (en $\mathrm{m}^{2}$ ) } & 1038592600 & 783772698 & $-24 \%$ \\
\hline \multirow[t]{2}{*}{ S06 } & \multicolumn{3}{|c|}{ Suelo urbano ocupado por equipamiento $\left(\mathrm{en}^{2}{ }^{2}\right)$} & 347005517 & 257458269 & $-25 \%$ \\
\hline & \multicolumn{3}{|l|}{ Factores dinámicos } & & & \\
\hline FD01 & \multicolumn{3}{|l|}{ Habitantes por hogar } & 2,27 & 2,27 & $0 \%$ \\
\hline FD02 & \multicolumn{3}{|l|}{ Habitantes por vivienda } & 1,84 & 2,45 & $33 \%$ \\
\hline FD03 & \multicolumn{3}{|c|}{$\begin{array}{l}\text { Superficie construida destinada a vivienda por habitante } \\
\text { (en } \mathrm{m}^{2} / \mathrm{hab} \text { ) }\end{array}$} & 63,40 & 39,52 & $-37 \%$ \\
\hline \multirow{2}{*}{ FD04 } & \multirow{2}{*}{$\begin{array}{l}\text { Materiales empleados en } \\
\text { viviendas por habitante (en } \\
\text { t/hab) }\end{array}$} & \multicolumn{2}{|c|}{ M3 Rehabitación } & 138,20 & 39,52 & $-71 \%$ \\
\hline & & \multicolumn{2}{|c|}{ M3 Sustitución } & 97,14 & 47,16 & $-51 \%$ \\
\hline \multirow{3}{*}{ FD05 } & \multirow{3}{*}{$\begin{array}{l}\text { Consumo anual de energía } \\
\text { en el alojamiento por } \\
\text { habitante (en kWh/hab) }\end{array}$} & M3 R & habitación & 7539 & 1985 & $-74 \%$ \\
\hline & & M3 S & istitución & 6910 & 2526 & $-63 \%$ \\
\hline & & M3 N & intervención & 7313 & 2844 & $-61 \%$ \\
\hline \multirow{3}{*}{$\begin{array}{l}\text { FD05 } \\
(\mathrm{C}+\mathrm{R})\end{array}$} & \multirow{3}{*}{$\begin{array}{l}\text { Consumo anual de energía } \\
\text { en climatización de en } \\
\text { viviendas por habitante (en } \\
\text { kWh/hab) }\end{array}$} & M3 R & habitación & 3963 & 1106 & $-72 \%$ \\
\hline & & M3 S & ıstitución & 3962 & 1109 & $-72 \%$ \\
\hline & & M3 N & intervención & 4454 & 2516 & $-43 \%$ \\
\hline \multirow{3}{*}{ FD06 } & \multirow{3}{*}{$\begin{array}{l}\text { Consumo anual de energía } \\
\text { en el alojamiento por } \\
\text { superficie de vivienda (en } \\
\mathrm{kWh} / \mathrm{m}^{2} \text { ) }\end{array}$} & M3 R & habitación & 106,50 & 85,37 & $-19 \%$ \\
\hline & & M3 S & ıstitución & 103,94 & 82,81 & $-20 \%$ \\
\hline & & M3 N & intervención & 118,57 & 118,57 & $0 \%$ \\
\hline & Consumo anual de energía & M3 R & habitación & 60,36 & 39,24 & $-35 \%$ \\
\hline FD06 & en climatización por & M3 S & ustitución & 60,36 & 39,24 & $-35 \%$ \\
\hline & $\left.\mathrm{kWh} / \mathrm{m}^{2}\right)$ & M3 N & intervención & 92,50 & 92,50 & $0 \%$ \\
\hline FD07 & Suelo urbano de uso residen & al por $r$ & abitante $\left(\mathrm{m}^{2}\right)$ & 164,61 & 124,23 & $-24 \%$ \\
\hline FD08 & Suelo urbano de uso equipa & entos $p$ & or habitante $\left(\mathrm{m}^{2}\right)$ & 55,00 & 40,81 & $-25 \%$ \\
\hline
\end{tabular}

Figura 71. Evolución y porcentaje de reducción de variables en 2100 con aplicación de medidas $M 1+M 2+M 3$.

Fuente: Elaboración propia 


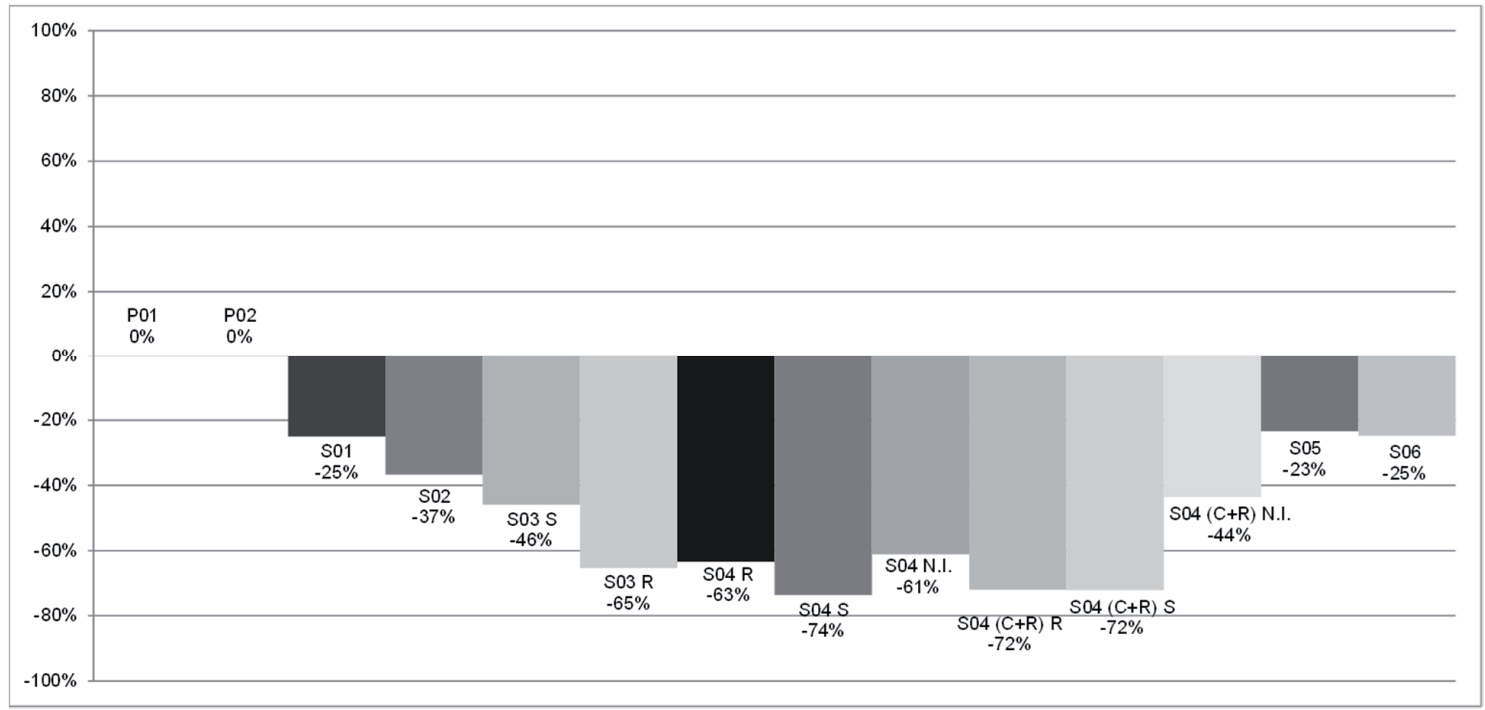

Figura 72. M1+M2+M3. Porcentaje de reducción de variables en 2100 con aplicación de medidas Fuente: Elaboración propia

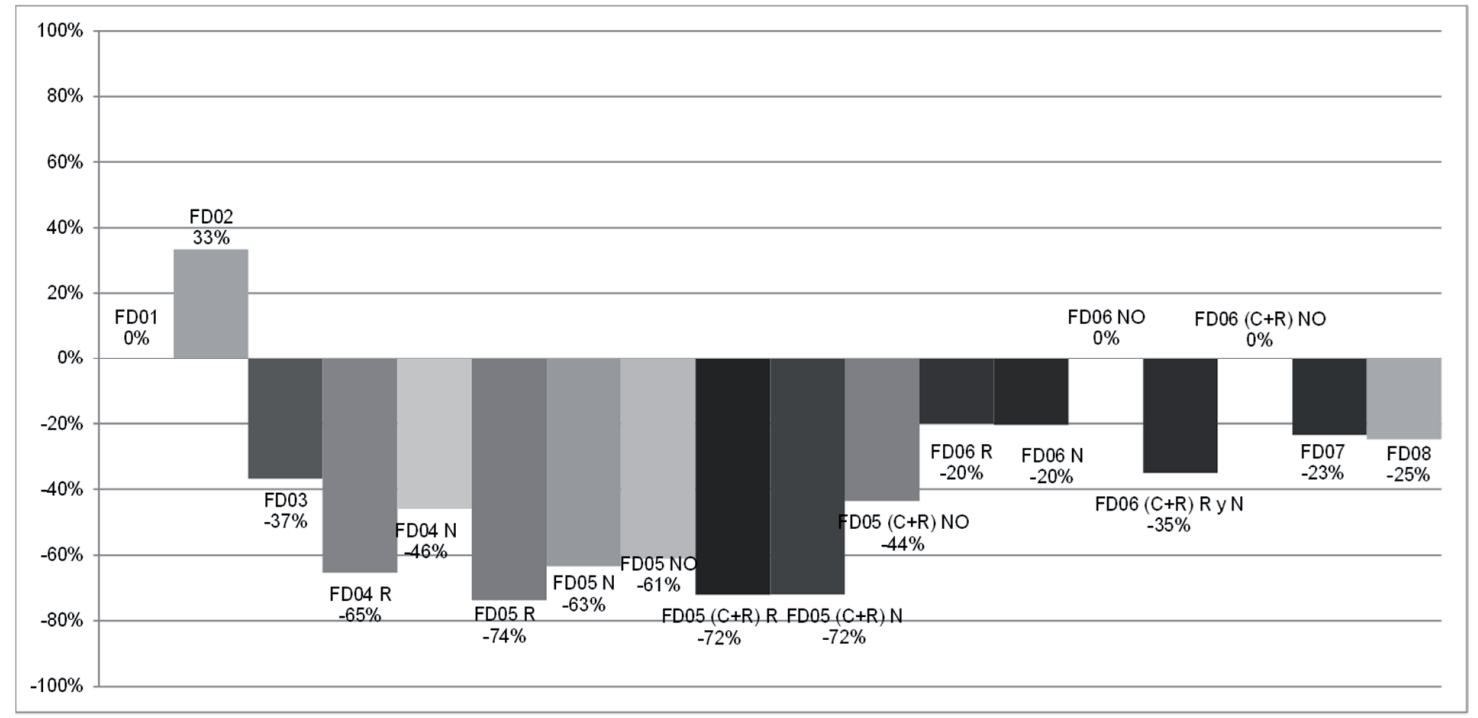

Figura 73. M1+M2+M3. Porcentaje de reducción de factores dinámicos en 2100 con aplicación de medidas

M1. Medida 1. Modificación de la variable S01 Número de viviendas

M2. Medida 2. Modificación de la variable S04 Energía anual consumida en el alojamiento mediante la limitación en el consumo en climatización

M3: Comparación de tipos de intervención sobre las viviendas (R, N, NR)

S: Sustitución

R: Rehabilitación

NI: No intervención

Fuente: Elaboración propia 


\subsection{Conclusiones de la aplicación del método de análisis en Madrid entre 2010 y 2100}

El método de análisis aplicado a los tres escenarios de futuro de Madrid ha permitido analizar a lo largo del tiempo variables y factores dinámicos en tres situaciones diferentes. A partir del análisis de los indicadores, se han detectado situaciones no deseables, se han definido estrategias (estabilidad, calidad y protección) y se han planteado medidas alternativas, evaluando el impacto de cada una de ellas. De los tres elementos que configuran el alojamiento (población, viviendas y recursos naturales), el número de habitantes es el que condiciona en mayor medida el resto de indicadores. En función de la evolución de este indicador, las variables (indicadores absolutos que caracterizan el alojamiento) tienen diferente evolución. En alguno de los casos estudiados, el incremento del número de habitantes conlleva un incremento de los recursos asociados a proporcionar alojamiento, aunque los factores dinámicos, como indicadores relativos, se mantengan en valores proporcionados.

Tras el análisis de varios escenarios y el impacto de las medidas evaluadas, se puede concluir que el método de análisis diacrónico es adecuado al objetivo inicial propuesto en la investigación. Los indicadores seleccionados describen la evolución del alojamiento a lo largo del tiempo y permiten identificar tendencias que conducen a situaciones inadecuadas. De esta manera es posible plantear medidas correctoras anticipadamente, mediante un nuevo análisis de indicadores, evaluar su eficacia en un periodo temporal definido.

Los resultados obtenidos en cada escenario planteado para Madrid indican que la consideración de actuaciones como la definición del número de viviendas en función de la evolución de la población o la adecuación del soporte construido a las características previstas de los hogares puede suponer a largo plazo ahorros anuales medios de energía del $20 \%$. Si además, en función del horizonte temporal de evaluación seleccionado, se comparan tipos de intervención diferentes (rehabilitación, sustitución o no intervención), estos ahorros se pueden incrementar hasta en el $30 \%$. Esta reducción se incrementa cuando se aplican normativas técnicas más exigentes adaptadas a las modificaciones de las variables externas, como son las condiciones climáticas. Considerando las previsiones de cambio climático en Madrid, la definición de las prestaciones exigibles a los edificios de viviendas puede ser un criterio imprescindible para la adaptación del soporte al contexto climático y conseguir un menor consumo de energía a largo plazo.

En lo que se refiere a los tipos de intervención plateados, para los escenarios seleccionados en Madrid, la rehabilitación gradual del parque existente de viviendas es la intervención que menores consumos energéticos anuales ofrece para un periodo de análisis amplio (hasta 60 años). La sustitución empieza a ser menos consumidora de energía a partir de ese plazo, por lo que para implementarse debería tenerse en cuenta esta cuestión temporal y no iniciar políticas de renovación antes de garantizar que se puede cumplir este periodo de amortización de la inversión. Por otro lado, la sustitución de las edificaciones llevaría implícito un mayor consumo de materiales que la rehabilitación En ese caso, sería fundamental buscar estrategias para la reducción de esta variable, mediante procesos como la 
reutilización o el reciclaje propio o de otros sectores La escala del análisis del parque edificado puede ayudar a definir la intervención en las viviendas. En la tesis se ha utilizado el periodo de construcción de las viviendas para el análisis y la propuesta de intervención sobre el soporte, aunque sería interesante la consideración de otras clasificaciones (tipología de edificios, ubicación en la trama urbana,...).

\section{CONCLUSIONES DE LA INVESTIGACIÓN}

El método de análisis diacrónico para la intervención en el alojamiento con criterios ecológicos propuesta en la investigación se ha validado mediante la aplicación al caso de Madrid en dos supuestos. Por un lado, la aplicación retrospectiva de medidas en el alojamiento de Madrid ha permitido evaluar el impacto en el presente que habría tenido la aplicación de ciertas medidas sobre el parque de viviendas. Por otro lado, el método que se propone tiene un carácter prospectivo, y se ha aplicado a varios escenarios posibles en Madrid hasta 2100. Para ello se han analizado diversas posibles evoluciones de los elementos del alojamiento y, en los casos que ha sido necesario, se han evaluado medidas de intervención para evitar anticipadamente situaciones no deseables desde el punto de vista ecológico. Algunas de las conclusiones más relevantes de la investigación son las siguientes.

\section{Intervenir en el alojamiento desde los límites}

La consideración del alojamiento desde la constatación de los límites materiales y energéticos que cuestionan el crecimiento continuo de nuestros sistemas ofrece una interesante perspectiva para el desarrollo de método de intervención en las ciudades. Las investigaciones en esta línea han utilizado el enfoque ecológico para estudiar los modos de aproximación de una población a la capacidad de carga del territorio en el que se asienta. De esta manera se quiere identificar la evolución del metabolismo asociado a la economía, entendido éste como el conjunto de flujos energéticos y materiales que recorren un determinado sistema socioeconómico. En estos estudios se señala la importancia de los análisis a largo plazo que permiten actuar anticipadamente y evitan la sobre explotación continua de recursos que conduce a situaciones irreversibles.

\section{Habitantes, viviendas y recursos naturales: elementos del alojamiento}

La consideración de que los habitantes (población), las viviendas y los recursos naturales (soporte) son los elementos constitutivos del alojamiento ha permitido definir un método de intervención en el alojamiento. Las relaciones que se establecen entre estos elementos a lo largo del tiempo determina la supervivencia del sistema. Por ello, el método de análisis se ha basado en la selección de una serie de indicadores, característicos de estos elementos, que se cuantifican para identificar anticipadamente situaciones en el futuro no deseables.

Las variables cuantifican, en términos absolutos, la evolución de los tres elementos: habitantes, viviendas o recursos naturales de un determinado alojamiento. Los factores dinámicos miden la relación entre estos tres elementos, fundamentalmente los recursos naturales y las viviendas en relación a la población. Todos ellos sirven 
para describir a lo largo del tiempo el metabolismo del alojamiento, que se define como el conjunto de flujos y transformaciones de materiales, energía e información destinadas a la producción y funcionamiento del alojamiento de un determinado territorio. De los tres elementos que constituyen el alojamiento, la población es el más determinante. La evolución de la población a lo largo del tiempo es la que condiciona los recursos necesarios para el funcionamiento del alojamiento. Ante un crecimiento continuo de la población, es inevitable que el consumo de recursos asociados a la producción y uso de las viviendas aumentará, independientemente de las medidas de eficiencia energética que se empleen. En algunos de los escenarios estudiados, el número de viviendas, la superficie de éstas y la relación con la población son variables que influyen más en el consumo de energía a largo plazo que las medidas de eficiencia energética sobre el soporte o el tipo de intervención, aunque estas últimas cuestiones pueden suponer ahorros importantes respecto a no aplicarlas.

\section{Un método diacrónico basado en estrategias, medidas e indicadores}

La aplicación de un enfoque ecológico al alojamiento ha permitido identificar semejanzas con el funcionamiento de los ecosistemas naturales. Gracias al estudio de los ciclos adaptativos se han definido fases en la evolución del alojamiento que permiten identificar tendencias que conducen a situaciones no deseables desde el punto de vista de las estrategias de supervivencia de los ecosistemas. Estas estrategias aplicadas a alojamiento son las siguientes:

- Estabilidad Adecuación del número de viviendas a las dinámicas de la población y hogares

- Calidad: Mejora de la eficiencia del metabolismo del alojamiento

-Protección: Reducción del consumo de recursos naturales

Si el periodo temporal es retrospectivo, la aplicación del método ayuda a conocer la evolución del alojamiento desde un enfoque ecológico. La aplicación prospectiva permite identificar anticipadamente situaciones no deseables y definir medidas para poder corregirlas. La aplicación del método a ambos periodos (restrospectivo y prospectivo) es necesario ya que el primero mejora el conocimiento de las características, el comportamiento y composición del parque edificado. El segundo permite definir medidas de intervención para mejorar el funcionamiento a largo plazo.

\section{El tiempo como factor de evaluación y la planificación y el seguimiento como instrumento para reducir el impacto ambiental del alojamiento}

Al igual que en los ecosistemas, la incertidumbre es el principal reto en la descripción de futuro del alojamiento. La aplicación del método a varios escenarios en Madrid ha constatado la importancia del tiempo como factor de evaluación de las medidas de intervención, demostrándose la importancia de la evaluación de las medidas en un periodo temporal dilatado y la necesidad de anticipación conduce a señalar la planificación a largo plazo como un instrumento fundamental para la reducción de consumo de recursos asociados al alojamiento en el ámbito urbano. La 
planificación, al igual que el seguimiento de los indicadores, es parte del método de análisis propuesto ya que permiten adaptar de forma gradual los elementos del sistema a los cambios, evitando situaciones de colapso o no deseables. Las fases de planificación y seguimiento se relacionan con otro proceso asociado al metabolismo: la recuperación de entropía en forma de información acumulada. Esta idea se resume en que un mayor conocimiento del funcionamiento del alojamiento, multiplica la resiliencia de este sistema, y le permite aprovechar su capacidad de adaptación ante la modificación de las condiciones.

\section{Un mejor conocimiento del alojamiento en Madrid a través de la aplicación del método diacrónico}

A través de la aplicación de este análisis al caso de Madrid, se ha podido conocer la evolución en el periodo 1940 a 2010 así como las características de las viviendas en relación a los otros indicadores. Tras la evaluación de las medidas aplicadas a este periodo, se ha comprobado que un planteamiento más exigente en la limitación del consumo de energía, una política de rehabilitación energética o una planificación del número de viviendas en función del número de habitantes, hubiera producido un escenario en 2010 menos consumidor de energía y de materiales. Asimismo, una velocidad de construcción más lenta de viviendas, hubiera supuesto que el parque de viviendas en Madrid habría tenido unas condiciones más adecuadas respecto al ahorro de energía en la actualidad. La cuantificación retrospectiva de las variables y factores dinámicos en función de las medidas propuestas ha permitido validar los criterios y estrategias definidos desde la perspectiva ecológica, así como el propio método propuesto. Estas medidas son, para el caso de Madrid, la adecuación de la velocidad de construcción de vivienda a evolución de la población y a la formación de hogares, la reducción del consumo de energía y materiales por habitante y por superficie construida, la reducción del suelo urbano dedicado al uso residencial por habitante y, una vez establecido unos valores adecuados, mantenimiento del suelo urbano dedicado a equipamientos por habitante. Se ha comprobado que una política de vivienda destinada a la rehabilitación, a la sustitución de los edificios existentes o a la no intervención, ofrece distintos resultados a largo plazo en lo que se refiere al consumo de recursos, incluso diferentes situaciones en función del horizonte temporal con el que se realice el análisis. Por tanto, la aplicación prospectiva a Madrid confirma que la planificación a largo plazo y el seguimiento de indicadores son instrumentos adecuados en la intervención en el alojamiento con criterios ecológicos. 


\section{BIBLIOGRAFÍA}

AGENCIA ESPAÑOLA DE METEOROLOGÍA. (2000). Valores climáticos normales 1971-2000. (Miniterio de Agricultura, Alimentación y Medio Ambiente) Recuperado el 2007-2011, de http:/www.aemet.es

AGENCIA ESTATAL DE METEOROLOGÍA. (2009). Generación de escenarios regionalizados de cambio climático para España. Recuperado el 2010, de http://www.aemet.es/es/serviciosclimaticos/cambio_climat

ALBERTI, M. (2009). Advances in urban ecology. Integrating humans and ecological processes in urban ecosystems. Seattle: Springer.

ALCAIDE, J. (. (2007). Evolución de la población española en el siglo XX por provincias y comunidades autónomas. Madrid: Fundación BBVA.

ÁLVAREZ, S. et al. (2006). Las síntesis emergética. Integrando energía, ecología y economía. Madrid: Fundación Fernando Fernández Bernáldez.

BASTOS, M. (1926). Aislamientos térmicos. Arquitectura, 359-363.

BERMEJO, R. (2008). Un futuro sin petróleo: colapsos y transformaciones socioeconómicas. Madrid: Los libros de la catarata.

BeRTALANFFY, L. (2006). Teoría General de los Sistemas. México: Fondo de Cultura Económica.

BOSSUT, J. (1949). Aislamiento y fisiología. Revista Nacional de Arquitectura(87), 134-136.

Bossut, J. (Junio de 1950). Las cámaras de aire en la costrucción moderna. Revista Nacional de Arquitectura(102).

BROWN, M. T., \& ULGIATI, S. (1978). "Energy quality, emergy and transformability: H.T. Odum's contributions to quantifying and understanding systema". (Elsevier, Ed.) Ecological Modelling, 201-213.

BROWN, M., \& BURANAKARN, V. (2003). Emergy indices and ratios for sustainable material cycles and recycle options. Resources, Conservation and Recycling(38), 1-22.

BUTTI, K., \& PERLIN, J. (1985). Un hilo dorado: 2500 años de arquitectura y tecnología solar. Madrid: Hermann Blume.

CABRÉ, A., DOMINGO, A., \& MENACHO, T. (2002). Demografía y crecimiento de la población española durante el siglo XX. En M. (. Pimentel Siles, Mediterráneo Económico 1. Monografía: Procesos migratorios, economías y personas. Almería, España: Caja Rural Intermediterránea Cajamar.

CAMUÑAS, A. (Mayo de 1943). "El ladrillo, material de reconstrucción". (33), 177-190.

CARPINTERO, Ó. (2005). El metabolismo de la economía española. Lanzarote: Fundación César Manrique.

CARPINTERO, Ó. (2006). La bioeconomía de Georgescu-Roegen. Montesinos.

CARPINTERO, Ó. (Septiembre de 2007). La apropiación humana del producción primaria neta (AHPPN) como aproximación al metabolismo económico. Ecosistemas(16 (3)).

CARPINTERO, Ó. (2010). Recursos naturales y crecimiento económico en España (19552000): de la "economía de la producción" a la "economía de la adquisición". Recuperado el 2011, de http://campus.usal.es/ ehe/Papers/carpintero.pdf 
CARPINTERO, Ó. (2010). Recursos naturales y crecimiento económico en España (19552000): de la "economía de la producción" a la "economía de la adquisición". Recuperado el 2011, de http://campus.usal.es/ ehe/Papers/carpintero.pdf

CARRERAS, A., \& TAFUNELL, X. (. (2005). Estadísticas históricas de España. Siglos XIX y XX ( $2^{\mathrm{a}}$ ed., Vol. I). Fundación BBVA.

CARRERAS, A., TAFUNELL, X. (Coords.). (2005). Estadísticas históricas de España (2a edición revisada y ampliada ed., Vol. I). Madrid: Fundación BBVA.

CERESUELA PUCHE, A. (1985). Rehabilitación ambiental con métodos tradicionales. Madrid: Colegio Oficial de Arquitectos de Madrid.

CIRCE. (2010). Enslic Building. Energy Saving through Promotion of Life Cycle Assessment in Buildings. Obtenido de http://circe.cps.unizar.es/enslic/texto/proj.html

COMISIÓN MUNDIAL DEL MEDIO AMBIENTE Y DEL DESARROLLO. (1988). Nuestro futuro común. Informe Brundtland. Madrid: Alianza Editorial.

COMUNIDAD DE MADRID. (1983). Crecimiento histórico de Madrid. Madrid: Consejería de Ordenación del Territorio, Medio Ambiente y Vivienda. Comunidad de Madrid.

CUCHÍ, A. (2007). Sobre una estrategia para dirigir el sector de la edificación hacia la eficiencia energética en la emisión de gases de efecto invernadero. Ministerio de Vivienda. Gobierno de España.

CUCHÍ, A., \& SWEATMAN, P. (2012). Informe GTR 2012. unva visión-país para el sector de la edificación en España. Grupo de Trabajo de Rehabilitación.

DAJOZ, R. (1974). Tratado de Ecología. Madrid: Ediciones Mundi Prensa.

Daumal, F., \& García-Ventosa, G. (1978). La energía y el ciclo vital del edificio. CAU(50), 3037.

FARIÑA TOJO, J. (1995). Cálculo de la entropía producida en diversas zonas de Madrid. Madrid: Cuadernos de investigación urbanística.

FEDERACIÓN ESPAÑOLA DE MUNICIPIOS Y PROVINCIAS. (2010). La vulnerabilidad al cambio climático a escala local. Madrid: Ministerio de Medio Ambiente Medio Rural y Marino.

FERNÁNDEZ CARVAJAL, A. (2003). La política de vivienda en España durante el franquismo. Ciudad y Estudios Territoriales, 639-653.

FERNÁNDEZ GÜELL, J. M. (2011). Recuperación de los estudios de futuro a través de la prospectiva territorial. Ciudad y estudios territoriales (167), 11-32.

FERNÁNDEZ-GALIANO, L. (1982). Termodinámica y construcción.

Fernández-Galiano, L. (1991). El fuego y la memoria. Sobre arquitectura y energía. Madrid: Alianza Forma.

FERNÁNDEZ-GALIANO, L., ISASI, J., \& LOPERA, A. (1989). La quimera moderna. Los poblados dirigidos de Madrid en la arquitectura de los 50. Madrid: Hermann Blume.

FOLEY, J. (2010). Los límites de un planeta sano. (Junio 2010).

FONSECA LLAMEDO, J. (1945). El problema de la vivienda. Madrid: Escuela Social de Madrid. Ministerio de Trabajo.

FUNDACIÓN DE LA ENERGÍA DE LA COMUNIDAD DE MADRID. (2012). Balance energético de la Comunidad de Madrid 2010. Recuperado el Diciembre de 2012, de http://www.fenercom.es/pdf/publicaciones/Balance-2010-fenercom-2012.pdf 
GARCÍA ARROYO, A. (1976). Aislamiento, bienestar y ahorro de energía. Informes de la construcción(279), 57-86.

GARCÍA ARROYO, A. (Marzo de 1981). Proyecto de investigación del IETCC para el ahorro de energía en la edificación bajo condiciones variables de clima y uso. (328), 41-46.

GARCÍA MARTÍnEZ, A. (2010). Análisis del ciclo de vida (ACV) de edificios. Propuesta metodológica para la elaboración de Declaraciones Ambientales de Viviendas en Andalucía. Recuperado el mayo de 2012, de Univesidad de Sevilla: http://fondosdigitales.us.es/tesis/tesis/1546/analisis-del-ciclo-de-vida-acv-de-edificiospropuesta-metodologica-para-la-elaboracion-de-declaraciones-ambientales-de-viviendas-enandalucia-life-cycle-assessment-Ica-development-environmental-declarations-dw

GEORGESCU-ROEGEN, N. (1971). La ley de la entropía y el proceso económico (Traducción al castellano 1996 ed.). Fundación Argentaria y Visor editores.

GEORGESCU-ROEGEN, N. (1989). Bioeconomía básica en economía, ecología y ética. México: Fondo de Cultura Económica.

GLAKEN, C. J. (1967). Huellas en la playa de Rodas. Naturaleza y cultura en el pensamiento occidental desde la Antigüedad hasta finales del siglo XVIII. Barcelona: Ediciones del Serbal.

GODET, M. (2007). Propectiva Estratégica: problemas y métodos.

GÓMEZ AZPEITIA, G., BOJÓRQUEZ MORALES, G., \& RUIZ TORRES, R. (2007). El confort térmico: dos enfoques teóricos enfrentados. Palapa, 2(001), 44-57.

GOMEZ MUÑOZ, G. (24 de Junio de 2014). Método de análisis diacrónico para la intervención en el alojamiento con criterios ecológicos. El caso de Madrid 1940-2100. Tesis doctoral. Madrid.

GREEN BUILDING CONCIL ESPAÑA. (2010). Informe Cambio GLobal 2020/2050. Sector Edficación. Centro Complutense de Estudios e Información Medioambiental, Madrid.

HALL, C., \& DAY, J. (Octubre de 2009). Los límites del crecimiento tras el cénit del petróleo. Investigación y ciencia, 69-77.

HERRÁIZ ROMERO, R. (2005). Evolución de la ocupación del suelo en la Comunidad de Madrid desde 1956 a 2005. Recuperado el Diciembre de 2011, de http://www.madrid.org/cartografia/planea/planeamiento/estudios/ocupacion_suelo/Evolucio n_1956_2005_Ocupacion_Suelo_CM.pdf

HOLLING, H., \& GUNDERSON, L. (2002). Panarchy: understanding transformations in human and natural systems. Washington: Island Press.

HOLMES, M., \& HACKNER, J. (2007). Climate change, thermal confort and energy: Meeting the design challenges of the 21st century. Energy and Buildings (39), 802-814 .

INSTITUTO DE ESTADÍSTICA DE LA COMUNIDAD DE MADRID. (2005). Características del parque de viviendas de la Comunidad de Madrid según el Censo de 2001. Madrid: Comunidad de Madrid.

INSTITUTO NACIONAL DE ESTADÍSTICA. (1991). Censo de Población y Vivienda 1991. Recuperado el 2008-2012, de http://www.ine.es/

INSTITUTO NACIONAL DE ESTADÍSTICA. (2007). Anuarios estadísticos históricos. Recuperado el 2008-2011

INSTITUTO NACIONAL DE ESTADÍSTICA. (2007). Censo de Población y Vivienda 2001. Recuperado el 2008, de Instituto Nacional de Estadísitica: http://www.ine.es 
INSTITUTO NACIONAL DE ESTADÍSTICA. (2011). Censo de proyecciones de población a corto plazo 2011-2021. Recuperado el Noviembre de 2011

INSTITUTO PARA LA DIVERSIFICACIÓN Y EL AHORRO DE ENERGÍA. (2011). Proyecto SECHSPAHOUSEC Análisis del consumo energético del sector residencial en España. Recuperado el Marzo de 2012, de http://www.idae.es/index.php/id.691/relcategoria.1368/mod.pags/mem.detalle

JOHANSEN BERTOGLIO, O. (1982). Introducción a la teoría general de sistemas. México: Limusa.

LIGGET, R., \& MILNE, M. (2011). Climate Consultant 5.2. Obtenido de http://www.energydesign-tools.aud.ucla.edu/

LOMAS, P. et al (2007). Environmental accounting as a management tool in the Mediterranean context: The Spanish economy during the last 20 years. Journal of environmental management.

LOMAS, P., DONATO, M. D., \& ULGIATI, S. (2007). La síntesis emergética: una valoración de los servicios de los ecosistemas con base termodinámica. Ecosistemas(16 (3)).

LÓPEZ DÍAZ, J. (2002). Vivienda Social y Falange: Ideario y construcciones en la década de los 40. Scripta Nova. Revista electrónica de geografía y ciencias sociales., VII(146).

LÓPEZ GÓMEZ, A. et al (1993). El clima urbano. Teledetección de la isla de calor en Madrid. Madrid: Consejo Superior de Investigaciones Científicas.

LOTKA, A. (1922). Contributions to the energetics of evolution. School of hygiene and public health, Johns Hopkins University.

LUXÁN, M. (Coord.). (2011). Habitar sostenible. Integración medioambiental en 15 casas de arqutiectura popular. Madrid: Ministerio de Fomento.

LUXÁN, M. et al. (2009). Actuaciones con criterios de sostenibilidad en la rehabilitación de viviendas en el centro de Madrid. Madrid, España: Empresa Municipal de la Vivienda y Suelo.

LUXÁN, M. et al (2009). Estudio para la definición de parámetros con criterios prestacionales que establezcan condiciones de habitabilidad en las viviendas. Madrid: Empresa Municipal de la Vivienda y Suelo.

LUXÁN, M. et al (2006). Proceso de aplicación práctica del Programa de Adecuación Arquitectónica y Sostenibilidad en la Rehabilitación de Edificaciones del Centro de Madrid. Madrid: Empresa Municipal de Vivienda y Suelo.

LUXÁN, M. et al. (2012). Análisis de tipología edificatorias Upgrade confort. Zona centro y norte. Madrid: EnergyLab.

LUXÁN, M. et al (2008). Protocolo de concesión de ayudas a la rehabilitación de viviendas con criterios de sostenibilidad. Madrid: Empresa Municipal de Vivienda y Suelo.

LUXÁN, M. et al. (2006). Criterios de sostenibilidad para la rehabilitación de viviendas en los barrios periféricos de Madrid. Madrid: Empresa Municipal de la Vivienda y Suelo.

MARGALEF LÓPEZ, R. (1974). Ecología (10ª ed.). Barcelona, España: Ediciones Omega.

MARGALEF LÓPEZ, R. (1993). Teoría de los sistemas ecológicos (2a ed.). Barcelona: Publicaciones de la Universidad de Barcelona.

MARTÍNEZ ALIER, J., \& ROCA JUSMET, J. (2000). Economía ecológica y política ambiental. México: Fondo de Cultura Económica.

MAYO GAYARRE, F. (1947). Directrices del régimen de protección a la vivienda. Madrid: Instituto Nacional de Vivienda. 
MEADOWS, D., MEADOWS, D. L., \& RANDERS, J. (1992). Más allá de los límites del crecimiento. Madrid: Ediciones El Pais Aguilar.

MEADOWS, D., MEADOWS, D., RANDERS, J., \& BEHRENS, W. (1972). Los límites del crecimiento: informe al Club de Roma sobre el predicamento de la Humanidad. Club de Roma.

MEADOWS, D., RANDERS, J., \& MEADOWS, D. (2006). Los límites del crecimiento: 30 años después. Barcelona: Galaxia Gutenberg.

MEILLAUD, F., GAY, J., \& BROWN, M. (Agosto de 2005). Evaluation of a bulding using the emergy method. Solar Energy, 79(Issue 2), 204-212.

MIGUEL ÁNGEL, B. (1995). Neorrealismo y arquitectura. El problema de la vivienda en Madrid. (301), 20-58.

MINISTERIO DE AGRICULTURA, ALIMENTACIÓN Y MEDIO AMBIENTE. (2011). Banco Público de Indicadores Ambientales . Recuperado el 2011, de http://www.magrama.gob.es/es/calidad-y-evaluacion-ambiental/temas/informacionambiental-indicadores-ambientales/banco-publico-de-indicadores-ambientales-bpia-/

MINISTERIO DE FOMENTO. (2000). Atlas estadístico de la edificación de viviendas y sus precios en España. Madrid: Centro de Publicaciones. Secretaría General Técnica. Ministerio de Fomento.

MINISTERIO DE FOMENTO. (2000). Atlas estadístico de las áreas urbanas en España. Madrid: Centro de Publicaciones. Secretaría General Técnica. Ministerio de Fomento.

MINISTERIO DE FOMENTO. (2003). Un siglo de vivienda social (1903/2003). Madrid: Ministerio de Fomento.

MINISTERIO DE FOMENTO. (2009). Fernando Ramón. Premio Nacional de Vivienda 2004. Madrid: Ministerio de Fomento.

MINISTERIO DE FOMENTO. (2011). Fernando Ramón. Premio Nacional de Vivienda. Madrid: Ministerio de Fomento.

MINISTERIO DE INDUSTRIA. (2003). Estrategia de ahorro y eficiencia energética en España 2004-2010. Recuperado el 2011, de http://www.minetur.gob.es/energia/desarrollo/eficienciaenergetica/documents/aprobaciones trategia.pdf

MINISTERIO DE MEDIO AMBIENTE. (2000). Indicadores ambientales: una propuesta para España. Madrid: Ministerio de Medio Ambiente.

MINISTERIO DE MEDIO AMBIENTE Y MEDIO RURAL Y MARINO. (2008). Análisis de la huella ecológica de España. Recuperado el Mayo de 2010, de Universidad Autónoma de Madrid: http://www.uam.es/personal_pdi/ciencias/jonate/Eco_Rec/Intro/HuellaEspa\%F1a.pdf

MINISTERIO DE MEDIO AMBIENTE Y MEDIO RURAL Y MARINO. (2010). Perfill ambiental de España. Informe basado en indicadores. Madrid: Ministerio de Medio Ambiente y Medio Rural y Marino.

MIRANDA MONTERO, M. (1987). Los censos de vivienda y la forma de uso de estos. Anales de Geografía de la Universidad Complutense(7), 461-467.

MOYA GONZÁLEZ, L. (1983). Barrios de Promoción Oficial. Madrid 1939-1976. Madrid: Colegio Oficial de Arquitectos de Madrid.

NAREDO PÉREZ, J. M. (1996). Sobre el origen, el uso y el contenido del término sostenible. En I. A. Dirección General de la Vivienda, La construcción de la ciudad sostenible. Ministerio de Fomento. 
NAREDO PÉREZ, J. M. (2003). Anatomía y fisiología de la conurbación madrileña: gigantismo e ineficiencia crecientes. En C. d. Urbanos, Madrid. Club de Debates Urbanos. Madrid: Instituto Juan de Herrera.

NAREDO PÉREZ, J. M., \& FRÍAS, J. (1987). Flujos de energía, agua, materiales e información en la Comunidad de Madrid. Pensamiento iberoamericano(12), 275-326.

NAREDO PÉREZ, J. M., \& GARCÍA ZALDÍVAR, R. (. (2005). La incidencia de la especie humana sobre la faz de la Tierra (1955-2005). Lanzarote: Universidad de Granada y Fundación César Manrique.

NAREDO PÉREZ, J. M., \& GARCÍA ZALDÍVAR, R. (2008). Estudio sobre la ocupación del suelo por usos urbano-industriales, aplicado a la Comunidad de Madrid. Recuperado el Diciembre de 2011

NAREDO PÉREZ, J. M., \& VALERO CAPILLA, A. (1999). Desarrollo económico y deterioro ecológico. Madrid: Fundación Argentaria y Visor editores.

NAREDO PÉREZ, J. M., MARCOS, C., \& CARPINTERO, Ó. (2010). Patrimonio inmobiliario y balance nacional de la economía española (1995-2007) Parte I: Composición y valor del patrimonio inmobiliario en España (1995-2007). Recuperado el 2011, de Biblioteca Ciudades para un Futuro más Sostenible: http://habitat.aq.upm.es/

NEILA GONZÁLEZ, F. J. (2004). Arquitectura bioclimática en un entorno sostenible. Madrid: Munilla-Lería.

NICOL, J., \& HUMPHREYS, M. (2002). Adaptative thermal confort and sustainable thermal confort. Energy and Buildings(34), 563-572.

OBSERVATORIO DE LA SOSTENIBILIDAD EN ESPAÑA. (2003). Cambios de ocupación del suelo en España. Implicaciones para la sostenibilidad. Recuperado el 2011, de http://www.sostenibilidad-es.org/sites/default/files/_Informes/tematicos/suelo/sueloesp.pdf

ODUM, E. (1969). The development strategy of ecosystems. Science(126), 262-270.

ODUM, E. P., \& WARRET, G. W. (2006). Fundamentos de Ecología (5a ed.). México: Thompson.

ODUM, H. (25 de Noviembre de 1988). Sel-organization, transformability and information. Science, 242(4882), 1132-1139.

ODUM, H., \& ODUM, E. (1981). Hombre y Naturaleza. Bases energéticas. Barcelona: Omega.

OFICINA ESPAÑOLA DE CAMBIO CLIMÁTICO. (2006). Plan Nacional de Adaptación al Cambio Climático. Madrid: Ministerio de Medio Ambiente.

OLCINA CANTOS, J. (2009). Cambio climático y riesgos climáticos en España. Investigaciones Geográficas(49), 197-220.

ORGANIZACIÓN DE NACIONES UNIDAS. (2010). World Population Prospects. The 2010 revision. Recuperado el Agosto de 2011, de http://www.un.org/esa/population

PLAN NACIONAL DE ADAPTACIÓN AL CAMBIO CLIMÁTICO (PNACC). (s.f.). Ministerio de Medio Ambiente. Obtenido de http://www.magrama.gob.es/

PRIGOGINE, I. (1995). ¿Qué es lo que no sabemos? A parte Rei Revista de Folosfía(10).

PRIGOGINE, I. (1996). El fin de las certidumbres. Santiago de Chile, Chile: Andrés Bello.

PROYECTO ENERGY SAVING THROUGH PROMOTION OF LIFE CYCLE ASSESSMENT IN BUILDINGS (ENSLIC BUILDING). (2010). Directrices para los cálculos de Análisis de Ciclo de 
Vida. Documento de trabajo. Recuperado el 2010, de http://www.circe.cps.unizar.es/enslic/texto/proj.html

PULSELLI, R. et al. (2007). Emergy análisis of building manufacturing, maintenance and use: Em-building indices to evaluate housing sustainability. Energy and buildings(39).

RAMÍREZ, S. (. (1999). Perspectivas en las teorías de sistemas. México: Siglo XXI Editores.

RAMÓN MOLINER, F. (1976). Alojamiento. Madrid: Cambio 16.

RAMÓN MOLINER, F. (1976). Manuales críticos del alojamiento español. Madrid.

RAMÓN MOLINER, F. (1977). Normativa en el alojamiento masivo. Arquitectos(10).

RAMÓN MOLINER, F. (Julio-Agosto de 1978). Arquitectura del dentro y del fuera. CAU Energía y Edificación(50).

RAMÓN MOLINER, F. (1980). Ropa, sudor y arquitecturas. Madrid: Hermann Blume.

RANZ, L. (1999). Análisis de los costes exergéticos de la riqueza mineral terrestre. Su aplicación para la gestión de la sostenibilidad.

REAL ACADEMIA ESPAÑOLA. (2001). Diccionario de la lengua española (22a ed.). España: Real Academia Española.

RECAÑo, J. (. (2002). Proyección de Hogares de la Comunidad de Madrid 2002-2017. Recuperado el Diciembre de 2011, de http://www.madrid.org/iestadis/fijas/informes/

ROS GARCÍA, J. M. (Enero-febrero de 2005). La fábrica de doble hoja en Madrid, un siglo de cerramiento moderno. Informes de la Construcción(495), 57-71.

ROSELL, A., \& SCHMITTNER, A. (Diciembre de 2012). La sensibilidad del clima al dióxido de carbono. Investigación y ciencia, 14-15.

RUEDA PALENZUELA, S. (1996). Metabolismo y complejidad del sistema urbano a la luz de la ecología. En I. A. Dirección General de la Vivienda, Ministerio de Fomento.

SALVADOR, A. (1929). Sobre la vivienda mínima. Arquitectura, 355-362.

SAMBRICIO, C. (2004). Madrid, vivienda y urbanismo: 1900-1960. De la "normalización de lo vernáculo" al Plan Regional. Madrid: Akal.

SODDY, F. (1921). Economía cartesiana: la influencia de la ciencia física en la administración del estado.

TERRADAS, J. (Enero-Abril de 2015). El pensamiento evolutivo de Ramón Margalef. (A. E. Terrestre, Ed.) Ecosistemas. Revista científica de ecología y medio ambiente, 104-109.

UNIVERSIDAD DE CALIFORNIA. LOS ÁNGELES. (2011). Climate Consultant 5.2. Recuperado el 2011, de http://www.energy-design-tools.aud.ucla.edu/

VALE, R., \& VALE, B. (1991). La casa autosuficiente. Madrid: Hermann Blume.

VALERO, A. (2008). Estudio de la evolución exergética del capital mineral de la Tierra.

VÁZQUEZ ESPÍ, M. (1996). La evolución de los paradigmas científicos: desde Galileo al "caos". Madrid: Departamento de Urbanística y Ordenación del Territorio. Escuela Técnica Superior de Arquitectura de Madrid. Recuperado el 2006, de http://habitat.aq.upm.es/gi/mve/daee/eppcc.pdf

VÁZQUEZ ESPÍ, M. (2001). Construcción e impacto sobre el ambiente: el caso de la tierra y otros materiales. Informes de la construcción, 52(471). 
VERDAGUER VIANA-CÁRDENAS, C. (2001). El paisaje construido: una perspectiva ecológica. Ecología: Una perspectiva actual . Real Sociedad Económica de Amigos del País de Gran Canaria.

VERDAGUER VIANA-CÁRDENAS, C. (1999). Paisaje antes de la batalla. Apuntes para un necesario debate sobre el paradigma ecológico en arquitectura y urbanismo. URBAN(3), 2943.

VIZCAÍNO, A., \& GONZÁLEZ, D. (2007). Tipología de soluciones racionalizadas. Análisis de los hogares españoles.

VVAA. (2007). Un vitrubio ecológico. Principios y práctica del proyecto arquitectónico sostenible. Barcelona, España: Gustavo Gili.

WADEL, G. (2009). La sostenibilidad en la construcción industrializada. La construcción modular ligera aplicada a la vivienda.

WALKER, B. et al. (2002). Resilience management in socio-ecological systemas: a working hypothesis for a participatory approach. Conservation Ecology.

WALKER, L. (2005). Margalef y la sucesión ecológica. Ecosistemas(14 (1)).

World Wildlife Foundation. (2006). Informe Planeta Vivo.

World Wildlife Foundation. (16 de Diciembre de 2012). Informe planeta vivo. Obtenido de WWF: http://www.wwf.es/noticias/informes_y_publicaciones/informe_planeta_vivo_2012/

YEANG, K. (2001). El rascacielos ecológico. Barcelona, España: Gustavo Gili.

ZABALZA BRIBIÁN, I. (2011). Adaptación de la metodología del análisis de ciclo de vida para la evaluación y la mejora del impacto energético y ambiental de la edificación en España.

ZAPIAIN AISPURU, M. (2010). Crónica de una muerte anunciada. Una revisión de Los límites del crecimiento. Recuperado el 2012, de Biblioteca Ciudades para un Futuro más Sostenible: http://habitat.aq.upm.es/boletin/n46/amzap.html 
LOS CUADERNOS DE INVESTIGACIÓN URBANÍSTICA publicados por el Departamento de Urbanística y Ordenación del Territorio desde el año 1993, difunden bimensualmente aquellos trabajos de investigación realizados en el área del Urbanismo, la Ordenación Territorial, el Medio Ambiente, la Planificación Sostenible y el Paisaje, que por sus características, muchas veces de investigación básica, tienen difícil salida en las revistas profesionales. Su objetivo es la difusión de estos trabajos, en el convencimiento de que es necesario potenciar el uso de este idioma entre el mundo científico para conseguir alcanzar ámbitos de difusión a los que, de otra forma, no se podría acceder.

Su formato no es el convencional de una revista de este tipo, con artículos de diferentes autores que, en realidad, abordan aspectos parciales de cada trabajo, muy adecuados para la difusión y el conocimiento rápido de los mismos, pero que no pueden profundizar demasiado debido a su limitada extensión, sino que se trata de amplios informes de la investigación realizada que ocupan la totalidad de cada número. Esto permite, sobre todo a aquellos investigadores que se inician, el tener accesibles los aspectos más relevantes del trabajo y conocer con bastante precisión el proceso de elaboración de los mismos.

La realización material de los Cuadernos de Investigación Urbanística está a cargo del Departamento de Urbanística y Ordenación del Territorio de la Escuela Técnica Superior de Arquitectura de Madrid, garantizándose el respeto de la propiedad intelectual, pues el registro es siempre en su totalidad propiedad del autor. Está permitida su reproducción parcial en las condiciones establecidas por la legislación sobre propiedad intelectual citando autor, previa petición de permiso al mismo.

\section{NORMAS DE PUBLICACIÓN}

Las condiciones para el envío de originales se pueden consultar en la página web:

http://www.aq.upm.es/Departamentos/Urbanismo/publicaciones/ciurpublicar.html

\section{FORMATO DE LAS REFERENCIAS}

Monografías: APELLIDOS (S), Nombre (Año de edición). Título del libro (No de edición). Ciudad de edición: Editorial [Traducción castellano, (Año de edición), Título de la traducción, No de la edición. Ciudad de edición: editorial].

Partes de monografías: APELLIDOS (S), Nombre (Año de edición). "Título de capítulo". En: Responsabilidad de la obra completa, Título de la obra (No de edición). Ciudad de edición: Editorial.

Artículos de publicaciones en serie: APELLIDOS(S), Nombre (Año de publicación). "Título del artículo", Título de la publicación, Localización en el documento fuente: volumen, número, páginas.

Asimismo, se recuerda que el autor tendrá derecho a tres ejemplares gratuitos.

\section{CONSULTA DE NÚMEROS ANTERIORES/ACCESS TO PREVIOUS WORKS}

La colección completa se puede consultar en color y en formato pdf en siguiente página web:

The entire publication is available in pdf format and full colour in the following web page:

http://www.aq.upm.es/Departamentos/Urbanismo/publicaciones/ciurnumeros.html

\section{ÚLTIMOS NÚMEROS PUBLICADOS:}

105 Irene Zúñiga Sagredo: "La forma del límite en las ciudades medias españolas", 66 páginas, marzo 2016.

104 Marian Simón Rojo: "La huella en el territorio del sistema agroalimentario (1900-2015)", 74 páginas, enero 2016.

103 Emilia Román López: "Protección, gestión y ordenación del paisaje salinero en Andalucía", 94 páginas, Noviembre 2015.

102 Antonio Matres Barrio: "Masas dialogantes: el futuro del urbanismo social", 84 páginas, Septiembre 2015.

101 María del Puy Alonso Martínez: "Diseño de áreas verdes con criterios ecológicos", 80 páginas, Julio 2015. 
PROGRAMA OFICIAL DE POSGRADO EN ARQUITECTURA MASTER PLANEAMIENTO URBANO Y TERRITORIAL

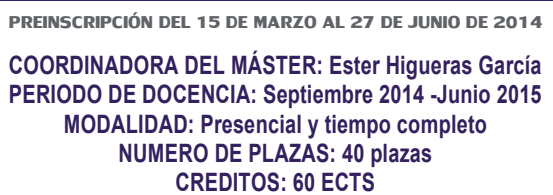

El Máster se centra en la comprensión, análisis, diagnóstico y solución de los problemas y la identificación de las dinámicas urbanas y territoriales en curso, atendiendo a las dos dimensiones fundamentales del fenómeno urbano actual: por un lado, el proceso de globalización y, por otro lado, las exigencias que impone la sostenibilidad territorial, económica y social. Estos objetivos obligan a insistir en aspectos relacionados con las nuevas actividades económicas, el medio físico y natural, el compromiso con la producción de un espacio social caracterizado por la vida cívica y la relación entre ecología y ciudad, sin olvidar los problemas recurrentes del suelo, la vivienda, el transporte y la calidad de vida. Estos fines se resumen en la construcción de un espacio social y económico eficiente, equilibrado y sostenible. En ese sentido la viabilidad económica de los grandes despliegues urbanos y su metabolismo se confrontan con modelos más maduros, de forma que al estudio de las técnicas habituales de planificación y gestión se añaden otras nuevas orientaciones que tratan de responder a las demandas de complejidad y sostenibilidad en el ámbito urbano.

El programa propuesto consta de un Máster con dos especialidades:

- Especialidad de Planeamiento Urbanístico (Profesional)

- Especialidad de Estudios Urbanos (Investigación Académica)

Se trata de 31 asignaturas agrupadas en tres módulos:

MÓDULO A. Formación en Urbanismo.

MÓDULO B. Formación en Estudios Urbanos e Investigación.

MÓDULO C. Formación en Planeamiento.

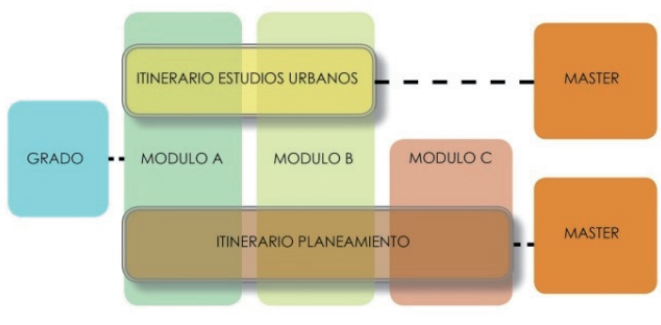

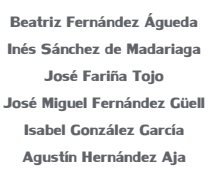

Agustín Hernández Aja

\section{PROFESORADO:}

Ester Higueras García

Francisco José Lamiquiz

Julio Pozueta

Fernando Roch Peña

Felipe Colavidas

Luis Moya

José María Ezquiaga
Llanos Masiá

Javier Ruiz Sánchez

Carlos Verdaguer

Enrique Villa Polo

Carmen Andrés Mateo

Álvaro Sevilla

ENTIDADES COLABORADORAS:

(0) C Ci[ur] =urban

CONTACTO: masterplaneamiento.arquitectura@upm.es www.aq.upm.es/Departamentos/Urbanismo/masters/index.html 
ALGUNAS DE LAS ACTIVIDADES REALIZADAS DURANTE EL CURSO 2014/15...

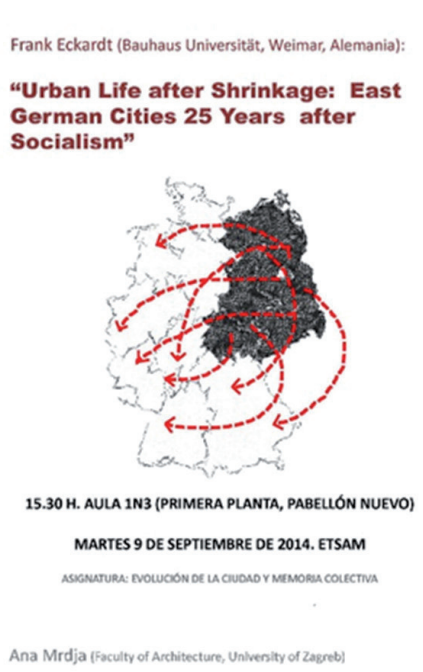

"Tourism planning and carrying capacity"

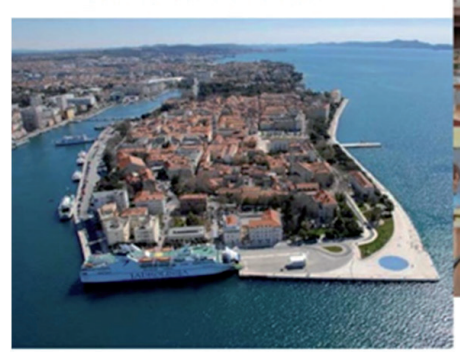

11.30 H. SALA DE GRADOS B (PABELLÓN ANTIGUO) JUEVES 18 DE SEPTIEMBRE DE 2014. ETSAM ASOMUTURA: SEMINARIO EN LINEAS OE INUESTGGOOON

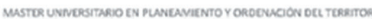

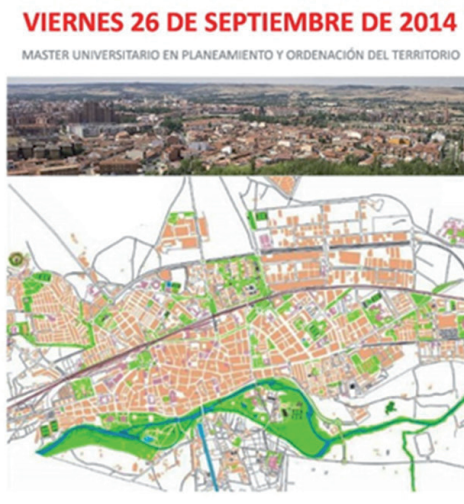

"Visita a la ciudad de Palencia"

RECEPCION EN EL ATUNTAMIENTO Y PASEO POR L C CIUDAD Y SUS BARRIOS

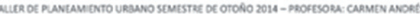

MIÉRCOLES 11 DE FEBRERO DE 2015. ETSAM MASTER UNIVERSTIARIO EN PLANEAME ENTO Y ORDERACÓN OEL TERRITORIO

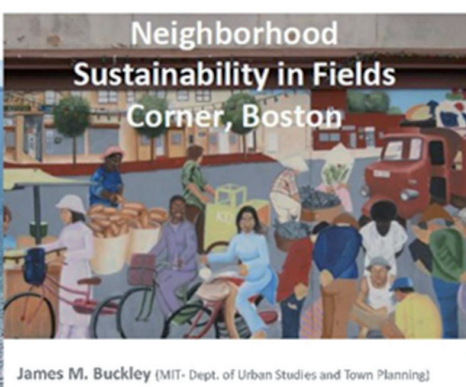

"Urban regeneration in USA"

11.30 H. AULA 1N3 (AULA MÁSTER)

INAUGURACON ACAOEMICA OEL STGUNDO SEMESTRE OEL MESTR
José Fariha Tojo (Catedratico UPM, Duyor)

Luis Felipe Alonso Teixidor (Catedratico "Ad Honorem" UPM, DuroT) Ramón López de Lucio fCatedratico "Ad Honorem" UPM, Du, or

"El sprawl y su paisaje"

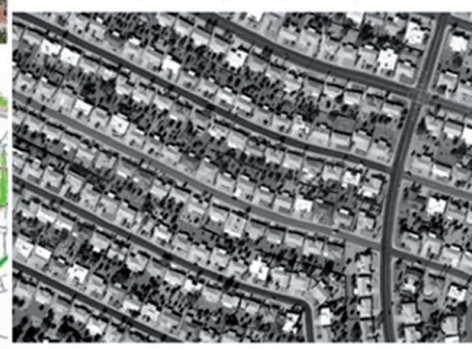

11.30 H. SALA DE GRADOS B (PABELLÓN ANTIGUO)

JUEVES 9 DE OCTUBRE DE 2014. ETSAM

ASIGNATUaA: SEMINANO EN LINEAS DE INUSSTGACION

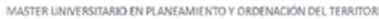

MIÉRCOLES 5 DE NOVIEMBRE DE 2014. ETSAM MASTER UNVERSTAR: EN PLANEAMIENTO Y OROEMACOON DEL TERRTORIO

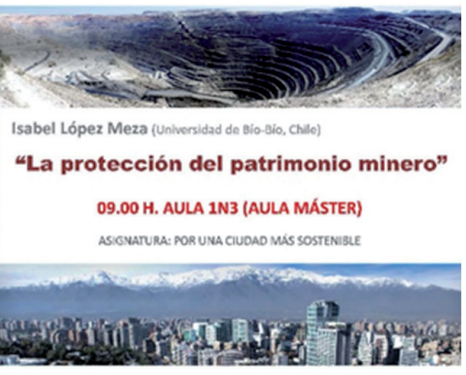

Mario Torres Jofré (Universidad de Chile) "La ciudad contemporánea.
Una perspectiva crítica"

16.00 H. AULA 1N3 (AULA MASTER) ASGGATURA: PRONECTAR LA CUDADCOMMPIEA

VIERNES 27 DE FEBRERO DE 2015 JUEVES 19 DE MARZO DE 2015 MIÉRCOLES 25 DE MARZO DE 2015

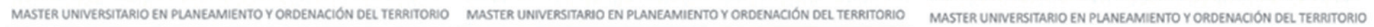

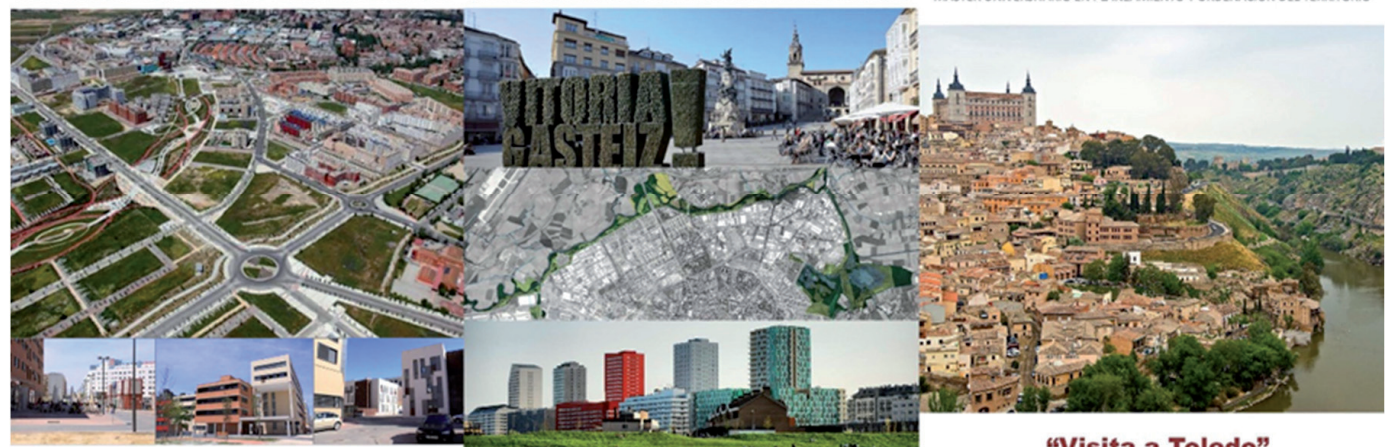

"Visita a Toledo"

"Visita a Móstoles Sur (Madrid)"

15.30 H. METRO MANUELA MALASAÑA (METROSUR)
"Visita a Vitoria-Gasteiz"

$12.00 \mathrm{H}$. PLAZA DE LA VIRGEN BLANCA (CENTRO)
16.00 H. PLAZA DE ZOCODOVER (CENTRO)

JOINT WORKSHOP - SPRING 2015 - EVOIVING CTIES

(1) (1) DUYOT 
Otros medios divulgativos del Departamento de Urbanística y Ordenación del Territorio:

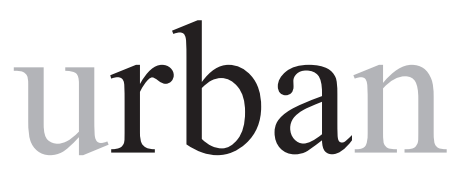

ReVISTA del Departamento de URBANÍSTICA y ORDENACIÓN del TeRrITORIO ESCUELA TÉCNICA SUPERIOR DE ARQUITECTURA

\section{PRESENTACIÓN SEGUNDA ÉPOCA}

DESDE el año 1997, URBAN ha sido vehículo de expresión de la reflexión urbanística más innovadora en España y lugar de encuentro entre profesionales y académicos de todo el mundo. Durante su primera época la revista ha combinado el interés por los resultados de la investigación con la atención a la práctica profesional, especialmente en el ámbito español y la región madrileña. Sin abandonar dicha vocación de saber aplicado y localizado, la segunda época se centra en el progreso de las políticas urbanas y territoriales y la investigación científica a nivel internacional.

\section{CONVOCATORIA PARA LA RECEPCIÓN DE ARTÍCULOS:}

Urban mantiene abierta una convocatoria permanente para la remisión de artículos de temática relacionada con los objetivos de la revista: Para más información:

http://www2.aq.upm.es/Departamentos/Urbanismo/institucional/publicaciones/urban/ns/instrucciones-para-autores/

Por último, se recuerda que, aunque La revista URBAN organiza sus números de manera monográfica mediante convocatorias temáticas, simultáneamente, mantiene siempre abierta de forma contínua una convocatoria para artículos de temática libre.

\section{DATOS DE CONTACTO}

Envío de manuscritos y originales a la atención de Javier Ruiz Sánchez: urban.arquitectura@upm.es

Página web: http://www.aq.upm.es/Departamentos/Urbanismo/public/urban/info.html

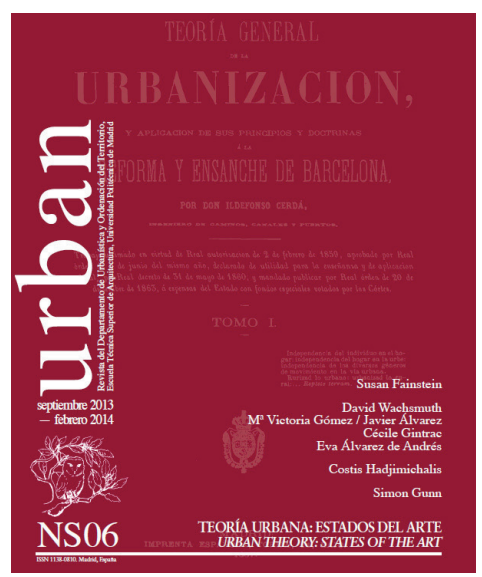

Consulta y pedido de ejemplares: ciur.urbanismo.arquitectura@upm.es

Web del Departamento de Urbanística y ordenación del Territorio:

http://www.aq.upm.es/Departamentos/Urbanismo

Donde figuran todas las actividades docentes, divulgativas y de investigación que se realizan en el Departamento con una actualización permanente de sus contenidos. 